DEPARTMENT OF THE INTERIOR

UNITED STATES GEOLOGICAL SURVEY

GEORGE OTIS SMITH, DIRECTOR

BULLETIN 382

\title{
THE EFFECT OF OXYGEN IN COAL
}

BY

DAVID WHITE

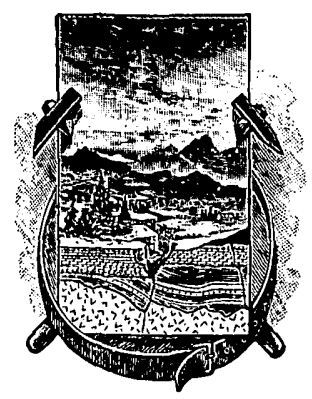

W ASHINGTON

GOVERNMEN'T PRINTING OFFICE

1909 



\section{CONTENTS.}

Yage.

Initial controlling fact

Stages of formation.

Deorycenation

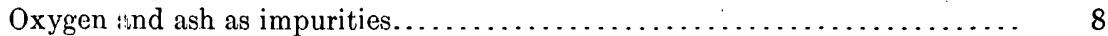

Evic ence of their nearly equal value........................ 8

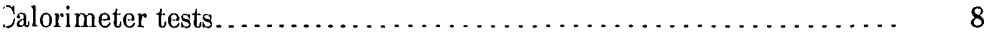

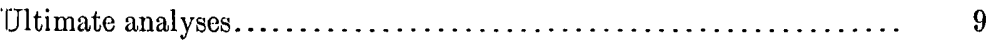

Arrangement of analyses.................................... 19

Fuels high in oxygen or ash ............................ 19

Fuels of lower ash and oxygen $\ldots \ldots \ldots \ldots \ldots \ldots \ldots \ldots \ldots \ldots, 20$

Relation to calorific value.............................. 21

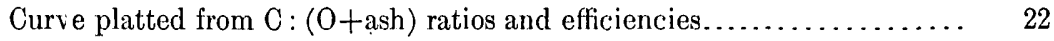

Determination of curve................................. 22

Detailed study of a curve segment........................ 22

"Variations from the curve................................ 23

'Jomparison with calculated thermal units.................... 24

Torecast of fuel efficiency from ratios....................... 24

Relations in moisture-free coals. . . . . . . . . . . . . . . . . . . . . . . . 25

Recalculation of analyses................................... $\quad 25$

Jompensated calorific values............................. 34

Value of moisture-free data................................ 35

Relative negative value of ash and oxygen...................... 36

Relative effect of the oxygen of moisture....................... 37

Estirnate of the empirical anticalorific value of oxygen.............. 39

"Negative value of oxygen and ash......................... 39

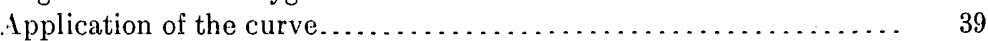

Fluctuation in effects of changes........................... 40

Estimate applied to the analyses.......................... $\quad 40$

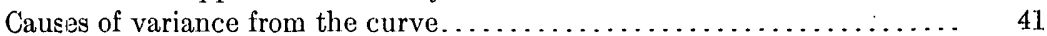

Jeneral statement....................................... 41

Causes not shown by ultimate analyses..................... 4.1

Yauses recognizable in analyses............................ 42

Varying available hydrogen......................... 43

Sulphur........................................ 44

Nitrogen........................................ 46

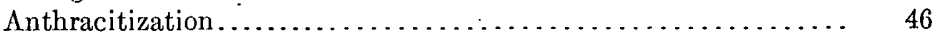

Weathering........................................ 48

Quantitative relation of oxygen to coking.......................... 48

Supposed algal ingredients in coals........................... 48

Bource and chemical effects.............................. 48

Tharacteristics of algal coals.............................. 50

Possible connection with coking quality .................... 50 
Quantitative relation of oxygen to coking-Continued. Page.

Hydrogen-oxygen ratios of coking coals...................... 51

Description of diagram in Plate III .......................... 51

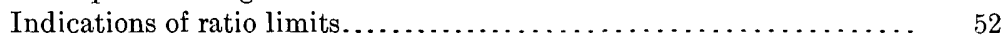

Application to algal hypothesis............................. 53

Coking of high fixed carbon coals............................. 53

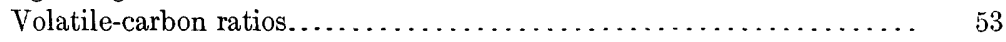

Consultation of efficiency errors........................... 54

Hydrogen and oxygen losses in the progressive development of coal...... 54

Available hydrogen as index of coking coals...................... 55

Hydrogen-oxygen ratio the best index.......................... 56

Status of algal hypothesis.................................... 56

Mixture of coals for coking................................... 57

General observations on the tabulated coals........................ 58

Range of the samples....................................... 58

Rank of peats and lignites................................. 58

Explanation of high oxygen................................... 59

Quantitative relation of volatile carbon and hydrogen................. 59

Loss of volatile matter.................................... 60

Relation of stage of coal formation to classification.................. 60

Like analyses for coals of different origin....................... 60

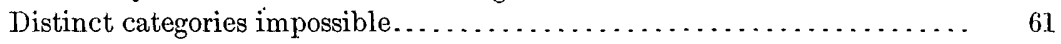

Comparison of types...................................... 61

Obliteration of distinctions as a result of regional metamorphism ......... 62

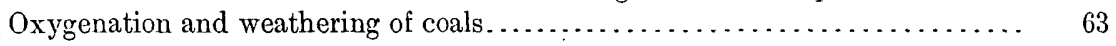

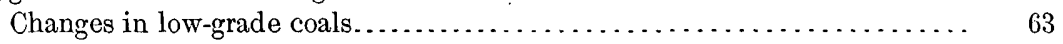

Efficiency losses in weathering................................ 63

Losses shown by analyses and ratio-efficiency curve............... 64

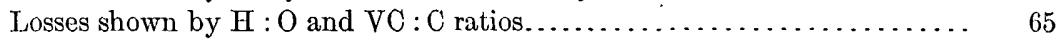

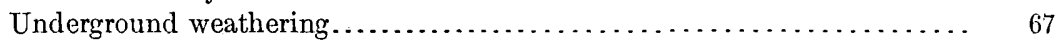

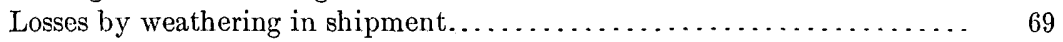

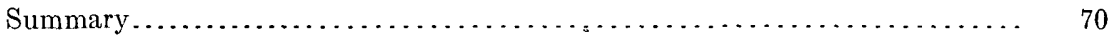

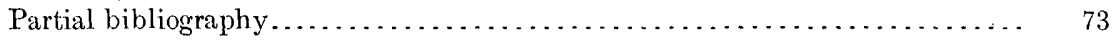

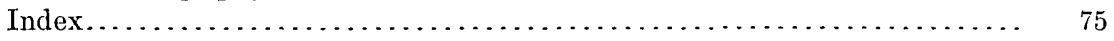

\section{ILLUSTRATIONS.}

Plate I. Ratio-efficiency curve of coals tabulated ...

II. Segment of ratio-efficiency curve.......................... 22

III. Diagram showing hydrogen-oxygen ratios of coals.............. 52 


\title{
THE EFFECT OF OXYGEN IN COAL.
}

\author{
By David White.
}

\section{INTRODUCTION.}

This paper is the result of a comparative study of ultimate coal analyses made and published by the United States Geological Survey. This study, at first casually undertaken to devise an acceptable classification of coals based on chemical analyses, was continued in connection with a microscopic examination of a number of the coals. The initial comparisons, made from a relatively small number of analyses, not only confirmed a previous conviction that the elimination of oxygen incident to the development of a coal is economically far more important than has been generally suspected, but also showed that oxygen is very nearly as harmful as ash in coal.

The immediate purposes of the present study were: (a) To determine more definitely, from a comparative examination of a large number of ultimate analyses, the relative importance of oxygen as an impurity in various coals; $(b)$ to illustrate the transition between various grades of coal of similar origin-transition mainly due to progressive devolatilization, brought about more or less directly by dynamic influences; $(c)$ to ascertain the relative proportions of oxygen, hydrogen, and carbon in coking coals, especially with reference to a theory tentatively framed to explain the coking quality; and $(d)$ to forecast the probabilities of successfully treating a large number of coals so as to render them amenable, in a softened condition, to satisfactory study under the microscope.

Although the hypothesis as to coking quality finds but partial support in the chemical analyses, its consideration has led to a method of predicting from an analysis with a fair degree of certainty whether any given coal will coke by the ordinary process. The unbroken transition between coals originally similar but now classed in widely different groups, whether of the same age or of different ages, as a result of dynamochemical action, appears demonstrated by the analyses as well as by field observation. This subject will not be 
specially discussed in this paper, though the tables offer forcible, if not convincing, evidence concerning it.

The great number of ultimate analyses published by the Survey, covering samples of coals of so many sorts collected throughout the wide range of American coal fields, furnishes an unrivaled wealth of analytical data concerning the fuels of the country; and the fact that all are made under one highly expert direction, and are standardized, renders them especially valuable for comparative study.

The discussion of chemical changes that have occurred in the coals and of the nature of the compounds now existing in them is left to the professional chemist, who is familiar with the great mass of literature concerning the chemistry of coals.

Acknowledgments are gratefully tendered to Messrs. M. R. Campbell and J. S. Burrows for placing at my disposal many of their recalculations of the analyses from the "as received" to the "airdried" basis and thus greatly lightening the labors of computation; also to Mr. Burrows for annotations as to the coking qualities of the coals. Thanks are also due to Mr. Wirt Tassin, of the National Museum, for frequent and generous gifts of information and counsel.

\section{DEOXYGENATION IN THE FORMATION OF COAL.}

\section{INITIAL CONTROLLING FACTORS.}

The great variation in kinds and qualities of coal is due to differences, many of them of wide range, in the consecutive influence or operation of three controlling and indispensable factors; that is, to differences (1) in the kinds and sources of the original ingredient matter; (2) in the conditions of accumulation and deposition of this matter; and (3) in the phase and stage of progress of the coal-forming process - the transformation of the organic matter into coals of various grades. The comparative importance of each of these cooperative and mutually related factors varies from coal to coal, and it is necessary to bear in mind that they combine not only in complex but also in constantly changing phases and efficiencies, so that their products, though often similar, are never exactly the same. It is to the third of these factors that the following discussion for the most part relates.

\section{STAGES OF FORMATION.}

When the organic matter, chiefly of various vegetal types, accumulates under conditions favorable for the formation of coal, the process of conversion goes forward. In the ordinary course of events this process embraces two fundamentally important stages: 
1. The putrefaction or fermentation stage, in which the action is essentially biochemical.

2. The stage of chemical and physical alteration, which is mainly induced and controlled by dynamic geologic influences, and in which the action may therefore, in contrast, be termed dynamochemical.

These two stages are practically consecutive, though slightly overlapping; and, on account of conditions that will readily be conceived and need not be discussed here, ${ }^{a}$ the intensity and extent of the operation or progress of each stage varies greatly. The physical characters and qualities of the younger and less mature coals, including lignites and peats, are largely determined by the relative progress of the biochemical action, the most evident visible effect of which is the disintegration of the organic structures, usually accompanied by darkening of the color. On the other hand, the further progressive devolatilization, as well as the lithification, dehydration, and metamorphism of the coals, characterize the dynamochemical stage. The biochemical action, essentially the work of anaerobic bacteria, is, geologically speaking, relatively soon terminated, even when it progresses to a point just short of complete destruction of the original organism; the succeeding work, under the influence of geodynamic agencies, is still in progress, the ultimate goal being the practically complete devolatilization of the coal and its transformation into graphite.

\section{DEOXYGENATION.}

In all the chemical changes marking both stages in the conversion of organic débris into coal, the preeminently important result to man is elimination of oxygen. Economically this is the most essential incident of the process. From a beginning with over 40 per cent of oxygen, in the cellulose and lignose of the woody matter, which comprises so great a part of the organic substance actually entering into coal formation, to the present nearly devolatilized state of an anthracite, with less than 2.5 per cent of oxgyen, deoxygenation has progressed continuously, though at varying rates, in every unweathered coal. As the original oxygen is more and more nearly eliminated, the heat efficiency of the coal increases. In other words, with respect to their efficiency as fuels, oxygen is an original impurity in coals, which improve according to the extent of its removal. It will be shown later that the deleterious effect of oxygen in coals greatly exceeds the common conception of it, being nearly equal to that of the same weight in ash. The negative importance of oxygen seems to be little realized outside of the ranks of coal analysts. 


\section{OXYGEN AND ASH AS IMPURITIES.}

\section{EVIDENCE OF THEIR NEARLY EQUAL VALUE.}

\section{CALORIMETER TESTS.}

At a conference held in Washington, March, 1907, for the purpose of discussing the classification of coals, I urged that a classification based on chemical composition, to be satisfactory for either technical or practical purposes, should give careful heed to the oxygen content, for the degree of deoxygenation would be found to be most intimately connected with the relative efficiency of the fuels. By using the limited number of ultimate analyses then made public by the fueltesting plant of the United States Geological Survey as a basis of illustration, it was shown that, among coals of equal ash, the ascertained calorific values of the air-dried samples corresponded closely to the order of the ratios of the total carbon to the oxygen $(\mathrm{C}: \mathrm{O})$. The number of ultimate analyses showing approximately equal ash was, however, so small as to be inconclusive. I therefore attempted, by means of a critical comparison of all the analyses, to discover a coefficient for use in compensating for the highly variạble ash content. From this study it was noted that, in general, so far as shown in the calorimeter, the deleterious effects of oxygen and of ash in the coals represented in the list were practically of very nearly equal importance. For example, the calorimeter tests seemed to show that two coals having the same carbon content, but with reverse proportions of ash and oxygen (one with 15 per cent ash and 4 per cent oxygen and the other with 4 per cent ash and 15 per cent oxygen) have nearly the same heat efficiency. In other words, oxygen and ash appear to be of nearly equal negative or anticalorific values.

The fact having been noted that the coals with constant ash arrange themselves as to efficiency largely in the order of the ratios of carbon to oxygen, it at once became evident, oxygen and ash being of equal negative calorific effect, (1) that coals with constant oxygen should also similarly rank not far from the order of their carbon-ash ratios; and (2) that the efficiencies of coals in which both oxygen and ash vary should correspond nearly equally well to the relative order of the ratios of the carbon to oxygen plus ash. Examination of a more extended series of analyses confirms the conclusions based on the original list.

In these comparative studies the contribution of the hydrogen of the coal to the heat value is assumed to be nearly constant; hence the hydrogen is ignored temporarily, as also are the sulphur and the nitrogen. The main purpose is to show that in a miscellaneous series of coals of all grades those with high oxygen content will, in general, have approximately the same calorific value as those with 
equally high ash if the $\mathrm{C}:(\mathrm{O}+\mathrm{ash})$ ratios are the same; or, in other words, that, taking coals as they run, oxygen and ash are, according to the calorimetric tests, to be regarded as equally undesirable.

\section{ULTIMATE ANALYSES.}

To illustrate somewhat graphically the approximate equality of the anticalorific values of these two great impurities in coal, while at the same time showing the relatively close correspondence of the calorific values to the sequence of the ratios $\mathrm{C}:(\mathrm{O}+\mathrm{ash})$, Table 1 (pp. 11-18) has been compiled showing a series of over 300 ultimate analyses of air-dried samples of fuels. All these analyses were made in the laboratories of the United States Geological Survey.

As first compiled the table included all the ultimate coal analyses which, in December, 1907, had come to hand. By mere coincidence they numbered 250. Nearly 70 additional analyses of samples by the geologists working in the various coal areas have since been. intercalated. These intercalations, many of which represent weathered material, have alphabetic designations affixed to the numbers, thus retaining the original series of numbers for the mined coals especially investigated by the Survey.

The air-dried coal samples, according to the later practice of the chemical laboratory, are those that, after pulverization, were dried in a special oven in a gentle current of air $10^{\circ}$ to $20^{\circ}$ above the temperature of the laboratory. ${ }^{a}$ In the earlier laboratory work the samples were crushed fine, spread out on shallow trays, and dried in the air of the laboratory for twenty-four to ninety-six hours, or until the loss between two successive weighings (made twelve to twentyfour hours apart) was small, usually less than 1 per cent. ${ }^{b}$

All but one of the analyses will be found in Professional Paper 48, or in Bulletins 260, 261, 290,316, or 332 of the United States Geological Survey. Most of the recalculations of the analyses and computations of ratios in this paper were done without the aid of the computing machine and are subject to correction. For original forms, including "as received" and "dry coal" recalculations, the reader is referred to the papers here mentioned.

It will be observed that the coals here listed represent most of the American coal fields. They come from 27 States and Territories. One is from Batan Island and one from Mexico. In age they range from basal Mississippian (Pocono) to Recent. The post-Paleozoic coals belong to the Kootenai (basal Cretaceous); Benton, Eagle, Mesaverde, and Laramie (Upper Cretaceous); "Upper Laramie," Fort Union, Bridger, and Gulf Coast Eocene; Pacific Coast Miocene;

\footnotetext{
$a$ For description of this process see Bull. U. S. Geol. Survey No. 290, 1906, pp. 29-30.

$b$ See Prof. Paper U. S. Geol. Survey No. 48, 1906, p. 177. For comparison of results see Bull. U. S. Geol. Survey No. 323, p. 8 .
} 
and Atlantic Coast post-Pleistocene. In kinds they embrace peats and xyloid and earthy lignites (brown coals), as well as subbituminous, bituminous (dry and coking), semibituminous, semianthracite, anthracite, and graphitic coals. In order not to omit any ultimate analysis of a coal investigated by the Survey, so far as they had come to hand up to the close of 1907 , the semigraphite from Providence is also included. The graphitization of this highly metamorphic Carboniferous coal is so nearly complete that, although a coal from the genetic standpoint, it can not be regarded as a fuel, for it is practically incombustible unless chemically treated. It is used mainly for foundry facing. The lower-class coals are distinguished in accordance with the simple and very practical system recently proposed by M. R. Campbell. ${ }^{a}$ This classification, based on weathering and salient physical characters, is briefly as follows:

Bituminous coals, except cannel and block (which are recognized by special well-known criteria), are more thoroughly jointed, and in weathering split generally in agreement with preexisting cleavage, the particles remaining prismatic even when very minute.

Subbituminous coals are black, generally less jointed, and have poor cleavage, which shows only in the larger blocks. On exposure to the atmosphere the lumps check irregularly, the resultant fragments, however small, being irregular in outline and having rough faces instead of cleavage planes. Weathering is characterized (very conspicuously in the longer exposed fragments) by separation of the coal in plates parallel to the bedding, this process continuing to invisible limits.

Lignites are distinguished from subbituminous coals only by their brown, instead of black, color and generally woody aspect. They are the "brown coals."

The higher grade coals are provisionally grouped as proposed by Prof. F. F. Grout. ${ }^{b}$

It will be noted that the samples analyzed are not always marketable coal; in many cases they represent fine coal, screenings, refuse, slack, dust (culm), waste and "bone." The low position of a number of the high-grade coals-for example, No. 30 (W. Va. 24) from the famous Pocahontas bed-is accounted for by the great amount of ash in the bony layer from which the sample was taken. 


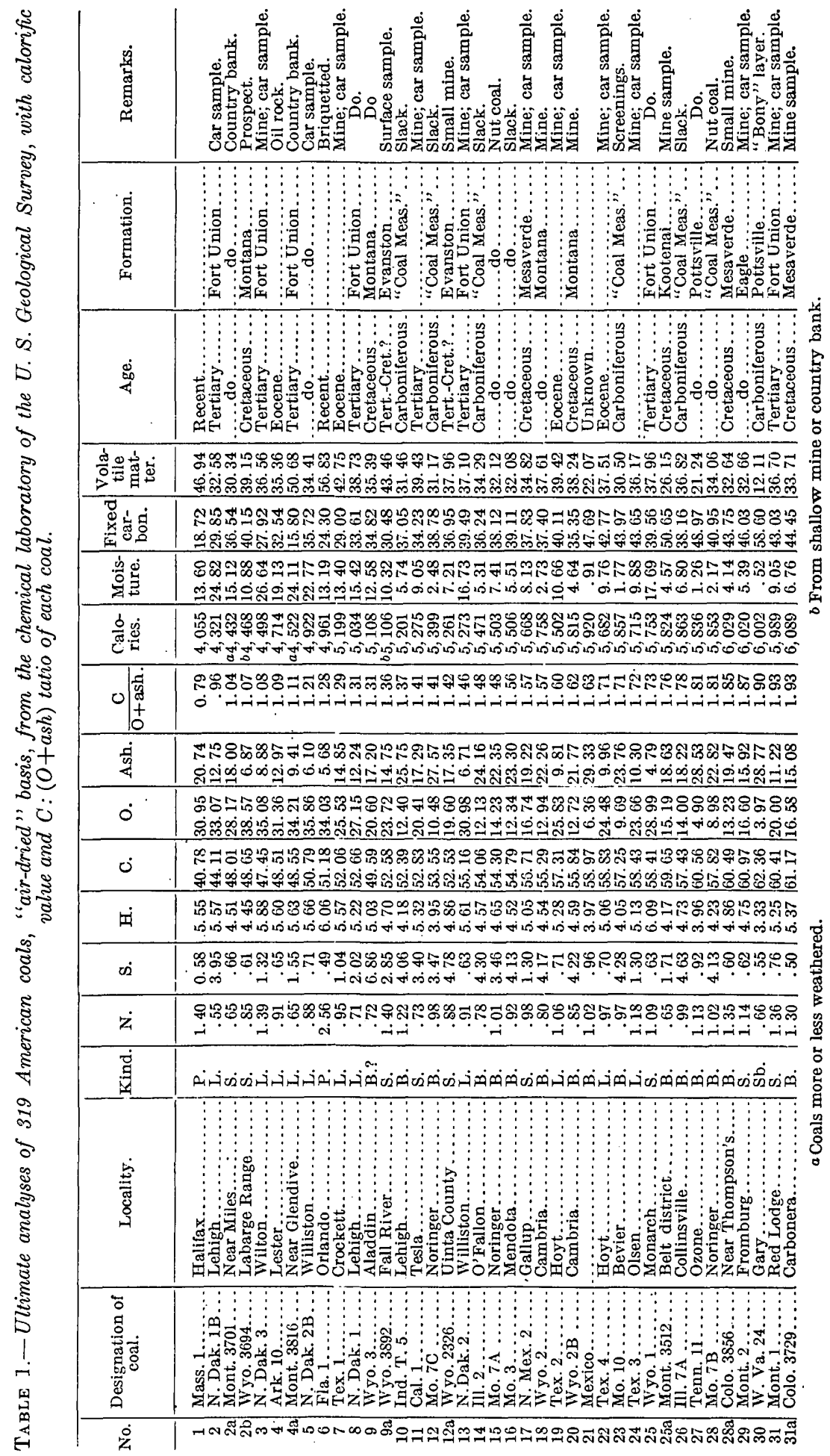




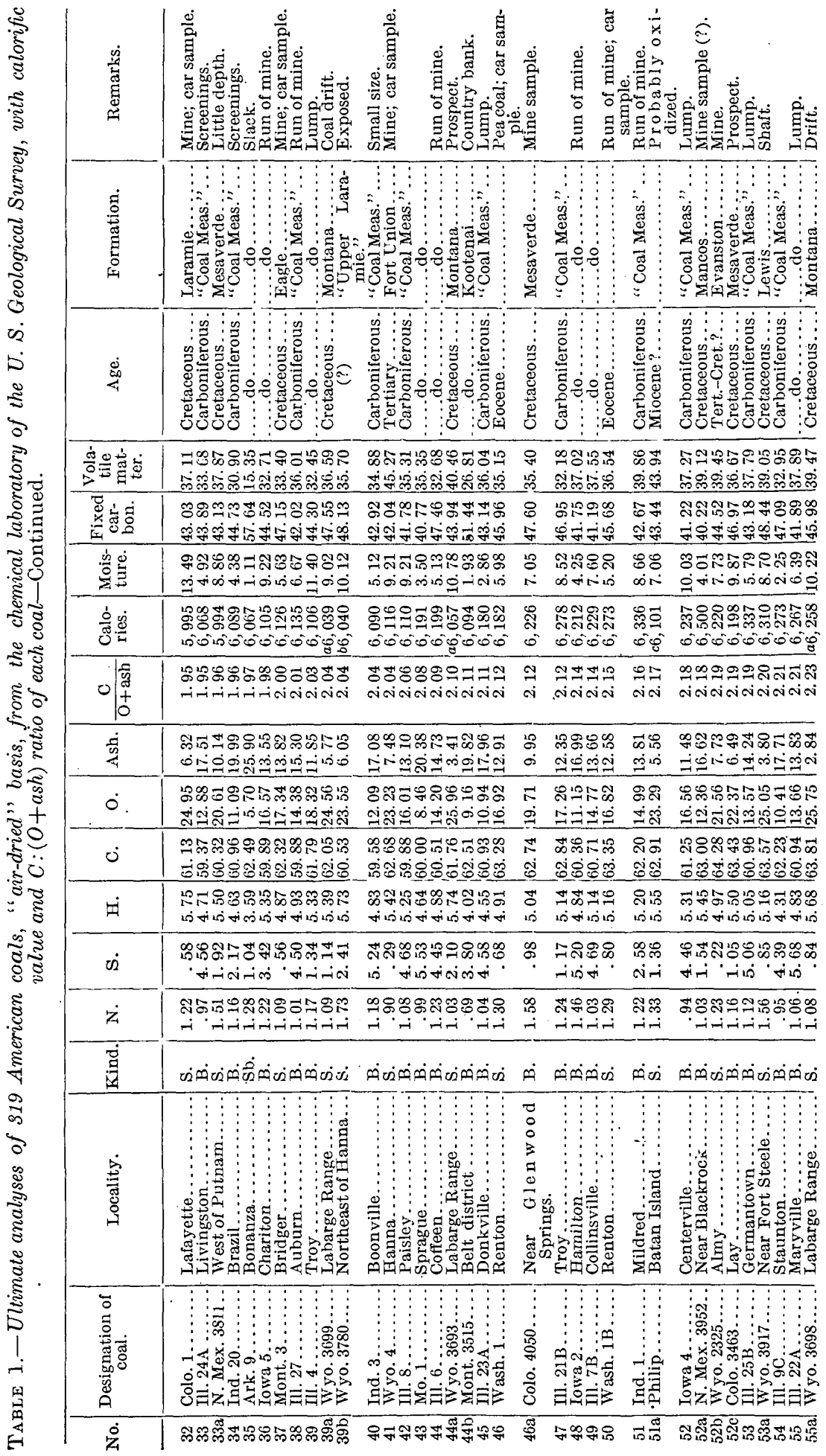






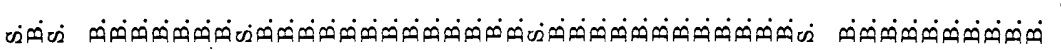

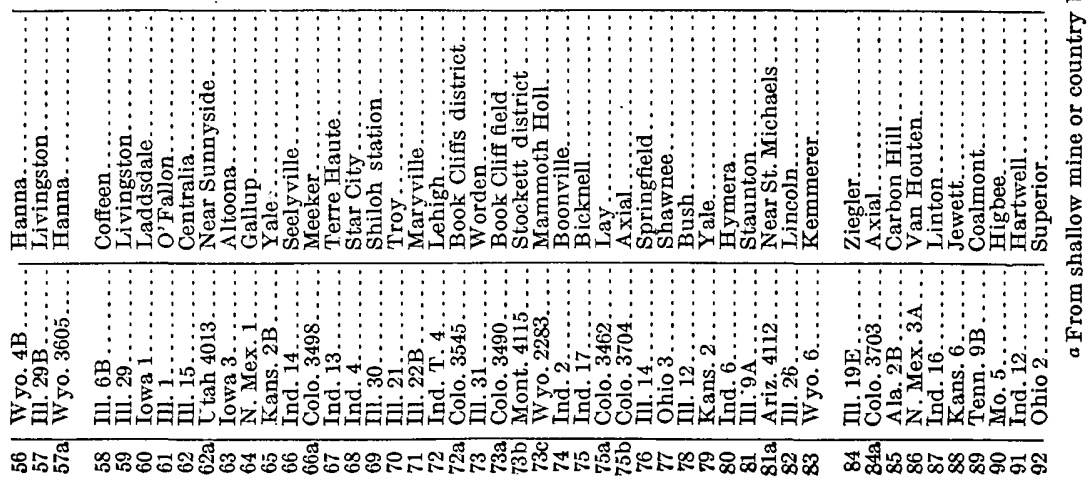




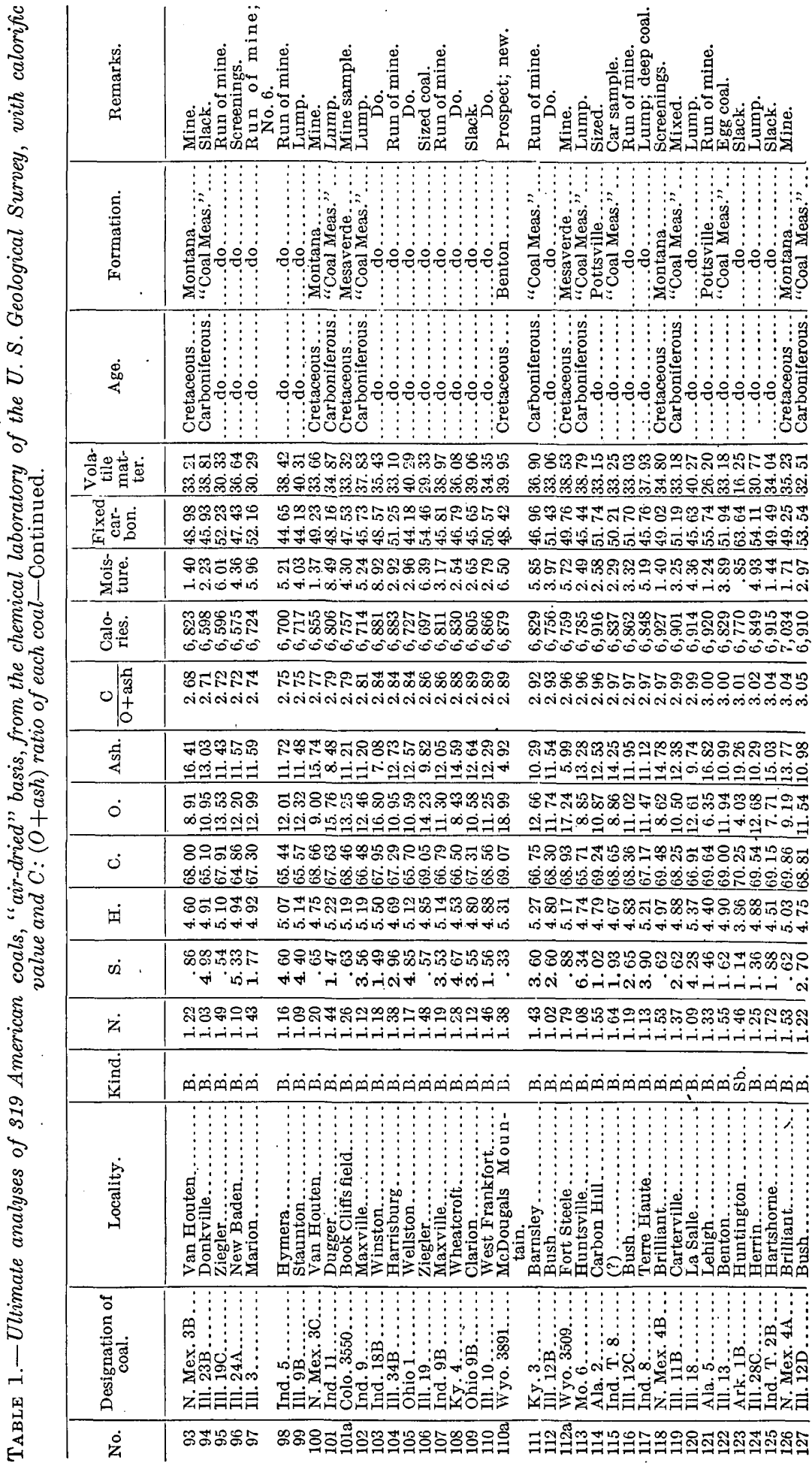




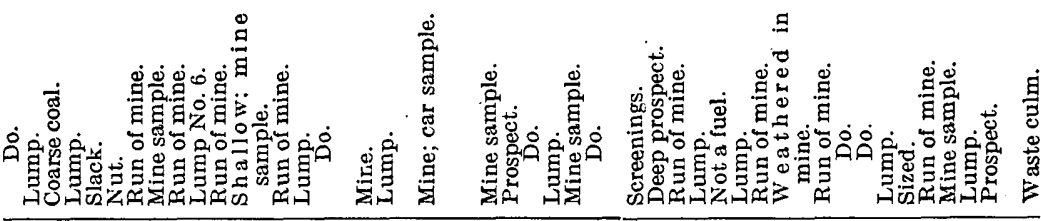

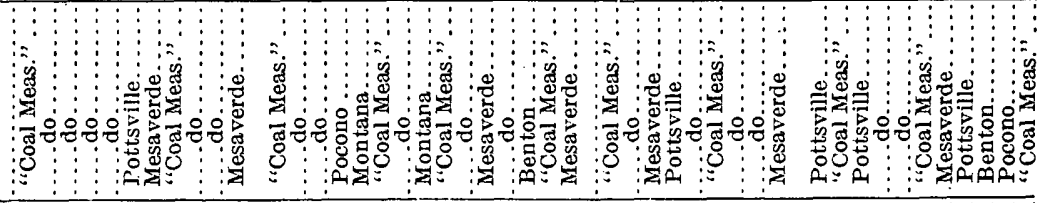

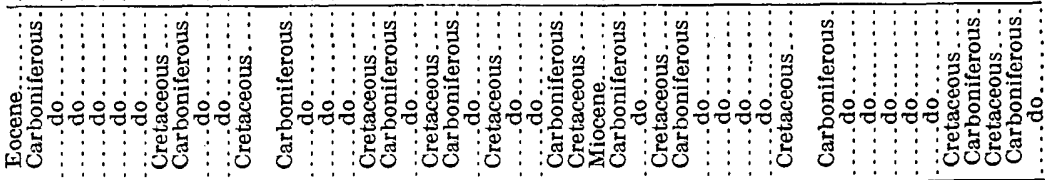

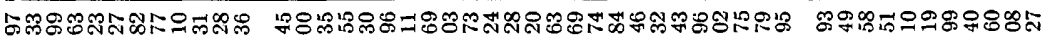

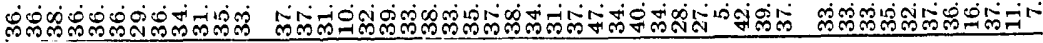

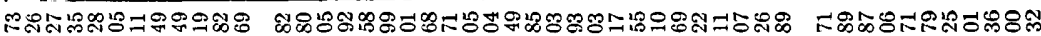

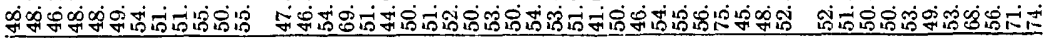

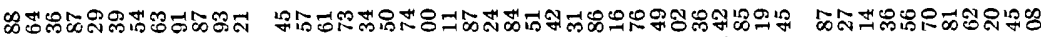

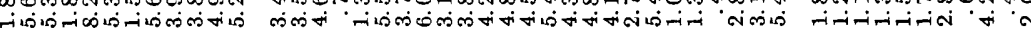

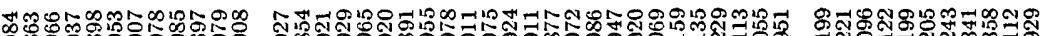

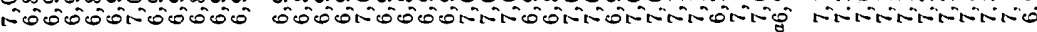

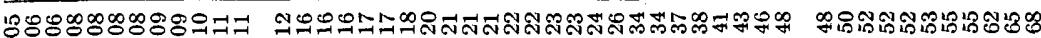

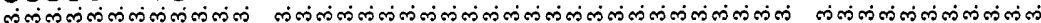

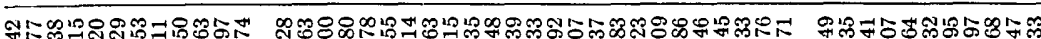

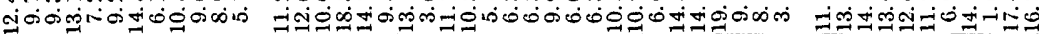

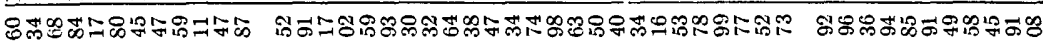

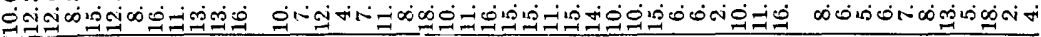

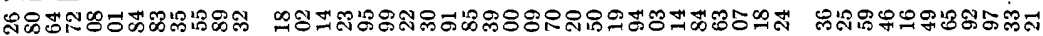

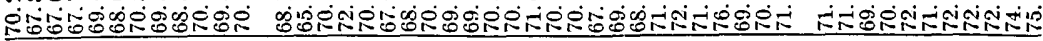

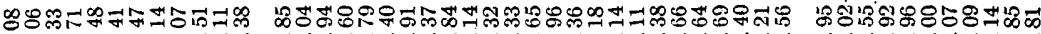

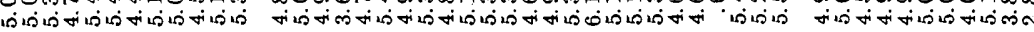

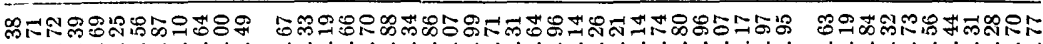

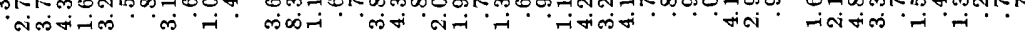

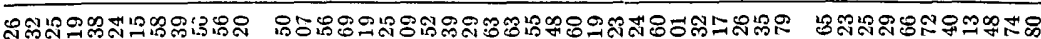

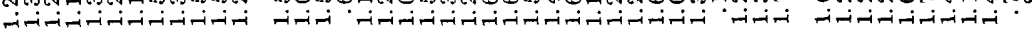

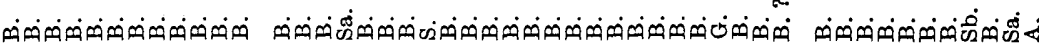

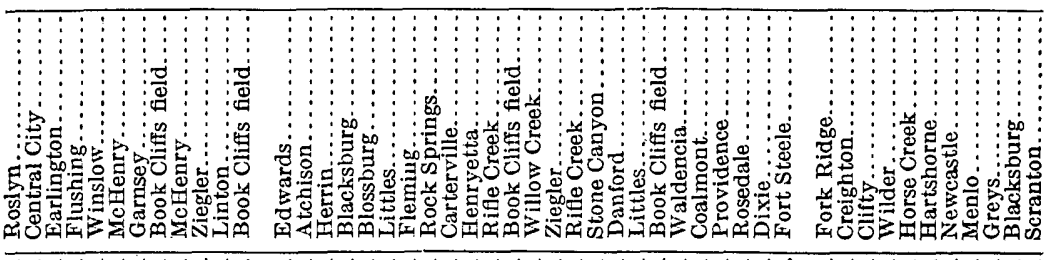

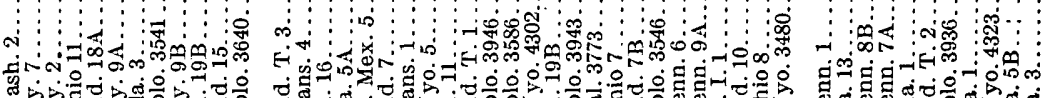

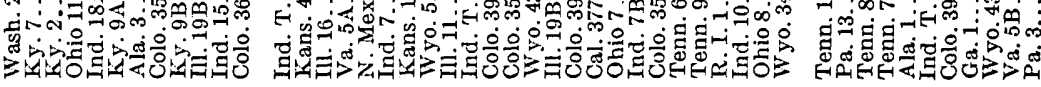

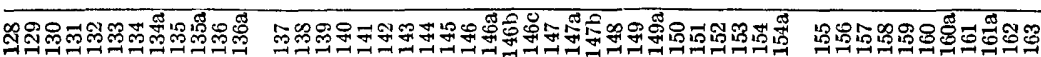
81144-Bull. 382-09-2 


\begin{tabular}{|c|c|}
\hline 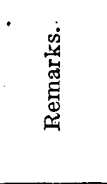 & 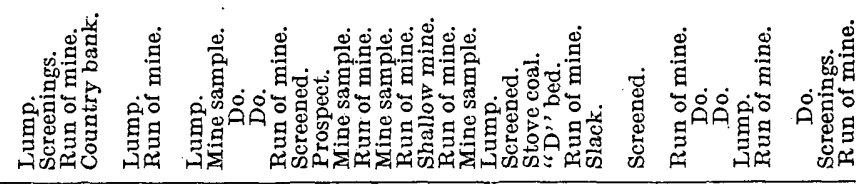 \\
\hline 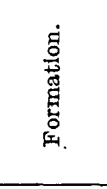 & 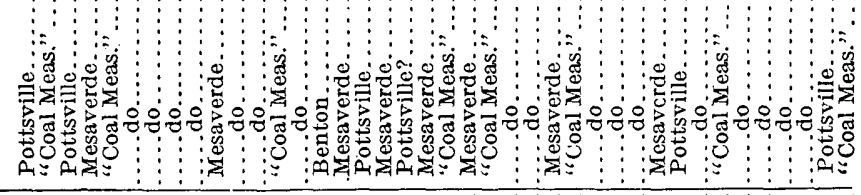 \\
\hline 我 & 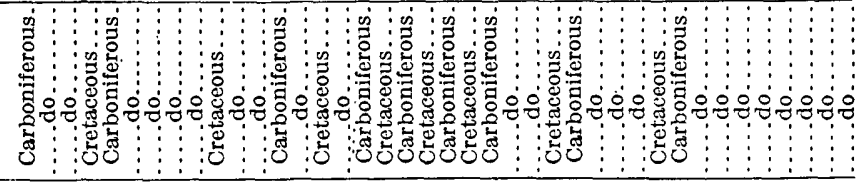 \\
\hline 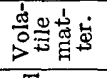 & 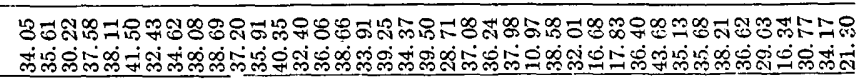 \\
\hline 要焉宫 & 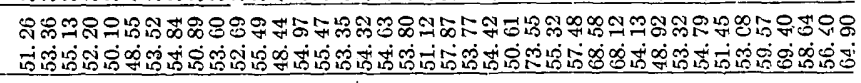 \\
\hline 奂通 & 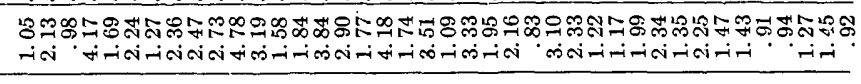 \\
\hline 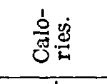 & 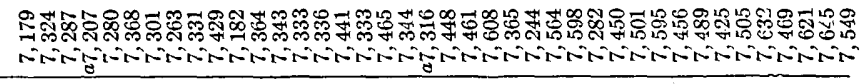 \\
\hline 0 & 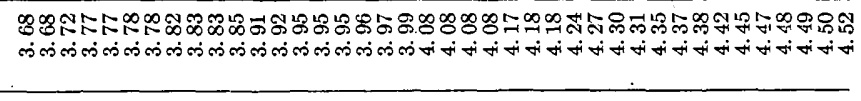 \\
\hline 昱 & 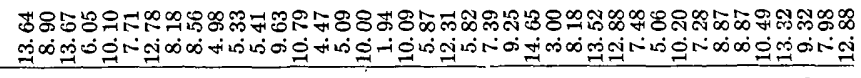 \\
\hline$\dot{0}$ & 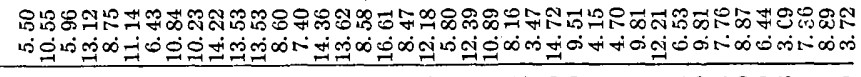 \\
\hline 0 & 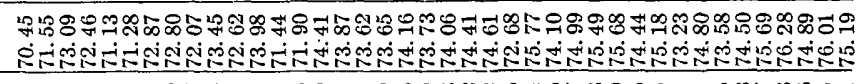 \\
\hline 届 & 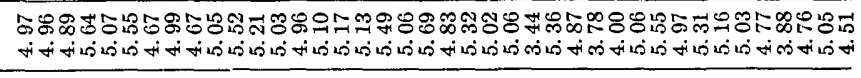 \\
\hline$\dot{\theta}$ & 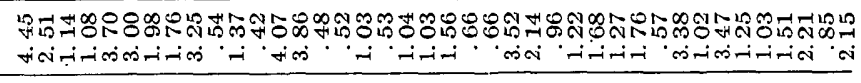 \\
\hline 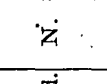 & 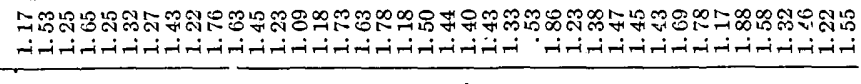 \\
\hline 焉 & 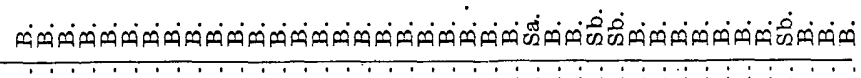 \\
\hline 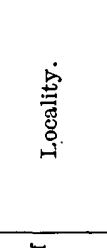 & 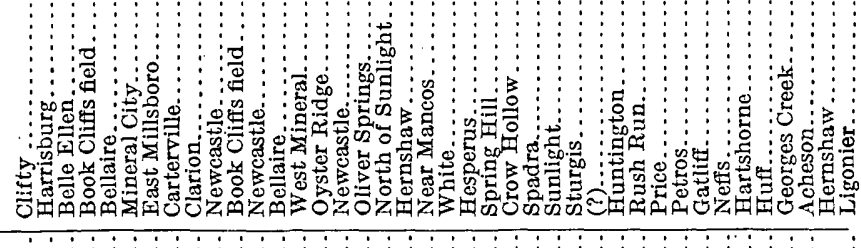 \\
\hline 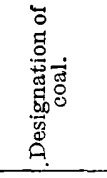 & 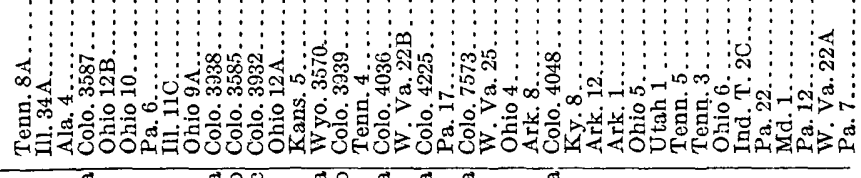 \\
\hline 8 & 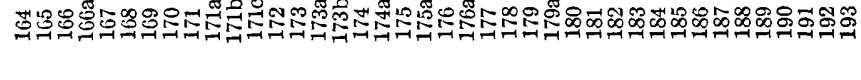 \\
\hline
\end{tabular}



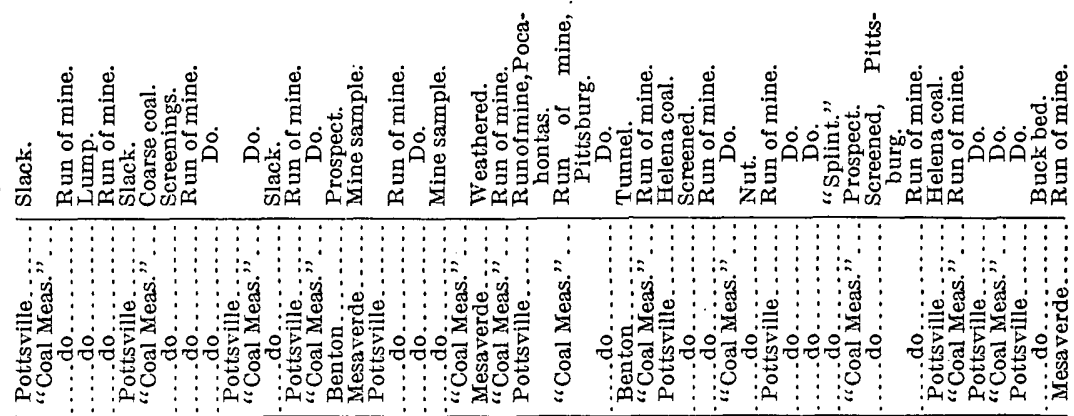

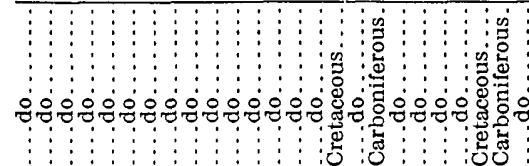

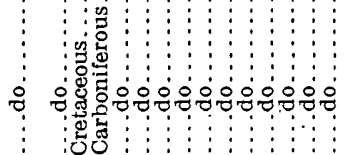

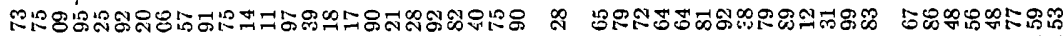

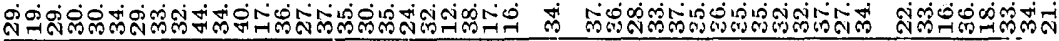

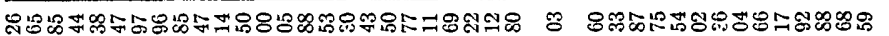

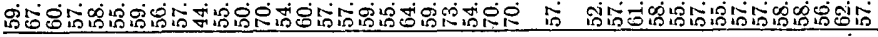

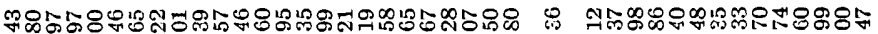

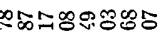
ginsinisio:

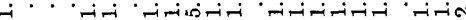

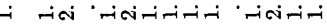

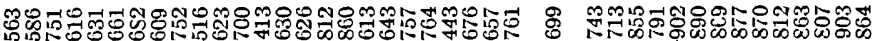

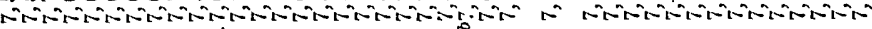

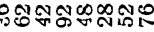
i. $-4-i-i$

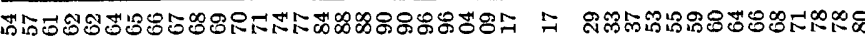

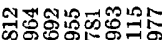

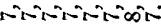

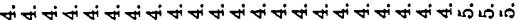

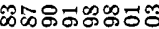

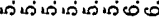

\begin{tabular}{|c|c|c|c|}
\hline 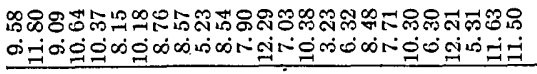 & 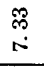 & 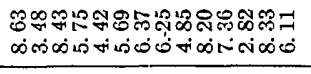 & 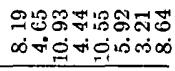 \\
\hline 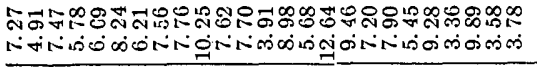 & $\underset{\mathscr{S}}{\stackrel{\circ}{\leftarrow}}$ & 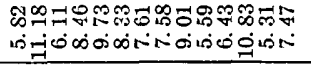 & $\begin{array}{l}\sin 20 \\
\sin \infty \\
\sin \alpha\end{array}$ \\
\hline 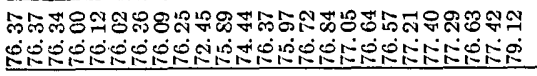 & 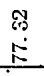 & pon & 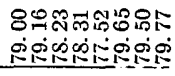 \\
\hline 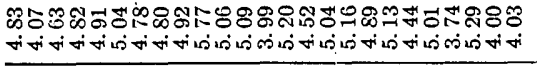 & $\begin{array}{l}8 \\
\text { is } \\
\end{array}$ & & \\
\hline 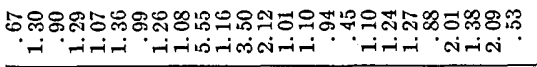 & $\stackrel{9}{\stackrel{-}{i}}$ & 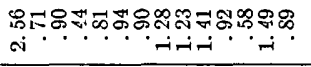 & 88.6 \\
\hline 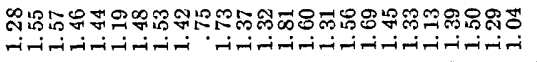 & $\stackrel{9}{i}$ & 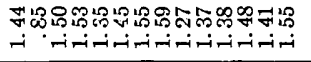 & min \\
\hline
\end{tabular}

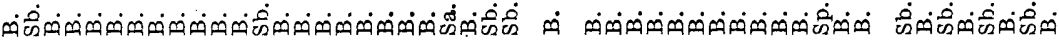

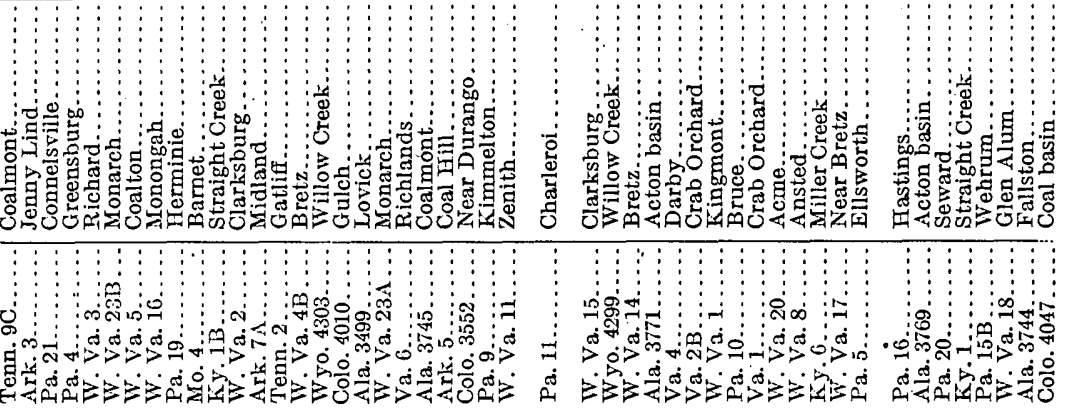

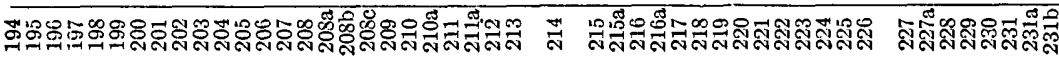




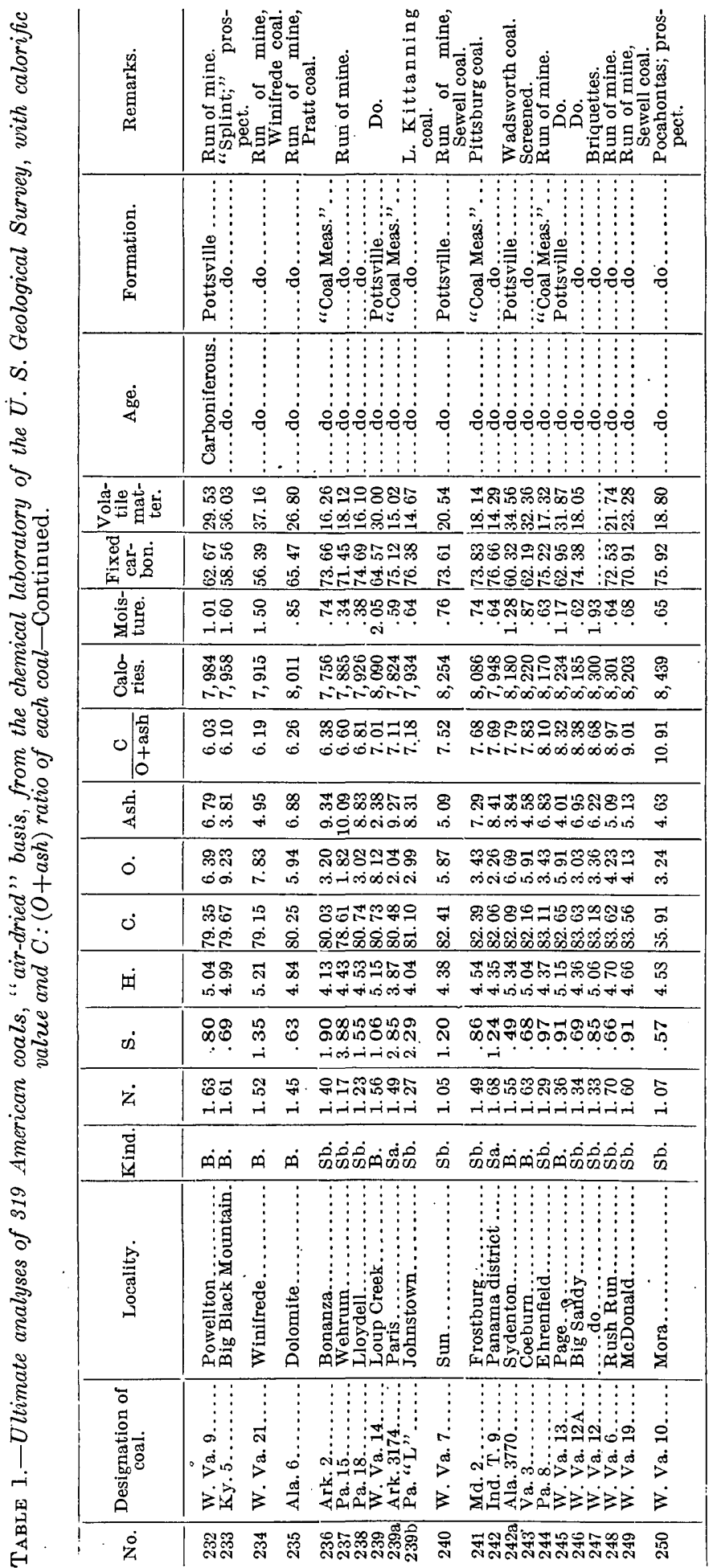


It must be borne in mind that the analyses in this table are arranged according to the numerical sequence of the $\mathrm{C}:(\mathrm{O}+\mathrm{ash})$ ratios of the samples. The calorific values determined directly from the same airdried samples by the Mahler bomb calorimeter are set down in the column adjoining that of the ratios. Most of the calorific determinations were made in duplicate.

It will be remembered that in the ultimate analyses of air-dried samples, such as are here considered, the highly variable remaining moisture is included in the percentages of hydrogen and oxygen. Therefore in many cases the greater part of the oxygen of the analysis belongs to the retained moisture. The amount of moisture, as set down to the right of the calories column in the table, varies from 26.64 (No. 3, N. Dak., 3) to 0.34 (No. 237, Pa., 15). The fixed carbon and "volatile combustible matter" ascertained from the proximate analyses, also on the air-dried basis, are placed next beyond the moisture column. It will be seen that the percentages of ash range from 29.33 (No. 21, Mexico) to 2.38 (No. 239, W. Va., 14); and of oxygen from 38.57 (No. 2b, Wyo., $3694^{a}$ ) to 1.82 (No. 237, Pa., 15). The arrangement of coals so widely varying in these two respects purely on the basis of the numerical sequence of the $\mathrm{C}:(\mathrm{O}+\mathrm{ash})$ ratios results in a mingling of fuels of very different kinds, characters, and ages, even bringing low-grade subbituminous coals (black lignites) into incongruous juxtaposition with Paleozoic coals of advanced devolatilization, the high oxygen of the former being balanced by the high ash of the latter.

FUELS HIGH IN OXYGEN OR ASH.

To show by specific illustrations the relative importance of oxygen and ash as indicated by the calorimetric tests, a few of the more conspicuous examples may be cited from Table 1: No. 8 (N. Dak., 1), from the Tertiary, has oxygen 27.15 and ash 12.24 , the ratio of the carbon to them being 1.31; while No. 10 (Ind. T., 5), from the "Coal Measures," has oxygen 12.40 and ash 25.75, the ratio of carbon being 1.37. In these two analyses the oxygen and ash are contrastingly paired. The difference between the calorific values of the two coals is not far from the value corresponding to the difference between the two ratios, as will be shown later. No. 25, a Fort Union coal, at Monarch, Wyo., shows oxygen 28.99 and ash 4.79; while in No. 27, from Ozone, Tenn., the percentages are nearly reversed, oxygen being 4.90 and ash 28.53. The difference between the calorific values of

\footnotetext{
a The abnormally high oxygen of this Wyoming coal is the result of weathering. For an oxygen content nearer normal, see No. 5 (N. Dak., 2B), with 35.86 ; or No. 25 (Wyo., 1), with 28.99 . That several of the lignites show more oxygen than the peats is due to the lesser moisture in the peat samples.
} 
these two coals accords within 1 per cent with the value corresponding to the difference in their $\mathrm{C}:(\mathrm{O}+$ ash $)$ ratios. Again, No. 30, a bony layer high in ash in the Pocahontas (lower Pottsville) bed, at Gary, W. Va., and No. 32, a Laramie coal, at Lafayette, Colo., are nearly paired, the oxygen being 3.97 and 24.95, respectively, and the ash 28.77 and 6.32 ; neither of the calorific efficiencies differs 0.75 per cent from the calorific values corresponding to the carbon ratios. A still closer agreement with No. 32 is presented by No. 35, from Bonanza, Ark.; the fixed carbon in pure coal of the latter is 78.97, while that of No. 32 is 'but 53.69. The Paisley, Ill. (No. 42), and the Sprague, Mo. (No. 43), coals have oxygen contents of 16.1 and 8.46 , respectively, their ash being 13.10 and 20.38; as compared with the calorific values corresponding to the respective ratios, ${ }^{a} 2.06$ and 2.08 , the former has a deficiency of 36 calories, the latter an excess of 25. The agreement of No. 41 (Hanna, Wyo.) with the coals just cited is equally close in spite of its low ash, the ascertained calories being but 14 less than the number corresponding to its ratio, 2.04. An almost equal agreement in calorific values is shown in the contrasting anaylst., No. 64, from the Upper Cretaceous, at Gallup, N. Mex., and No. 65, from the "Coal Measures," at Yale, Kans., in which the oxygen is 21.14 and 5.13 and the ash 7.10 and 21.82 , respectively. The error is not much greater between No. 100, from the Upper Creta. sus, at Van Houten, N. Mex., and No. 101, from the Carboniferous, at Dugger, Ind., in both of which the oxygen, at 9 and 15.76, is balanced by ash, 15.74 and 8.48.

\section{FUELS OF LOWER ASH AND OXYGEN.}

Passing on to coals of better quality, similar comparisons may be made between 119,120, and 121, in which there is marked alternation in the amounts of these impurities, though the total difference in the efficiency is less than 20 calories. A greater contrast in age and character of the samples is found in No. 140, from the basal Mississippian ("Lower Carboniferous"), at Blacksburg, Va., and No. 144, from the Upper Cretaceous, at Rock Springs, Wyo. In the former the proportions are oxygen 4.02, ash 18.80; in the latter, oxygen 18.32 and ash 3.63. The Virginia coal is semianthracite, with a fixed carbon in pure coal of 86.89 ; the Wyoming is a subbituminous coal, having a fixed carbon of but 57.19. These have efficiencies, the first 33 and the other 30 calories less than the values corresponding to their respective ratios, 3.16 and 3.20. The efficiencies of No. 153, from the Indiana coal field, and No. 155, from the Ten-

$a$ For calorific values corresponding to the ratio means, and for percentage ratios of volatile carbon, fixed carbon, available hydrogen, etc., see the same numbers in Table 2 (pp. 20-33).

$b$ Unusually high available hydrogen compensated by very high sulphur. 
nessee Pottsville, appear to conform very nearly to the means corresponding to the ratios, although the coals offer marked alternation in oxygen and ash. The Huntington, Ark., coal (No. 182) has a fixed carbon (in pure coal) of 79.25, and a Mesaverde coal, at Price, Utah (No. 184), but 52.68. The oxygen and ash nearly reciprocate at 4.70 and 12.88 against 12.21 and 5.06 , the ratios being 4.30 and 4.35 , respectively. The Huntington coal appears to have a deficiency of 60 calories, while the Utah coal has an equal number in surplus, the variance in either case being not more than 0.8 per cent of the calorific value.

Not to weary the reader with the details of further illustrations, a few additional comparisons are suggested as follows: Nos. 185 and $186 ; 193,194$, and $195 ; 199$ and $200 ; 216$ and 218; also Nos. 165 and $167 ; 131$ and $132 ; 94$ and $95 ; 39$ and 40 .

The more conspicuous contrasts noted in so many of these analyses naturally involve great differences in the kind and stage of development or maturity of the compared coals, whose proximate association in the table is due to the sequence of the raties. The regularity of the coals with similar analyses, though fromedifferent regions or of different kinds, is well illustrated by Nos. 60 to $63 ; 91$ and $92 ; 145$ and $146 ; 173$ and 174 ; and 220 to 223.

\section{RELATION TO CALORIFIC VAI, ¿E.}

However conspicuous or striking the contrasts offered by the examples specially cited above, the essential and most important evidence ' for the approximately equivalent negative values of oxygen and ash lies in the relatively close conformity, throughout the whole series, of the ascertained calorific values to the $\mathrm{C}:(\mathrm{O}+\mathrm{ash})$ ratios; so that not only do coals having the'same ratio closely approach the same efficiency values, but also the latter arrange themselves mainly in accordance with the sequence of the ratios. This may readily be noted in the series $25-50 ; 60-70 ; 87-125 ; 139-145 ; 164-176 a ; 182-$ 201 ; 211a-226; and 241-250.

It must not be forgotten that in this treatment the hydrogen, sulphur, and nitrogen are assumed to be constant and therefore negligible; also that the oxygen of the analyses includes the oxygen of moisture as well as that really of the coal-that is, presumably in hydrocarbon combination.

The nearness to equality in the negative values of oxygen and ash is indicated fairly distinctly in Table 1 . In a later section it will become more distinct, in connection with the discussion of the limits of variation from the ratio means, and the effect of the neglected "constants" as a cause of variance from a strict sequence in the calorific values. 
CURVE PLATTED FROM C: (O+ASH) RATIOS AND EFFICIENCIES.

\section{DETERMINATION OF CURVE.}

In order to ascertain the mean calorific values corresponding to the various ratios, the efficiencies of all the coals in the tables have been platted in Plate I. The horizontal component is the $\mathrm{C}:(\mathrm{O}+\mathrm{ash})$ ratio; the vertical is the heat value shown in the calorimeter tests. As thus platted the efficiencies are seen to describe a very clear and narrowly defined curve. The line in the figure is arbitrarily drawn to conform to the trend of this curve. Before proceeding, it may be remarked that the lower end of the curve is provisionally left dotted on account of the small number of wholly satisfactory analyses of the lowest grade coals, many samples having been more or less affected by exposure to the air. Also at the upper end additional analyses are needed for its more exact determination.

Considering that the hydrogen, sulphur, and nitrogen contents are here absolutely ignored and treated as negligible constants, the comparative proximity and regularity in the distribution of the efficiencies along the course of the curve is certainly remarkable. This regularity is explained (see p. 44) as due to the dominant control of the carbon, on the one hand, balanced by the chief impurities, oxygen and ash, on the other, in determining the calorific efficiencies of the ordinary types of the fuels, the hydrogen being either relatively stationary or, when in excess, more or 'less completely counteracted by relatively high sulphur, nitrogen, or unusually high ash, which may be slightly more deleterious than the oxygen. By referring to Table 1 it will be observed that the instances of wider departure from the curve are largely confined either to the weathered samples or to approaching anthracitization. The curve is particularly interesting because it is adjusted to a miscellaneous collection of coals of all grades, ages, and localities. It is not improbable that slight readjustments or special curves will be required for special groups of coals, like the cannels, or to suit the peculiarities of the coals of a given area.

\section{DETAILED STUDY OF A CURVE SEGMENT.}

The relative values of oxygen and ash and the approximation of the curve are diagrammatically expressed in Plate II, which shows on a large scale a section of the curve, embracing Nos. 25-50 of Table 1. Several of the intercalated analyses of samples, in some instances weathered, collected by the field geologists and recently published in U. S. Geol. Survey Bulletin 316, are here omitted. All fuels tested by the Survey are, however, included. The samples represent coals in Wyoming, Montana, Illinois, Tennessee, Missouri, West Virginia, Colorado, New Mexico, Arkansas, Iowa, and Washington. For description of the kind and age of each coal the reader is referred 


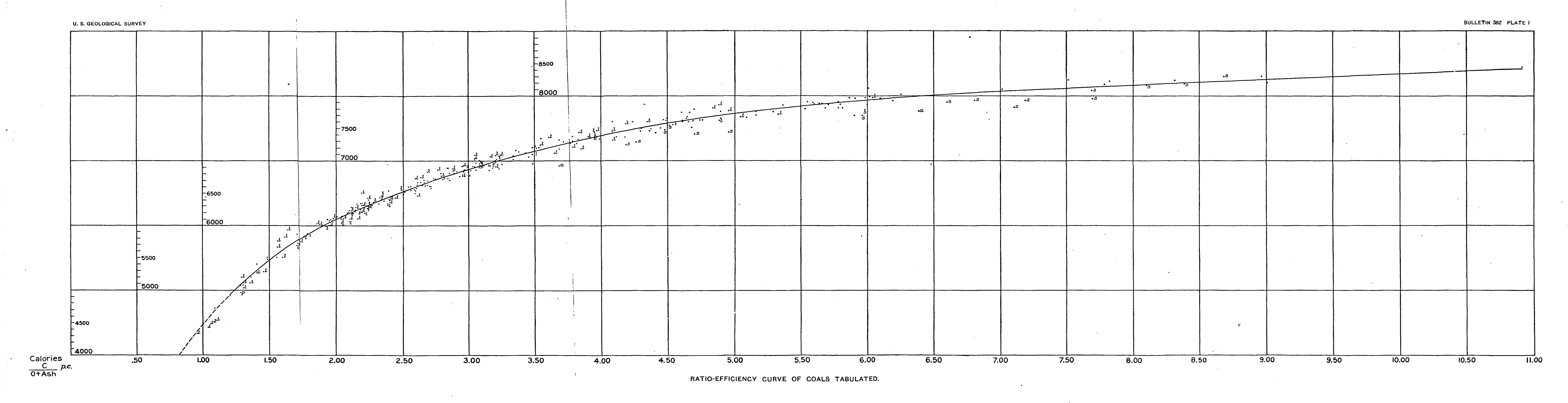




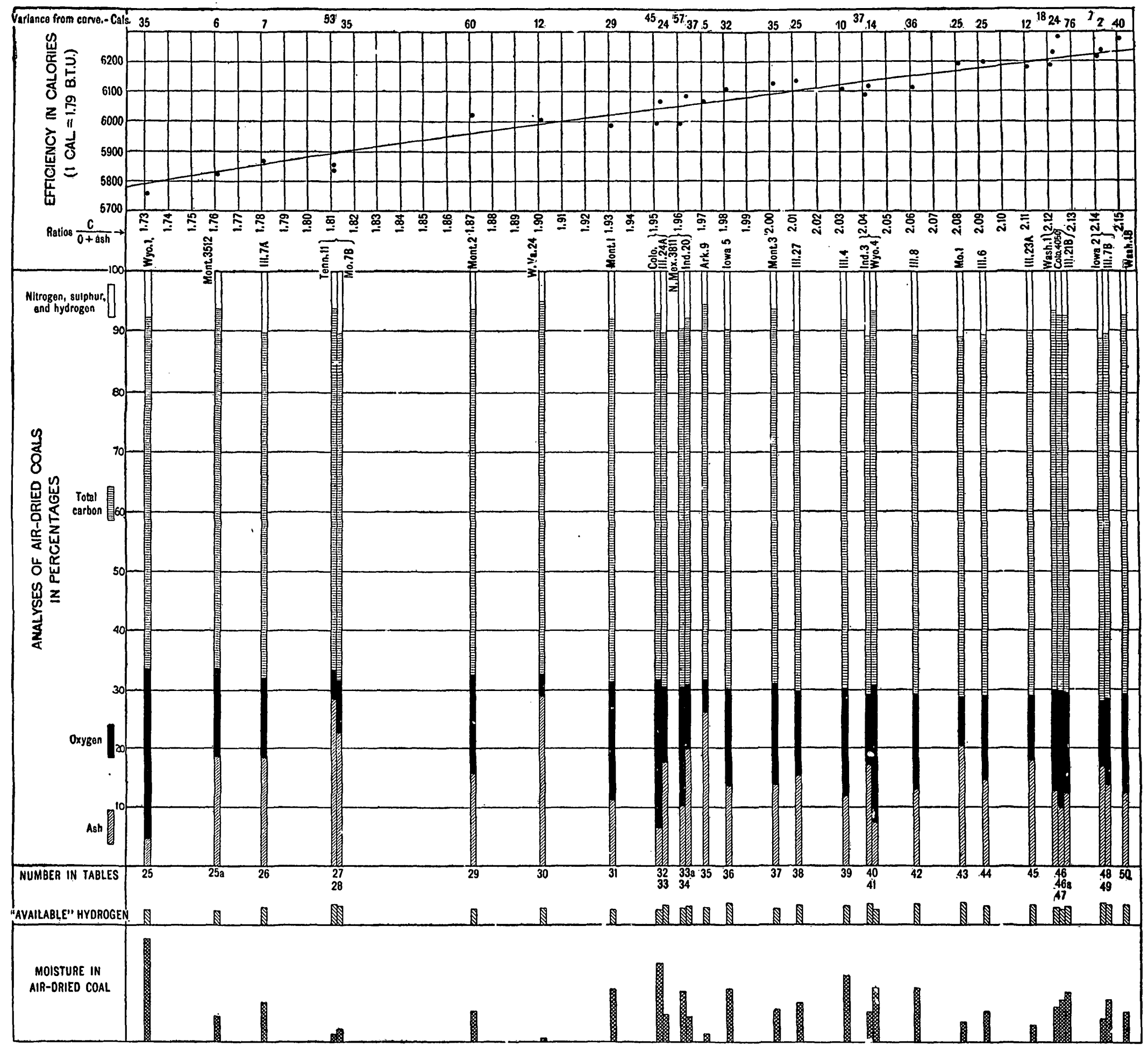


to Table 1. The segment of the curve taken from Plate $I$ occupies the upper part of the diagram. As in Plate I, the vertical component represents the calorific efficiency and the horizontal component represents the $\mathrm{C}:(\mathrm{O}+\mathrm{ash})$ ratio of the coal.

The lower middle portion of the diagram shows the ash, oxygen, and carbon of the respective analyses, each analysis being platted in a position corresponding to that of its ratio in the horizontal component of the curve. The hydrogen, sulphur, and nitrogen, whose aggregate complete the 100 per cent in the analysis, are left blank and undifferentiated above the carbon. For information, what is termed "available" hydrogen $\left(\mathrm{H}-\frac{\mathrm{O}}{8}\right)$ and the moisture contained in the air-dried coal are separately platted at the base of the diagram.

The disposition of the calorific values close along the line of the curve in Plate II seems to indicate (1) the approximately equal importance of oxygen and ash in impairing the efficiency of the coal in the calorimeter; (2) the relatively close agreement of the ascertained efficiencies to the $\mathrm{C}:(\mathrm{O}+\mathrm{ash})$ ratio-efficiency curve; (3) the dominant control of the carbon, oxygen, and ash in determining the calorific value of the coal; and consequently (4) the relative constancy or negligibility of the other elements (assumed constants) nitrogen, sulphur, and hydrogen.

\section{VARIATIONS FROM THE CURVE.}

The curve errors-that is, the variations of the actually ascertained calorific values from the curve line-are noted, each in horizontal position corresponding to the analysis; at the upper border of the diagram. A review of these errors or variations shows an average departure of but 29 calories for the 29 analyses of the diagram.

In this connection it may be interesting to compare the calorimetrically determined values with those indicated by the curve and with the efficiencies as calculated from the chemical analyses. Reference to Professional Paper No. 48 of the Survey, in which such calculations of the efficiencies of coals were published, shows that eight of the samples which reappear in this diagram are included in that report. ${ }^{a}$ The greatest variance in the chemical calculations of these eight analyses is 171 calories. The average variance is 89 calories. The average ratio-efficiency curve error for the same eight analyses, as shown in the dingram, is 23 calories; the highest individual error in the entire diagram is 76 calories.

The efficiency variance, that is, the variation of the calorimeter determination from the ratio $\mathrm{C}:(\mathrm{O}+\mathrm{ash})$ efficiency curve-as read with

a Report on the operations of the coal-testing plant of the U. S. Geological Survey at the Louisiana Purchase Exposition, St. Louis, Mo., 1904: Prof. Paper U. S. Geol. Survey No. 48, 1906. The samples there included are as follows: No. 25 , error +171 ; No. 31, error $+119 ;$ No. 32 , error +136 ; No. 35 , error + 60; No. 39, error + 44; No. 43, crror - 15; No. 44, error + 140; No. 48, error +29 . 
some care from the large-scale original of Plate I-is noted for each of the 319 analyses in a column at the right in Table 2. The curve drawn in the diagram (Pl. I) is not entirely regular nor mathematically correct, but it is probable that its subsequent correction, based on additional data, will have the effect of lowering the mean variances of the analyses as now platted. The calorific variances in Table 2 are therefore subject to revision. Omitting from further consideration the Rhode Island graphitized coal, which, being incombustible in its natural state, can not be regarded from the fuel standpoint as a coal, the highest error for an individual analysis is 312 calories, for the anthracite culm (No. 163) at Scranton. For the 318 analyses the average error is 67.2 calories. This includes the weathered coals and samples from shallow country banks and prospects, as well as the coals undergoing the final devolatilization marking anthracitization, all of which, as has already been observed, show relatively large errors. If, however, we but exclude 18 of the highest coals, embracing those having a fixed carbon of over 79 per cent in pure coal and a $\frac{\mathrm{VC}}{\mathrm{C}}$ ratio of less than 9.25 (per cent) we shall have for the 300 remaining analyses a mean error of 60.09 calories. This average, it may be noted, does not exclude the weathered coals in the table.

\section{COMPARISON WITH CALCULATED THERMAL UNITS.}

Referring again to Professional Paper 48, in which the calorific values as calculated from the chemical analyses are published, we find that among the 57 ultimate coal analyses there given, all of which are included in Tables 1 and 2, the greatest individual error ${ }^{a}$ is 312 , as large as the maximum in all the coals of the tables, while the average error is 87.5 calories. The average ratio-efficiency curve error for the same 57 analyses, as shown in Table 2 , is 58.7 calories. It may be proper to allow 2 or 3 calories additional to the average of Table 2 for personal equation in reading from the curve. In passing we may note that in very many cases the curve error appears to be less than the probable error of the calorimeter. The empirical anticalorific values of ash and oxygen as roughly calculated from the curve and the influence of sulphur in the coals are considered later (pp. 39, 44).

\section{FORECAST OF FUEL EFFICIENCY FROM RATIOS.}

The close relationship between the calorific values and the curve not only conclusively shows the nearly equal anticalorific values of the oxygen and ash, it also shows that the heat value of the coal as a whole is practically determined by the balance between these two principal impurities, on the one hand, and the total carbon on the other. The ordinary method of estimating the heat value of a coal, 
in accordance with Du Long's formula, generally used by chemists, is to calculate the sum of the heat units afforded by the carbon, hydrogen, and sulphur. The formula as recommended by the committee of the American Chemical Society is $8080 \mathrm{C}+34460\left(\mathrm{H}-\frac{\mathrm{O}}{8}\right)+2250 \mathrm{~S}^{a}$

The comparative study here presented demonstrates an approximate negative parity of oxygen and ash assumed in the application of Du Long's formula. It is surprising that a simple process like the ratio-efficency curve which takes account only of the carbon, the preponderant source of heat units, and of the two great anticalorific ingredients of the fuel, should in a relative way so nearly indicate its calorific value. Such an effect seems explicable only (1) by the relatively uniform amount of heat contributed by the hydrogen as compared to that of the variable carbon, notwithstanding its great heating power; and (2) by the relatively constant negative potency, as well as proximity to anticalorific equality of ash and oxygen, whether the latter be in hydrocarbon combination or in the form of moisture. In this connection it may be noted that the calorific value in No. $2 \mathrm{~b}$ is but 150 calories below the curve, though the coal contains no available hydrogen whatever, according to the analysis.

That the curve errors are not more exaggerated on account of the variability of the hydrogen, both in total amount and in the "available" form, is surprising. In the high-grade cannels, like that at Lesley, Ky. (H 6.82, O 73.54, O 7.95, ash 9.35, moisture 1.31), and in the bogheads, the relatively high hydrogen produces an efficiency considerably above the curve. For this class of coals either a coefficient for excess may be used or a higher curve drawn.

\section{RELATIONS IN MOISTURE-FREE COALS.}

\section{RECALCULATION OF ANALYSES.}

In Table 1 the analyses of the air-dried coals naturally included under the hydrogen and oxygen percentages the moisture remaining in the fuel. For the purpose of observing the true proportions of the oxygen arid hydrogen assumed to belong to the moisture-free coals themselves it is necessary to take from the percentages this included moisture. In Table 2 the moisture is excluded from the oxygen and hydrogen columns. Yet in order to preserve the conformity of the analysis to the original air-dried status of the fuel, on the basis of which the calorific values were actually determined, the moisture is set down as a separate entry, included in the 100 per cent of the analysis. Ash, carbon, nitrogen, and sulphur remain as before. The fixed carbon and the volatile matter, as determined by the proximate analysis, are repeated from Table 1 , as also are the $\mathrm{C}:(\mathrm{O}+\mathrm{ash})$ ratios and the calorific values. 


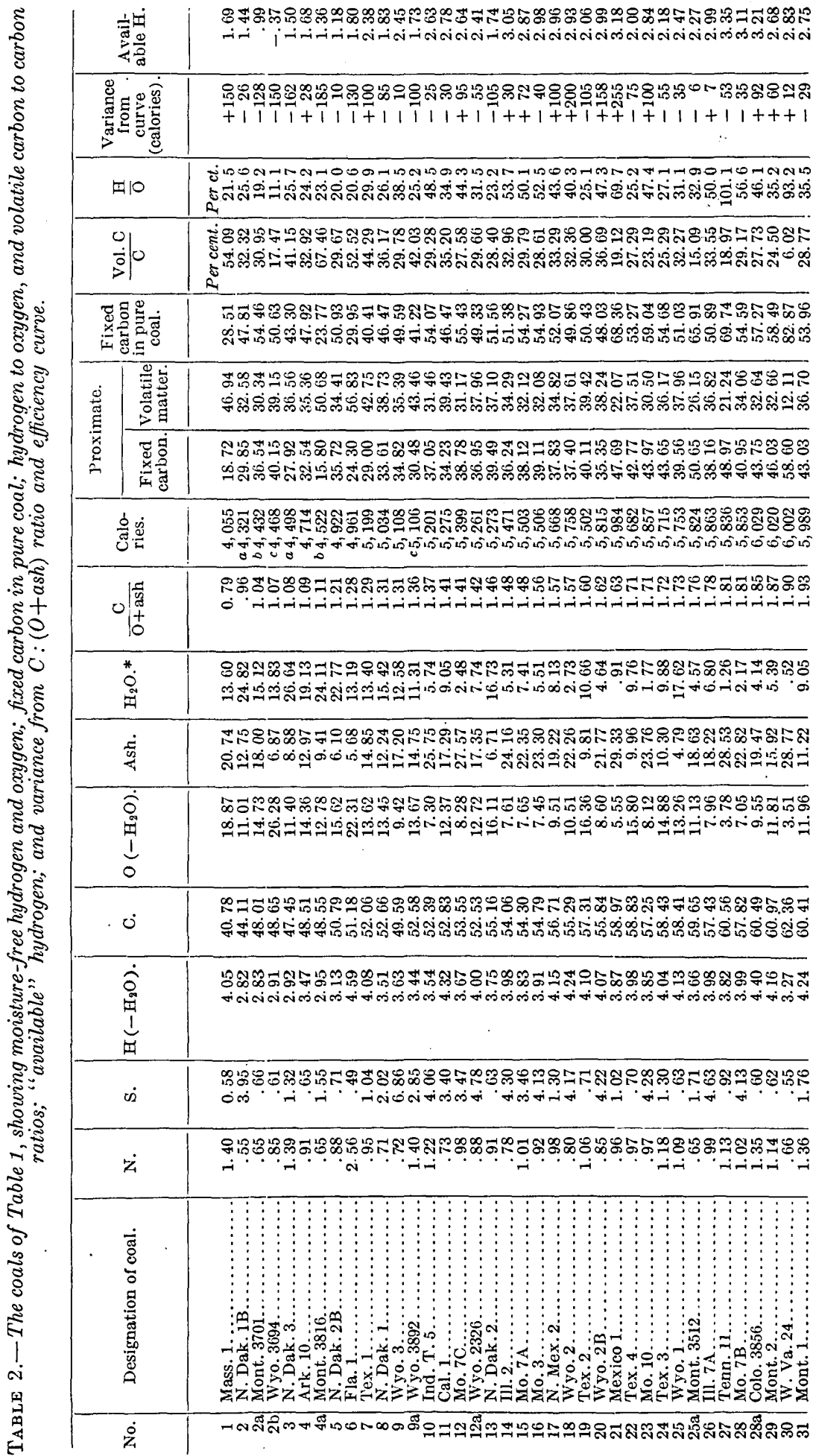


ำ

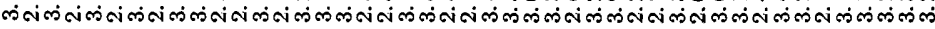

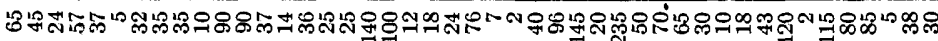
$+1+1++++1 \mid 11111++1111++1+++11+11++111111+1++++$

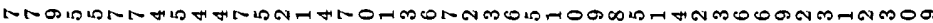

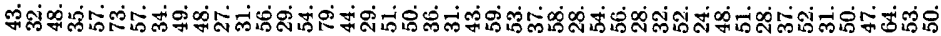

๓ ลผ ผึ่

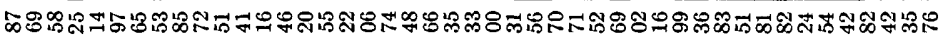

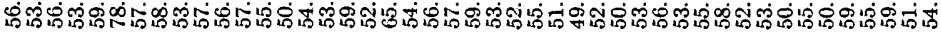

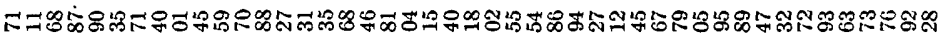

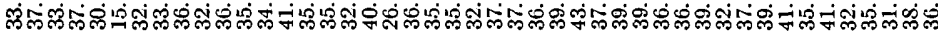

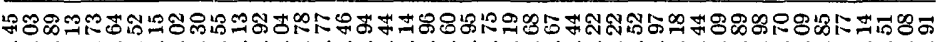

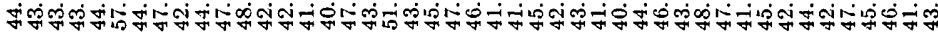

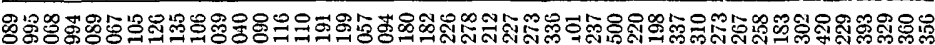

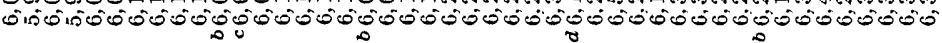

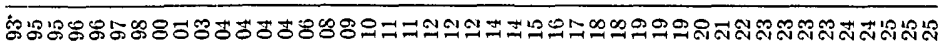

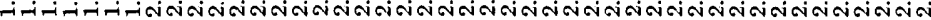

ㅇํㅇำ

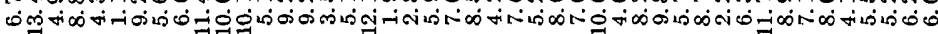

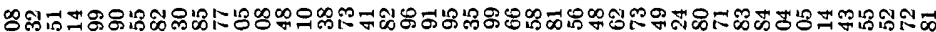

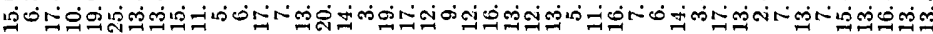

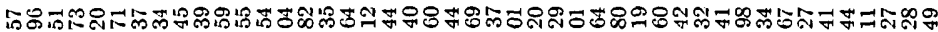

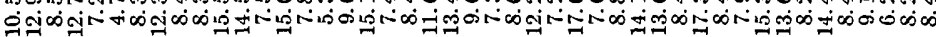

ニఇผ

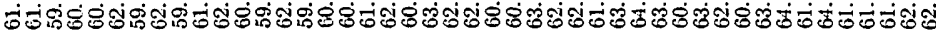

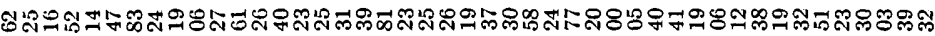

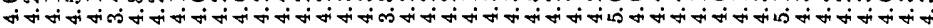

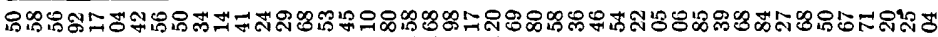

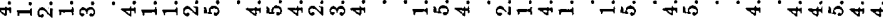

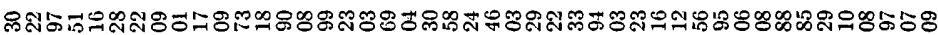

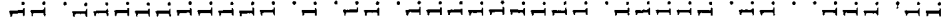

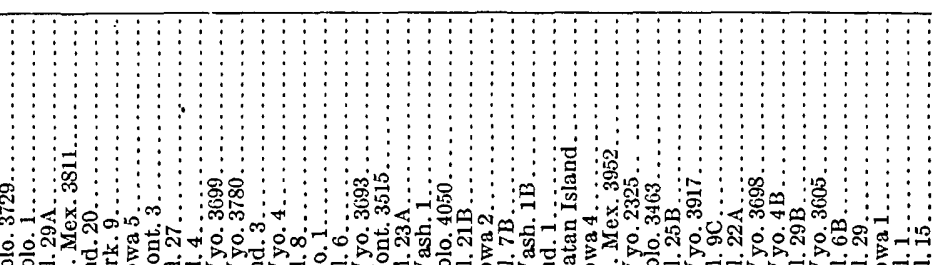

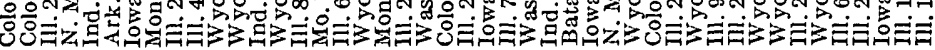

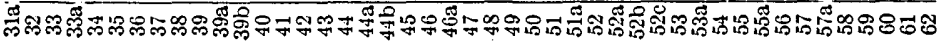




\begin{tabular}{|c|c|c|}
\hline : & 施苞 & 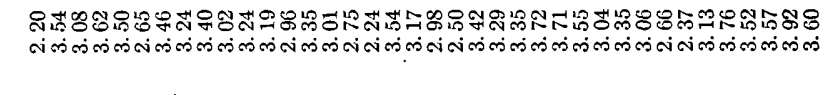 \\
\hline$\xi$ & 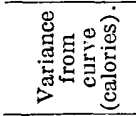 & 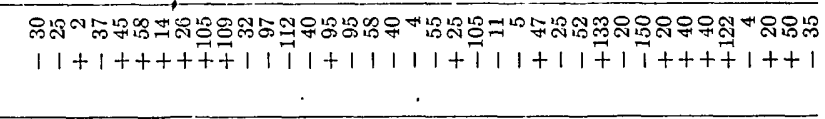 \\
\hline 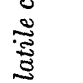 & म10 & 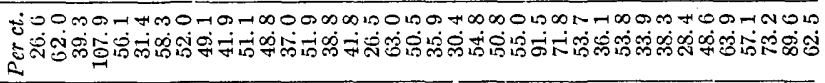 \\
\hline هं & ن & 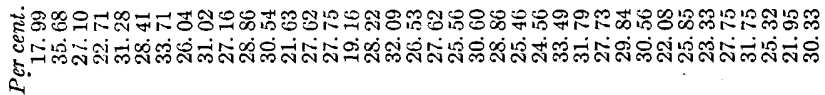 \\
\hline sis & 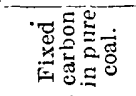 & 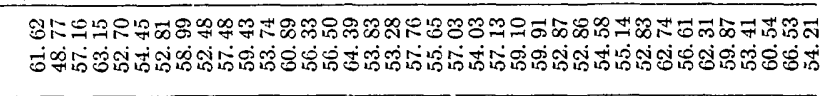 \\
\hline 1 & 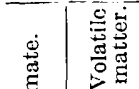 & 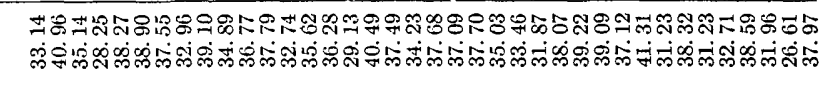 \\
\hline ร & 跑 & 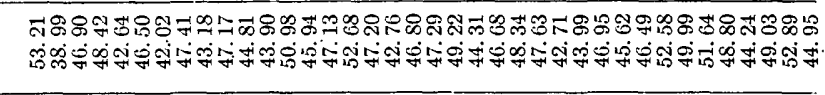 \\
\hline 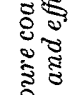 & $\dot{\partial}$ & 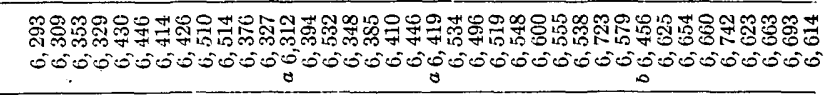 \\
\hline$\varepsilon$ & $\left.\right|_{0} ^{0}$ & 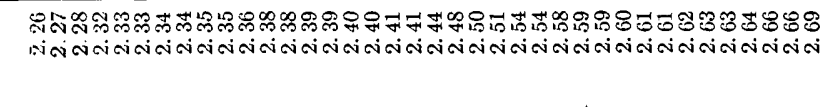 \\
\hline 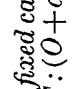 & 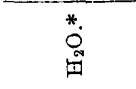 & 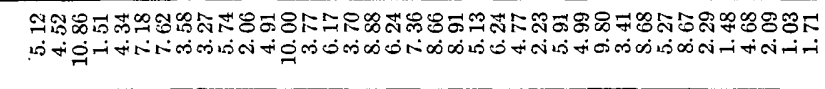 \\
\hline & 它 & 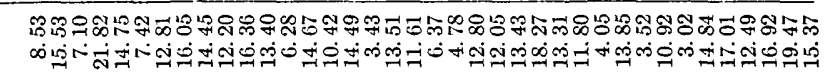 \\
\hline है & $\begin{array}{l}\dot{0} \\
\text { Tิ9 } \\
1 \\
1 \\
0\end{array}$ & 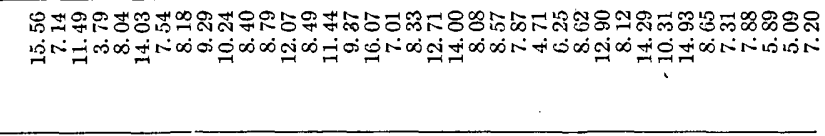 \\
\hline & ن & 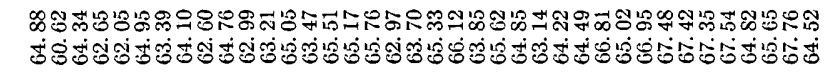 \\
\hline 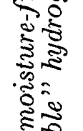 & $\begin{array}{l}\dot{0} \\
\text { 垔 } \\
1 \\
\text { I }\end{array}$ & 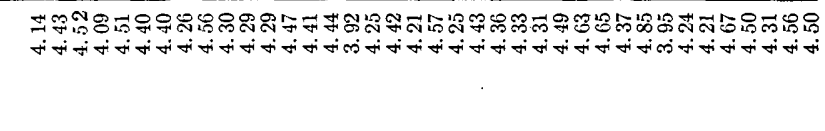 \\
\hline. & $\dot{\phi}$ & 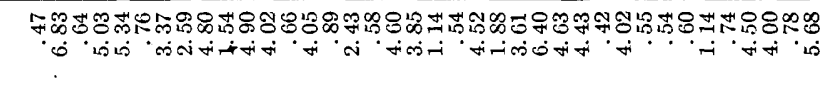 \\
\hline 象 & $\dot{z}$ & 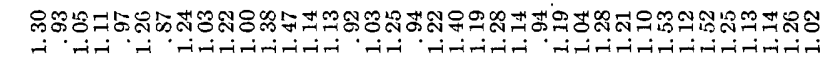 \\
\hline है & 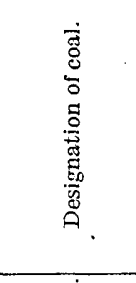 & 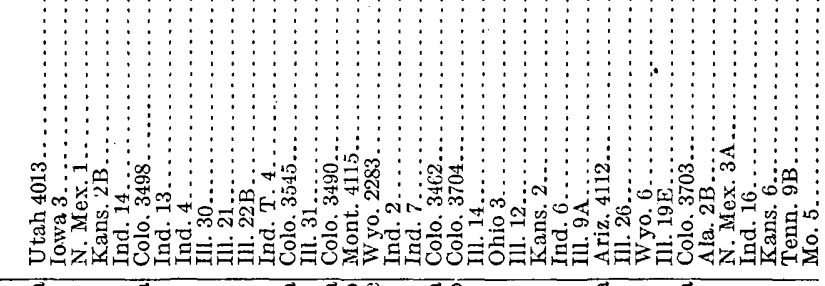 \\
\hline & $\dot{\dot{\alpha}}$ & 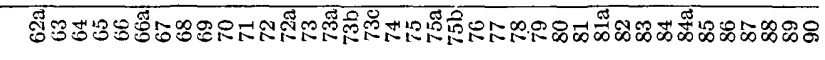 \\
\hline
\end{tabular}




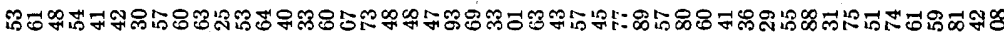

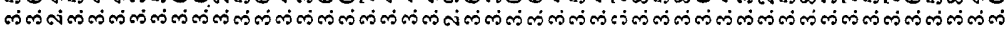

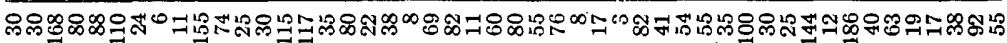
$+1711 \hat{1}+1+\overrightarrow{+}++1+71 \cdot 1++++++111+1++++++111+++++1++1+++$

On DOA เท่

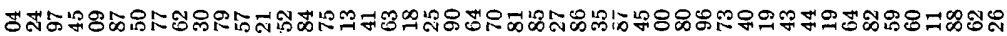

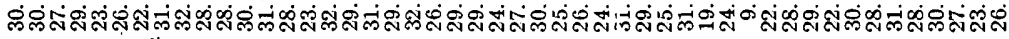

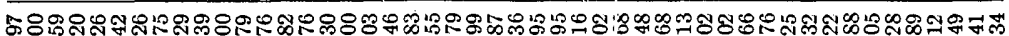

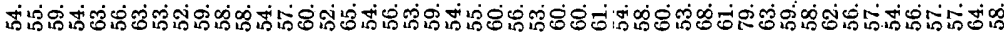

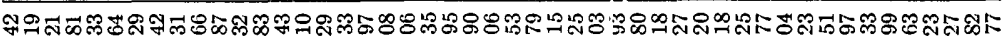

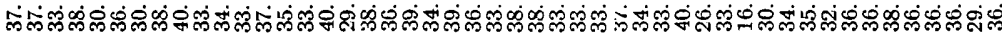

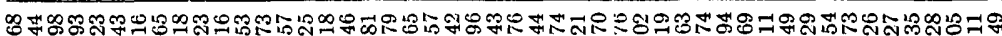

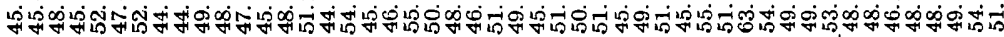

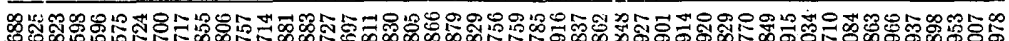

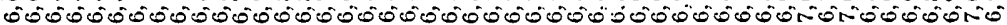

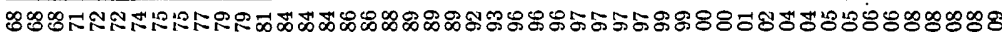

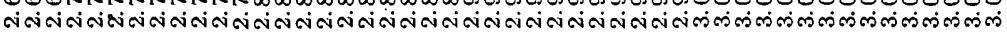

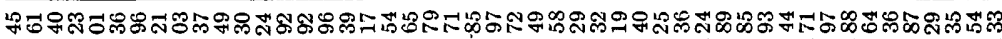

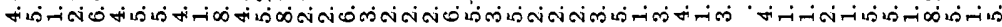

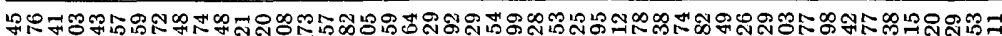

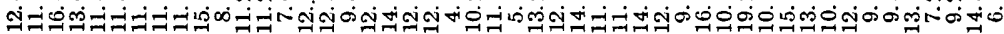

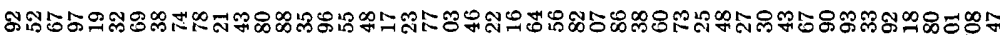

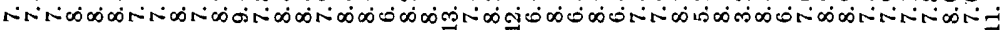

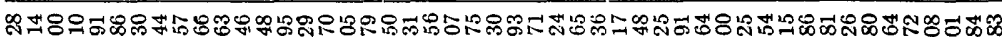
ஆ்

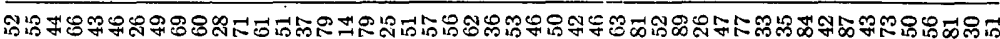

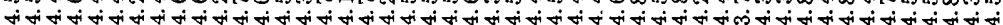

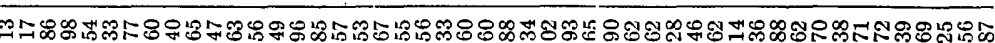

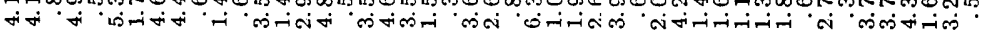

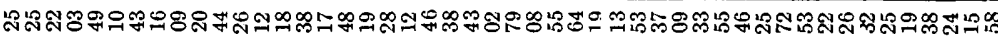

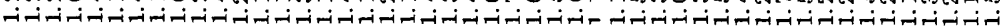

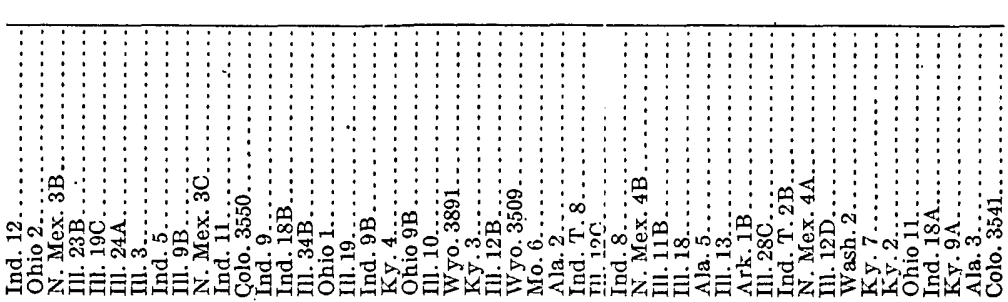

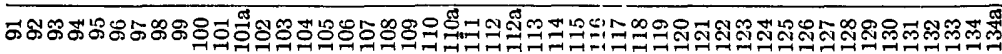




\begin{tabular}{|c|c|c|}
\hline है & 光迎 & 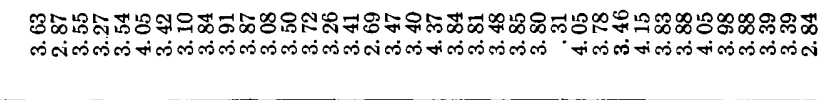 \\
\hline & 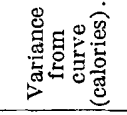 & 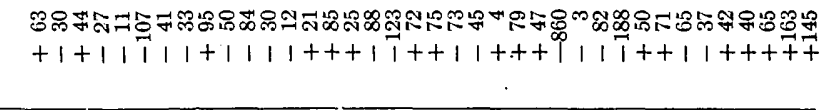 \\
\hline & A10 & 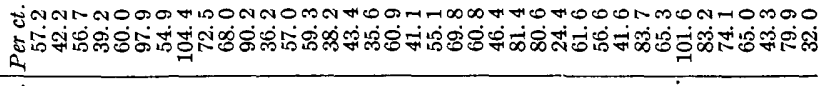 \\
\hline 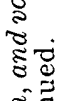 & $\begin{array}{l}0 \\
\dot{0} \\
i\end{array}$ & 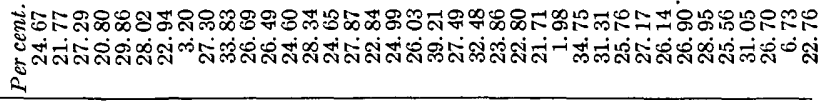 \\
\hline בृ & 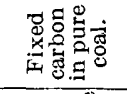 & 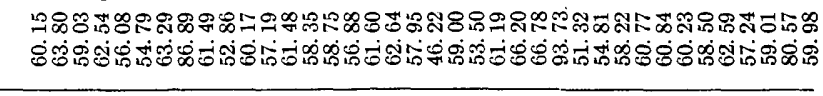 \\
\hline รั) & 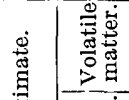 & 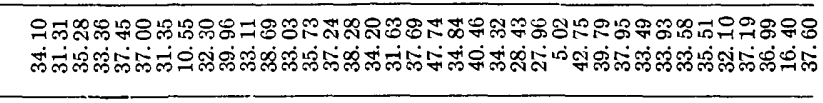 \\
\hline & 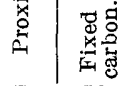 & 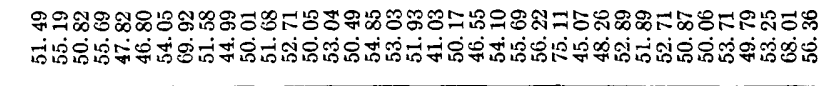 \\
\hline ริ) & 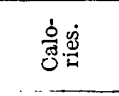 & 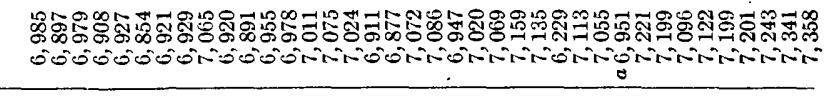 \\
\hline 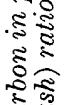 & $0 \mid \begin{array}{l}10 \\
\overbrace{0}^{2}\end{array}$ & 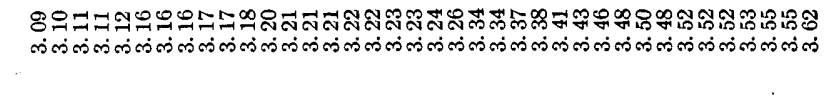 \\
\hline & $\stackrel{\leftrightarrow}{\circ}$ & 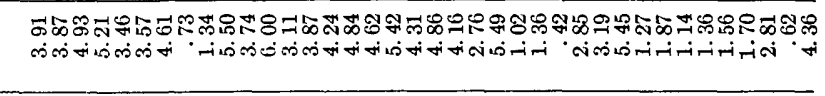 \\
\hline & 窇 & 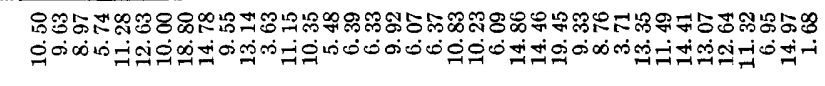 \\
\hline (ְ) & $\begin{array}{l}\dot{0} \\
\text { में } \\
1 \\
0\end{array}$ & 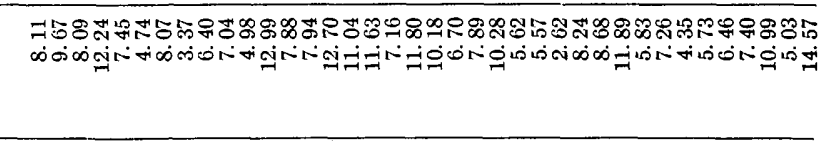 \\
\hline & $\dot{0}$ & 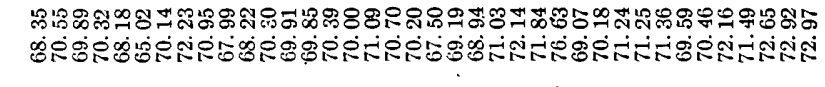 \\
\hline 今 & 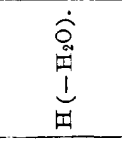 & 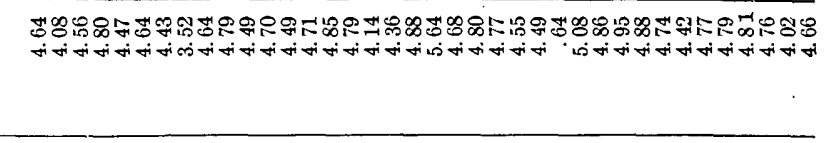 \\
\hline 莡 & $\dot{v}$ & 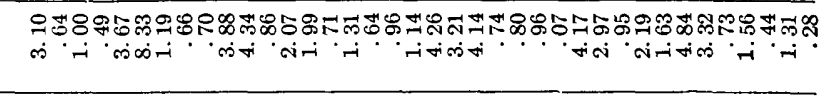 \\
\hline in & r' & 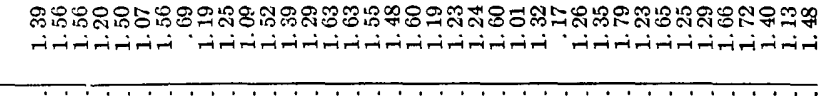 \\
\hline & 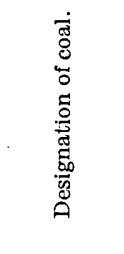 & 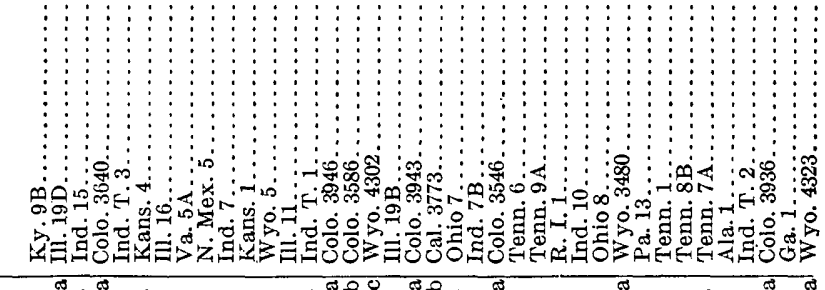 \\
\hline & $\dot{0}$ & 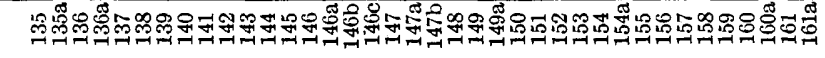 \\
\hline
\end{tabular}




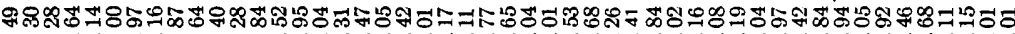

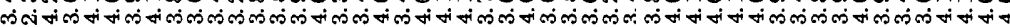

มำำ

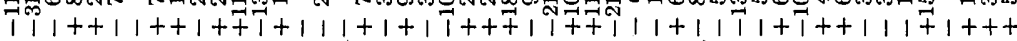

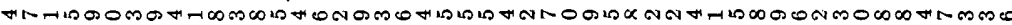

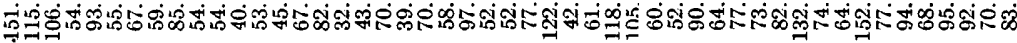

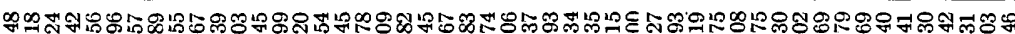

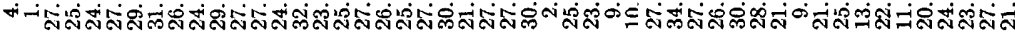

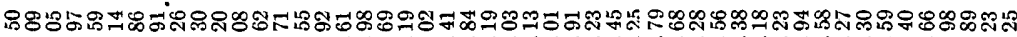

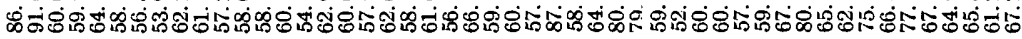

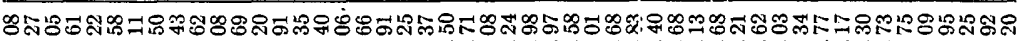

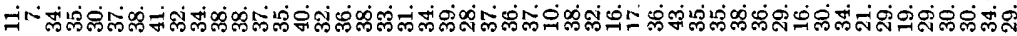

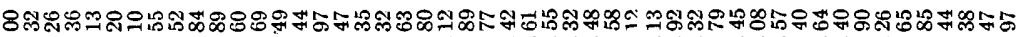
춘

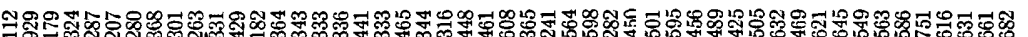

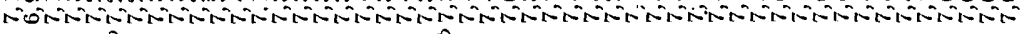
0

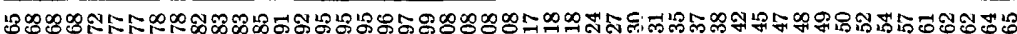
ம்ற ம

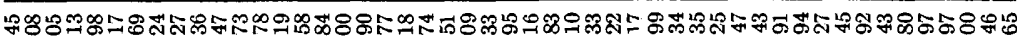

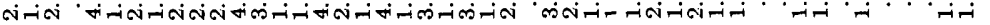

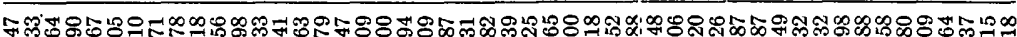
出

แลก์8

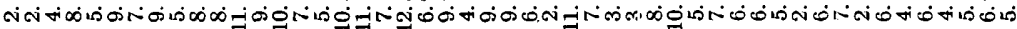

ஜำ多:

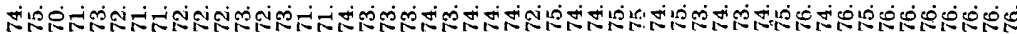

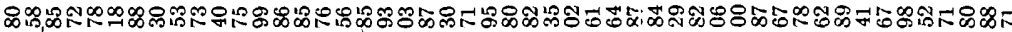

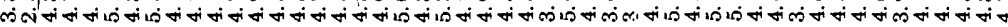

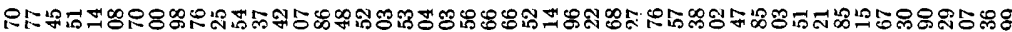

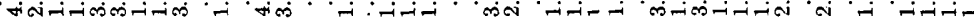

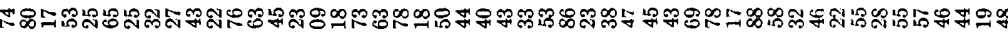
-i ri -i

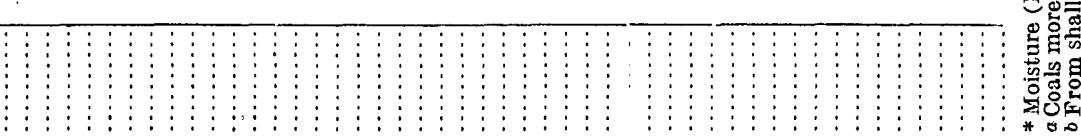

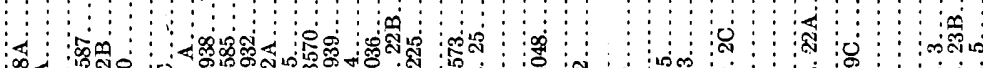
m

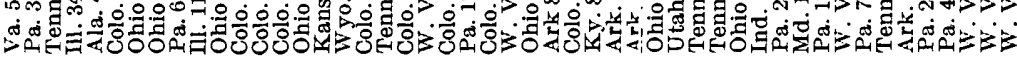

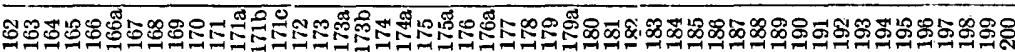
81144-Bull. 382-09-3 


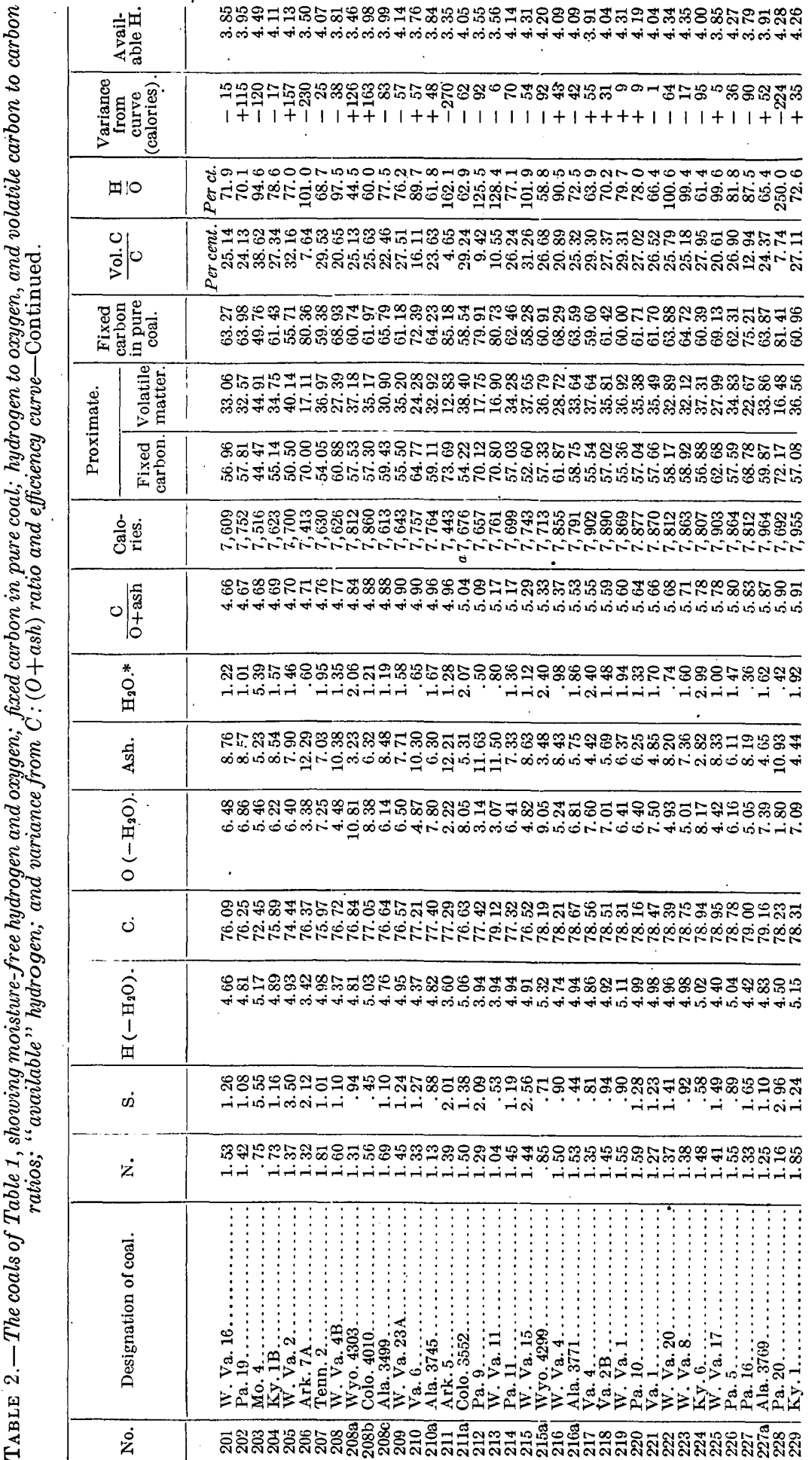




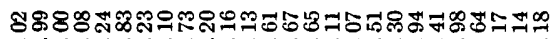

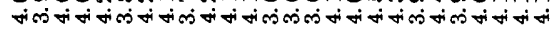

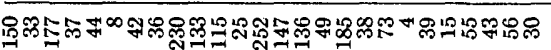
$\overrightarrow{1}+\overrightarrow{+}++1+\hat{1} \overrightarrow{1}+\hat{\imath} \overrightarrow{1} \overrightarrow{1}++1+1++1+$

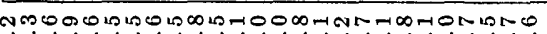
సं

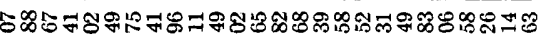
ஸ่

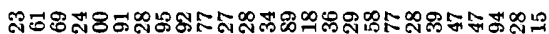

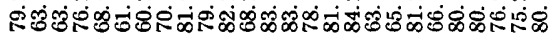

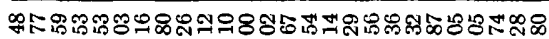

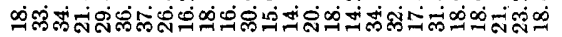

잉ㄷำ

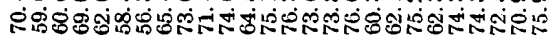

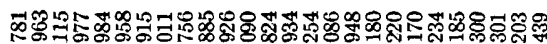

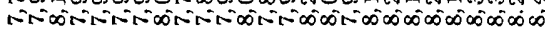

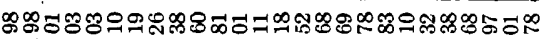

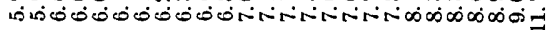

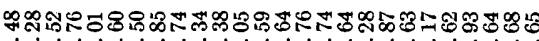
-

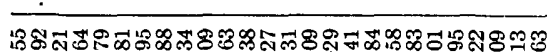

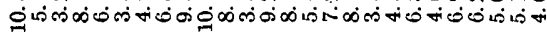

ธำดั

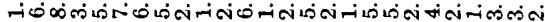

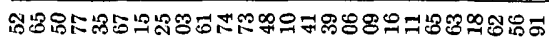
సशำ

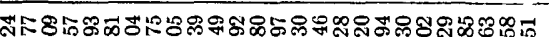

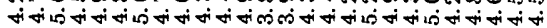

ஜษำด +i

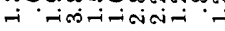

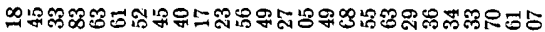

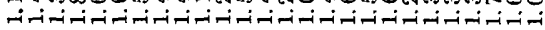

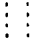


The slight recalculation of the analyses shown in this table offers the data necessary for the observation of the relative amounts of hydrogen and oxygen assumed to be in actual hydrocarbon compounds; and these, as well as the relative amounts of volatile carbon (total carbon less fixed carbon) are made available for comparison as ratios, $\mathrm{H}: \mathrm{O}$ and $\mathrm{VC}: \mathrm{C}$, without further departure from the air-dried basis of the analysis. The fixed carbon of the proximate analysis not only shows marked local variations, but also is subject to considerable error in the process of determination. By combining the volatile carbon in ratio with the more constant and accurately determined total carbon, following the method employed by Professor Parr, ${ }^{a}$ the fixed carbon error of the proximate analysis is minimized.

The criteria for the study of the composition of the fuels are advantageously supplemented by the calculation of the fixed carbon in "pure -coal" (ash and water free) by the method recommended by Professor Grout. ${ }^{b}$ By this method the fixed carbon in "pure coal" is determined by dividing the fixed carbon by the sum of the fixed carbon and "volatile combustible matter" as given in the proximate analysis. For use in comparison the variance of the ascertained calorific value from the curve value is noted for each coal; also the amount of available hydrogen.

\section{COMPENSATED CALORIFIC VALUES.}

It may be of interest to remark at this point that the $\mathrm{C}:(\mathrm{O}+\mathrm{ash})$ ratios, if recalculated on the moisture-free basis of the oxygen as given in Table 2, fluctuate widely from the ratios in Table 1; but if the calories also be recalculated to compensate for the eliminated water weight-that is, if the ascertained calories on an air-dried basis be divided by 100 minus moisture in air-dried coal-we shall have corresponding new theoretical efficiencies in larger denomination. On referring the new ratio to its serial position higher in the scale of the old ratios it will generally be found that the compensated calorific value will again fall near its proper, though entirely new and different, position in the succession of calorific values. For example, the $\mathrm{C}:(\mathrm{O}+$ ash) ratio of No. 25, when computed from the moisture-free oxygen of Table 2, will be found to be 3.23 instead of 1.73 ; and the air-dried efficiency of 5,753 calories is changed to 6,989 calories when compensated for a loss of 17.69 per cent weight of moisture. Inspection of the ratio series in Table 2, or of the curve, shows that a coal having a ratio of 3.23 should have an $\in$ fficiency of approximately 7,000 calories.

A few other examples, taken at random, of coals having high moisture may be presented. No. 64 of the tables, a New Mexico Cretaceous coal, whose ratio is 2.28 , its efficiency error being very small, has a moisture of 10.86 per cent. On the moisture-free basis the 
ratio of this coal becomes 3.46 and the compensated efficiency 7,127 ; by reference to the curve or to the proper point in the succession of the ratios in Table 2 it will be seen that the calorific value of a coal having a ratio of 3.46 should be about 7,137 . In other words, this coal, whose curve error was +6 on the cir-dried basis, appears to have an error of +10 when projected on the moisture-free basis among the high-grade bituminous coals of Tennessee, Ohio, and Pennsylvania. Another coal having relatively high moisture content in its air-dried condition is No. 144 of the tables. This coal from Wyoming has a moisture content of 6 per cent and a ratio of 3.20, its efficiency error being -30 ; on the moisture-free basis the ratio of this coal becomes 4.23, the compensated calories becoming 7,399. Passing up the scale of the ratios it appears that a coal having a ratio of 4.23 should have a calorific value of a little less than 7,4:30; so that this coal which had a deficiency of 30 on the air-dried basis, when projected as moisturefree with a higher ratio, shows a deficiency of about 80 calories in its new position on the curve. No. 203, a Paleozoic coal from Missouri, with moisture 5.39 and a ratio of 4.68 , has an error of -120 calories, probably due to the very high sulphur. The moisture-free ratio of this coal is 6.78 , the compensated calories being 7,944 . The calorific value for a coal having a ratio of 6.78 should, according to the curve, be not far from 8,030 ; so that the ersor when this coal is projected on the moisture-free basis to a position. among the highest grade semibituminous coals becomes -85 calories instead of -120 , as developed on the air-dried basis. Again, No. 32, a Laramie coal from Lafayette, Colo., has a moisture of 13.39 and a ratio of 1.95 , its variance from the curve being -45 calories; the retio on the moisture-free basis for this coal is 3.17 , the recalculated efficiency being 6,929. Passing down the columns to No. 142 we find that the efficiency for a coal with a ratio of 3.17 should be 6,970 , showing an error of -41 ; in other words, this coal, which had an error of -45 in its normal air-dried condition, has almost the identical error when recalculated to eliminate the moisture and referred to a new position very much higher in the curve.

\section{VALUE OF MOISTUR]E-FREE DATA.}

Comparisons of this kind are of value chiefly as indicating the consistent progression of the ratios and the stability of the curve as applied both to moisture-laden and to moisture-free coals. The dry coals fall in the same scale as the air-dried and with nearly equal precision. For the entire series of cosls in the table the average total for the carbon, oxygen, and ash is about 91.82. It is perhaps permissible to interpret this agreement of the moisture-free ratios and compensated values as indicating approximate equivalence in anticalorific value for the oxygen of the moisture and the oxygen of the coal itself, as well as for the ash. 
An inspection of Table 2 shows that in many coals of the same ratio and of nearly equal efficiency there are striking differences in the amounts of fixed carbon (in pure coal), and a wide range in the $\mathrm{H}: \mathrm{O}$ ratios, the latter being also apparent with respect to coals with the same percentage of fixed carbon. Similarly a less noticeable fluctuation is seen in the relations of the VC: $\mathrm{C}$ ratios both in coals of the same efficiency and in those of equal fixed carbon. The variations thus disclosed appear, in some instances, to explain the departures of the ascertained efficiencies from the calorific values indicated by the ratio curve.

The data in this table offer not only a better opportunity to study the relative values of oxygen and ash, since the oxygen is restricted to that assumed to belong to the coal itself, but also a basis for considering the comparative anticalorific importance of the oxygen of the moisture in the air-dried samples tested. The latter question becomes, under the circumstances, largely a matter of observation of the effects of the varying percentages of oxygen, ash, and moisture, in a miscellaneous and somewhat heterogeneous aggregate of coals.

The relative values of these impurities may be more precisely estimated if the coals are grouped as to kinds and districts, rather than merely by the ratio sequence, and each kind is studied by itself. Possibly, also, new and slightly modified curves will be found in groups of this sort.

\section{RELATIVE NEGATIVE VALUE OF ASH AND OXYGEN.}

The question whether oxygen or ash is negatively more potent is difficult to determine from the comparison of so wide a range in kind, condition, and age of coals. The difficulty is further complicated and rendered more delicate by the fact that so many of the errors or variances from the curve lie within the range of error in the work of the calorimeter, the average ratio-curve error for the total number of analyses being very much less than 1 per cent of the average calorific value. The question is therefore, for the present, left somewhat in doubt. From study of the tables, however, I am inclined to believe that the oxygen is possibly of slightly greater anticalorific importance in the lowest grade of bituminous and the subordinate group of coals, while in the higher bituminous and the semibituminous fuels the ash is probably of greater negative value. From a casual glance it would appear that in the air-dried samples the greater anticalorific value lay in the oxygen. But the possibility that many of these coals have taken up oxygen under exposure to air or weathering conditions enjoins caution in forming conclusions; for, as I shall indicate later, the oxidized coals are generally characterized by deficiencies, as compared to the curve, in calorific value. On the other 
hand, the arrangement of the coals is such that the slightly greater available hydrogen prevalent in the coals with high ash (on account of their generally higher class) may be regarded as counterbalancing a small margin of the disadvantage attributable to the ash, thus appearing to indicate for the ash a slightly greater anticalorific value. However, the number of instances of parity of coals with alternating percentages of the two impurities, in which no unusual available hydrogen accompanies the high ash, is so great as to preclude any important difference of negative value in favor of the ash. But it will be observed in passing down the columns of the table that coals with high hydrogen are usually accompanied also by high sulphur, whose diluent influence in the analysis tends to neutralize the effect of the high available hydrogen. Thus it becomes more readily practicable in general to treat the hydrogen as constant, and so to ignore it, along with the nitrogen and sulphur, in forecasting the calorific values of the fuels by means only of the $\mathrm{C}:(0+$ ash $)$ ratios.

On the whole, the calorimetric tests make it evident that high oxygen (with its usually slightly lower available hydrogen concomitant) and high ash (in most cases accompanied by slightly higher available hydrogen) counterbalance, so that practically, taking coals as they come, the calorific values of two coals in which the two great impurities alternate, carbon being constant, are almost exactly equal. The facts presented in the tables show plainly and conclusively why the Paleozoic coals of the Eastern Interior basin can not possess the efficiency of Appalachian standard coals of the same ash percentage; and why the very low-ash, but high-oxygen samples of low-class, subbituminous, and lignitic coals of the Cretaceous or Tertiary exhibit a calorific efficiency no greater than that of high-class Paleozoic coals having contrastingly high ash and correspondingly low oxygen, if the total carbon is the same.

It will later be shown that some of the maximum variations in the available hydrogen are responsible for $\varepsilon$ number of the larger variances from the ratio curve in Tables 1 and 2. The latter are not, however, sufficiently numerous or large to require a coefficient for compensation.

It is probable that for a group of cannels and bogheads in which the hydrogen is excessively high a highes: special cannel curve will be found desirable. The construction of such a curve based on the ascertained component ratios and efficiencies will be much simpler, and perhaps in general more reliable, than a coefficient for the abnormally high hydrogen of this group.

\section{RELATIVE EFFECT OF THE OXYGEN OF MOISTURE.}

The obstacles to distinguishing between the negative values of the oxygen of the coal proper and the oxygen of moisture, in the calo- 
rimeter results, are largely the same as those affecting the discrimination between the relative values of ash and oxygen. In fact, the effect of moisture on the standing of the coals as determined by the $\mathrm{C}:(\mathrm{O}+$ ash) ratios is generally so little as to excite surprise. For example, the efficiency shown in the test of No. 31, a Fort Union coal from Deer Lodge, Mont., which has 9.05 per cent moisture, or No. 32, the Laramie coal at Lafayette, Colo., with 13.49 per cent of moisture, differs less than 1 per cent from the efficiency of No. 30, the Pocahontas bone at Gary, W. Va., which has but 0.52 per cent moisture. Other coals, such as Nos. 71, 72, and 72a, afford similar striking contrasts, the calorific values being so little affected and so regularly conformable to the curve as to make it clear that no great difference can exist between the negative values of the oxygen of moisture and that combined in the coal.

In connection with this question of the relative values of the two oxygens attention should be called to the approximate coincidence and complete conformity of the ratios of the moisture-free coals and of their respective compensated calorific values with the curve of the air-dried coals, as noted on page 34 .

A review of the efficiency variations in Table 2 tends to show slightly more frequent calorific deficiencies in coals having abnormally high moisture. But, on the other hand, allowance must be made for the fact that most of the samples very high in moisture are low in the scale of coal formation, and consequently most susceptible to deterioration on exposure to atmospheric oxygen. There is no doubt in my mind that many such deficiency variances are due to this cause. Furthermore, so many of the instances of calorific deficiency which might perhaps correctly be ascribed to high moisture are attendant on unusual deficiencies in the available hydrogen, that at the end one is left uncertain whether, so far as may be judged by the behavior of the air-dried samples in the calorimeter, the moisture oxygen in general differs much from other oxygen in its harmful effect. This does not, of course, preclude the recognition of a difference under practical boiler-grate conditions.

The varying capacity of coals of the same age and district, under apparently the same conditions as to progressive metamorphism, to hold water seems to depend largely both on the character of the original constituent organic matter and on the conditions governing the first or biochemical stage of coal formation.

Since coals with high oxygen and low ash have the same calorific values as others in which the terms are reversed, if the other percentages are constant, it becomes evident that, in general, the carbonoxygen ratio of the coal (ash free, or ash constant) corresponds fairly closely to the rank of the coal in efficiency. The same ratio also indicates, for coal of the same origin, its progress in the scale of coal transformation. 


\section{ESTIMATE OF THE EMPIRICAL ANTICALORIFIC VALUE OF OXYGEN .}

\section{NEGATIVE VALUE OF OXYGEN AND ASH.}

In the preceding pages it has been shown that, in general, throughout a miscellaneous collection of coals of all grades, the heating value of the fuel is roughly indicated by the amount of the total carbon as compared to the sum of the oxygen and ash. Also that, so far as concerns the calorific efficiencies of the coals, alternating amounts of oxygen and ash essentially offset each other, providing the total carbon be constant, though strictly speaking a slight excess of negative potency appears to lie in the ash. On the whole, however, in view of the tendency of two of the aissumed constants, sulphur and hydrogen, to compensate each other, as will be pointed out in the next section, we may conclude that, from the practical standpoint, oxygen and ash may be regarded, according to the calorimetric tests, as essentially interchangeable.

\section{APPLICATION OF THE CURVE.}

The curve platted from the $\mathrm{C}:(\mathrm{O}+\mathrm{ash})$ ratios and the calorific efficiencies provides an indirect method of ascertaining the average - amounts of calorific change corresponding to any given ratio change, for different parts of the curve. For any one length or section of the curve the amount of this calorific change may be taken as a scale of approximately equal units, by which any fractional ratio change may be measured. Hence it is not difficult roughly to estimate the anticalorific values of 1 per cent added to or subtracted from the oxygen or ash in a coal analysis.

Inspection of the curve, as provisicnally drawn, shows the following approximate values of curve segments covering changes of 0.05 and 0.01 in the ratios (horizontal component) at a number of points:

Calorific changes corresponding to ratio changes of 0.05 and 0.01 at stated points in curve.

\begin{tabular}{|c|c|c|}
\hline Part of curve. & $\begin{array}{c}\text { Ratio change } \\
0.05 .\end{array}$ & $\begin{array}{c}\text { Ratio change } \\
0.01 .\end{array}$ \\
\hline Ratio. & Calories. & Calories. \\
1.00 & 115.0 & 23.0 \\
1.50 & 80.0 & 16.0 \\
2.00 & 50.0 & 10.0 \\
2.50 & 40.0 & 8.0 \\
3.00 & 35.0 & 7.0 \\
3.50 & 28.0 & 5.6 \\
4.00 & 22.0 & 4.4 \\
4.50 & 19.0 & 3.8 \\
5.00 & 13.3 & 2.6 \\
5.50 & 10.0 & 2.0 \\
6.00 & 8.0 & 1.6 \\
\hline
\end{tabular}




\section{FLUCTUATION IN EFFECTS OF CHANGES.}

The practical application of these units at once discloses wide fluctuations in the relative effects of changes of 1 per cent in the joint impurity. These are due (1) to the constantly changing elements upon which the ratios are based, and (2) to the marked difference between the ratios as a curve component, with constantly progressive dividends and divisors, and the component of the efficiencies. The essential result is an increase in the negative value of the impurities in passing from one part of the curve to another, as the following figures show:

At ratio 1.00 the value of 1 per cent of added oxygen or ash is about 47.5 calories; at ratio 1.50 the value of 1 per cent of added or subtracted oxygen or ash averages approximately 64.5 calories; at 2.00 the average approximates 65.4 calories; at 2.50 it approximates 78 calories; at 3.00 it approximates 92 calories, the effect becoming more strongly marked in subtraction; at 3.50 it averages about 97 calories; at 4.00 the variation between the added and the subtracted 1 per cent is slightly greater, the average of both at that point being about 93.9 ; the decline is still more marked at 5.00, where 1 per cent of the joint impurity is valued at nearly 82.2 calories, while at 5.50 , its effect is about 77 calories; and at 6.00 it falls to about 72 calories. At this point (ratio 6.00) deduction of 1 per cent of the impurity amounts to an addition of about 77.6 calories, while addition of the same percentage causes a change of about 69 calories. These values are based in each case on the average of the differences between the ratios in Table 1 and those obtained by adding 1 per cent and by subtracting 1 per cent from the total oxygen plus ash.

\section{ESTIMATE APPLIED TO THE ANALYSES.}

A clearer idea of the application of this indirect method may easily be gained by practical experimentation with the analyses in the table, the ratio changes resulting from increase or diminution of the impurities being compared with the calorific differences indicated by the corresponding changes in the curve. For example, No. 145 of Table 1 has a ratio of 3.21 , the corresponding efficiency being 6,990 calories. The addition of 3 per cent of oxygen or ash to this coal produces a coal whose $\mathrm{C}:(\mathrm{O}+\mathrm{ash})$ ratio will be 2.82 . The calorific value of a compensated coal having this ratio will be found to be about 6,750 calories, showing a difference of about 240 calories on account of the addition of 3 per cent of oxygen, the impairment averaging, therefore, about 80 calories to each 1 per cent of added impurity. If, on the contrary, we subtract 3 per cent from the oxygen or ash of the coal in No. 145, we shall have a coal with a ratio of 3.72 , whose efficiency, according to the curve, will be about 7,260 calories, 
an increase of approximately 270 calories, as the result of deducting 3 per cent of impurity; that is, 90 calories to each 1 per cent. Or, to take another example at random, No. 183 in Table 1, with a ratio of 4.31, has a calorific curve value of $7,5 \mathrm{i} 5$. The addition of 3 per cent of oxygen or ash produces a coal with a ratio of 3.67 , whose efficiency will be approximately 7,238 calories, a calorific difference of 277 , being approximately 92 calories to each added 1 per cent of the joint impurity. Contrariwise, the subtraction of 3 per cent in the analysis of No. 183 defines a coal having a ratio of 5.21, according. to which the calorific value of the coal will be 7,780 , showing a difference of approximately 265 calories resulting from the difference in the impurity, or 88 calories as the average advantage derived from the elimination of 1 per cent of the impurity.

Tests of this kind may be applied to all of the coals in the table. They are, however, inaccurate and of little value, though interesting. The fluctuations are very wide and vary from the amounts calculated from the value of the combustible displaced or concentrated by the addition or subtraction, respectively, of the inert impurity.

\section{CAUSES OF VARIANCE FROM THE CURVE.}

GENERAL STATEMENT.

The causes of the wider fluctuations of the ascertained efficiencies from the $\mathrm{C}:(\mathrm{O}+\mathrm{ash})$ ratio and efficiency curve appear in most cases to lie in the percentages of those elements that have been ignored as negligible constants, hydrogen, sulphur, and nitrogen. Besides these we have, also, among the data of the analysis the less definite, though no less absolute, effects of (1) oxidation by weathering and (2) the devolatilization incidental to anthracitization. There are, however, other causes which seem incapable of detection from the mere ultimate analyses. Although of subordinate importance, these will first be considered.

CAUSES NOT SHOWN BY ULTLMATE ANALYSES.

First are the differences in the hydrocarbon compounds entering into the substance of the coal. These compounds, whose number and structure appear still to be largely unknown, presumably vary in stability, in quantity, and more or less in calorific values. Some of these differences are probably due to the nature of the original ingredients. The bogheads, for example, are described as largely composed of the remains of gelatinous algæ, which appear to have exercised a selective attraction for certain bituminous compounds, and which are excessively rich in volatile combustible having an illuminating value far above that derived from ordinary gas coals. Pyropissite, which is largely composed of resins, is an extreme example in this category. 
The obviously abundant resin in some of our Cretaceous low-grade ${ }^{a}$ bituminous and subbituminous coals and lignites doubtless contributes to the calorific excess which attends many of the unweathered samples. A number of these coals figure among the extreme excess variances among the efficiencies marked " $\mathrm{L}$ " to the left in the curve diagram, Plate I.

Another, possibly the principal, of the intangible causes not revealed by the analyses is the error in oxygen determination in the process of making the ultimate analysis. Since the oxygen is the residual of the analysis, ascertained by subtracting from a total of 100 per cent the sum of the percentages of the other elements, it is evident that it contains the residual error which may possibly. be cumulative. Among the lower ratios a slight error in oxygen determination does not cause a very marked effect on the calorific variance, but in the higher grade coals a fraction of 1 per cent may make a considerable difference in the ratios, and a consequent erroneous indication of the efficiency. In a coal having a ratio of 2.00 an error of about 1 per cent of oxygen in the analyses will amount to a curve difference of about 63 calories. It is possible that the surprisingly low oxygen of several of the semibituminous coals ${ }^{b}$ may in part be due to error in its determination.

An important source of error in oxygen determinations is connected with the presence of pyrite in the coals, for the production of sulphur dioxide causes an oxygen deficiency equal to three-eighths of the sulphur in the pyrite. The residual error (oxygen) of the analysis is also affected by the reduction of iron carbonate when that is present in the coal, the results being too high carbon and oxygen and too low ash. Small errors in oxygen calculations are also due to the recognized tendency in high-ash coals of the aluminous silts to hold back hydrogen and of siliceous sediments to withhold oxygen. The relatively few cases in which the marked variances are not fairly well explained by these or other causes, and in particular the very small average error of the efficiency curve, indicate a high standard of accuracy in the coal analyses on which this report is based.

As a third cause of variance not visible in the analyses is the oxygen taken up on exposure to the air or weathering, which constitutes a serious cause of variance on the side of deficiency. This matter will be again referred to (p. 63) in connection with the subject of the weathering of coals.

\section{CAUSES RECOGNIZABLE IN ANALYSES.}

The causes of variance that may, frequently at least, be recognized in the analyses will now be considered. 
VARYING AVAILABLE HYDROGEN.

In Table 2 the proportions of hydrogen are shown both by means of its ratios with the oxygen in moisture-free coal, and as "available" hydrogen $\left(\mathrm{H}-\frac{\odot}{8}\right)$. As might be expected, a number of the large errors seem to be explained by the relatively very large or very small percentage of hydrogen. Yet the evidence is not free from conflict, since in numerous analyses a high available hydrogen is shown without any corresponding error of excess calories; in others calorific excess attends a relatively low hydrogen. As coals in which the excess of calories would seem to be due to high hydrogen, citation may be made of Nos. 7, 21, 33, 36, 43, 52a, 86, 126, 168, 208b, and 247. Compare also Nos. 23, 38, 51, 53, 79, and 130. Several of the coals cited, however, are very low in sulphur, which, by reducing the amount of the negligible constants, enlarges the space for the other elements, especially carbon, and so promotes a higher efficiency for the fuel. There are on the other hand but few samples in which the lack of hydrogen seems clearly accountable for deficiency of calories. Probably of this sort are Nos. 19, 106, 112, 135a, 144, and 246. The low curve efficiencies of Nos. 163, 181, 190, 206, 211, and 236 are also possibly due to low hydrogen, though in these coals (marked "S" in Pl. I) which are undergoing anthracitization the volatile carbon likewise is very low; and since, in some of the advanced coals, an abnormally low volatile carbon appears to be a cause of calorific deficiency, it is possible that most of the coals last cited may be impaired by loss of volatile carbon as well as of hydrogen. ${ }^{a}$ Outside of the semianthracites and more advanced semibituminous coals there do not seem to be many coals in the tables whose lack of calories is possibly traceable to low hydrogen. In Nos. 84, 93, 110a, 171c, and 196, the calories are high in spite of the low available hydrogen; while in No. $2 \mathrm{~b}$ there is no available hydrogen at all, but on the contrary a deficiency of 0.37 , yet the efficiency-curve error is but 150 calories. High efficiency with a relatively low available hydrogen is a common characteristic of the unweathered younger and less altered coals, in which the diluent sulphur is low. It is to be remembered that the efficiencies and errors here discussed relate to the ratio curve, and not to those calculated from Du Long's formula.

The number of coals in which a relatively high available hydrogen or $\mathrm{H}: \mathrm{O}$ ratio is attended by a calorific deficiency, instead of excess, is surprisingly large. Examples are Nos. 27, 48, 56, 105, 138, 203, 215, 228, 237, and 238. (See also Nos. 40, 74, 76, 153, 158, 162, 164, $1.78,185,197$, and 215.) Several of these coals have high sulphur, whose double effect is not fully overcome by the relatively high

$a$ The relative values of both VC: $\mathrm{C}$ ind $\mathrm{H}: \mathrm{O}$ in the coals are better shown in Plate III than in Table 2. 
hydrogen, as will presently be illustrated. Samples Nos. 228, 237, and 238 have abnormally low volatile carbon and very low oxygen; to the former the deficiency is probably due.

On the whole it may be said that while high available hydrogen tends to cause curve variances on the side of excess, there are comparatively few coals in which its effects are not so far neutralized by a high sulphur content, or (in case of very low sulphur) by an enlarged proportion of carbon or, perhaps, by a very high ash (Nos. 27 and 65), as to reduce the excess error to less than 100 calories. There appear to be 10 coals whose excess error of over 100 calories seems more or less distinctly due to the high available hydrogen. For the cannel-boghead group, whose hydrogen is characteristically greatly in excess, a higher curve should be drawn. The average total hydrogen in the 319 air-dried samples in Table 1 is 4.92 per cent.

SULPHUR.

In many respects sulphur is the most important of the neglected elements affecting the accuracy of the ratio-efficiency curve. Although the errors on account of this ingredient are generally slight, usually less than 1 per cent of the calorific value, its effect is no doubt relatively important in many cases.

In combustion the heat values of sulphur are generally recognized as depending on the state or condition in which it occurs. As free sulphur it is comparatively harmless and may exert its full theoretical calorific efficiency; in pyrite, marcasite, or other sulphides, its heat contribution is greatly lessened by the fact of combination, and also differs with the surrounding conditions; in sulphates, whether infiltrative, interstitial, or in the form of scales in the joints and cleavage planes of the fuel, it is a dead load to be borne at the expense of the other fuel elements. Unfortunately information as to the state of the sulphur in the samples tested and analyzed is unavailable for this report; ${ }^{a}$ so that I am obliged to ignore the differences in the effects of the different kinds, and regard only the apparent influence in general and as a whole when the sulphur is in large or exceptionally small percentages.

Since the efficiency of the coals is very closely controlled, as has been shown, by the balance between the carbon and the two chief anticalorific elements, oxygen and ash, the sulphur, as well as the nitrogen and hydrogen, has in the preceding pages been treated as constant. But as a matter of fact, while the hydrogen and nitrogen appear to be constant in kind, differing only in quantity, the sulphur differs greatly both in quantity and in kind or effect. In the series of analyses shown in the tables the sulphur ranges, on the air-dried

$a$ In most of the high-sulphur coals of the Eastern Interior basin the sulphur is probably chiefly in the form of sulphides. 
basis, from a minimum of 0.22 per cent in No. $52 \mathrm{~b}$ from Wyoming, to a maximum of 8.33 per cent in No. 138 from Kansas. Its average percentage in the 319 coals is 2.13 .

Since sulphur even in its best condition has a sinaller calorific value than carbon, it is plain that any unusually high percentage of it, unless compensated by increased available hydrogen, another of the constants, virtually dilutes the combustible of the coal and causes a falling off in its efficiency. Therefore a comparison of the analyses . in the tables with reference to sulphur is necessarily chiefty confined, since we are not cognizant of the state of the sulphur in each sample, to the diluent effect in some of the coals of an abnormal proportion of this inferior combustible, and the effect of comparatively low sulphur in others. Accordingly, the practical and main purpose of the study is to observe the amount of the error or variance from the ratio-efficiency curve in consequence of unusual fluctuations in the sulphur percentages. As examples in which deficiencies in ascertained calorific value, as compared with the curve indications, are probably due to unusually high sulphur, may be cited Nos. 48, 65, 76, 80, 94, 96, 102, $138,157,185,230$, and 237 in the table. The errors in most of these cases are, however, small. The diluent effect of a difference in sulphur may in many coals be roughly approximated by rating the unit sulphur effect at the difference between its theoretical value $(2,250)$ according to Du Long's formula and the calorific value of the unit of the rest of the coal which it partly displaces. The effect of the available hydrogen variation may be calculated at 34,460 according to Du Long's formula.

In passing down the columns it will be noted that as a rule the coals that are high in sulphur are also relatively high in hydrogen, the highest percentages of the former being usually attended by the greatest excesses of the latter. ${ }^{a}$ The general result is the neutralization of the bad sulphur effect by the high hydrogen. In many cases the effect is converted from a deficiency to a small excess. As illustrating analyses in which the sulphur effect is not fully neutralized, comparison may be made of Nos. $9,11,16,28,40,48,55,58,63,73,74$, $92,105,113,138,142,143,164,178$, and 203 . Some of these are coals with the highest available hydrogen. Two of the most striking are No. 138 from Kansas and No. 203 from Missouri. Other instances of complete neutralization are Nos. $14,20,23,33,36,38,43,4.8,53$, $69,66,79,82,98,99,147 \mathrm{~b}, 153,167,168,172$, and 205 . On the other hand, it will be noted that the coals with very low sulphur are more often accompanied by a low available hydrogen. ${ }^{b}$ Some of the larger efficiency errors on the side of excess are coincident with the exceptional cases of very low sulphur and unusually high hydrogen. Examples are Nos. 21, 52a, 81a, 86, 93, 100, 118, 126, 128, 141, and 161a;

a Examples are Nos. 14, 20, 23, 40, 42-44, 45, 48, 49, 65, 66, 79, 82, 147-149, 153, 185, 187, 203, and 205.

$b$ This applies to the Cretaceous and Tertiary coals in the tables. 
also Nos. 31a, 134, 134a, 171a, 173b, and 179a. These fall for the most part among the Cretaceous coals, and their superior efficiency is probably connected with the high content of resin.

The review of the analyses with respect to sulphur shows, in general, that except among the fuels approaching anthracitization the the coals with highest sulphur usually have the highest available hydrogen, those with lowest sulphur being usually relatively low in hydrogen; and accordingly that in most cases the effect of an excess of sulphur is nearly counterbalanced by the presence of an excess of hydrogen. Conversely, the effects of unusual proportions of hydrogen are, in general, largely neutralized by a parallel variation in the sulphur contents of the coal. These facts explain, in most cases, the smallness of the ratio-efficiency curve errors in the presence of the greater variations of the available hydrogen. The mutually neutralizing action of the sulphur and hydrogen is the main circumstance making it so readily practicable to treat these elements as negligible in forecasting the efficiency of the coal solely on the basis of the carbon, oxygen, and ash. It should be noted that compensating the oxygen for loss with sulphur of pyrite (see p. 42) would by lowering the $\mathrm{C}:(\mathrm{O}+\mathrm{ash})$ ratio tend to reduce the prevailing errors of deficiency in high-sulphur coals, while slightly reducing the available hydrogen.

\section{NITROGEN.}

Of this, the third and last of the neglected constants, I have not attempted a careful study with reference to error influence. From a casual inspection of the tables I am inclined to regard it as largely eliminated from the peats at an early date in the dynamochemical process, the remainder being, perhaps, mechanically retained in a free state, or in an unknown state of combination in the more advanced coals. It seems to be practically passive, and of so little range in amount as usually to produce no marked effect as a diluent. Its average percentage in Table 1 is 1.21. The study of the effect of nitrogen on the calorific values requires a series of analyses including larger groups of peats and of the succeeding low grades of coals.

\section{ANTHRACITIZATION.}

Both the greatest individual error and the greatest average variance from the curve are found among the highest of the semibituminous coals, which are undergoing anthracitization or in the anthracitic group itself. A glance at the percentages of fixed carbon in pure coal in Table 2 shows that nearly all the coals that have a fixed carbon of 79 or more are deficient in calories unless they have a high volatile carbon (see the $\mathrm{VC}: \mathrm{C}$ ratios). The maximum variance among the 312 coals of the table is in the anthracite culm at Scranton, which shows a deficiency of 312 calories from the curve. In many of these 
coals the deficiency is probably due to loss of hydrogen, as shown in the available hydrogen column of the table.

Of the 18 coals with as much as 79 per cent fixed carbon and a volatile carbon ratio of 9.25 or less, only 2 show excess errors. These 18 coals (excluding the Rhode Island semigraphite, which is not a fuel) are here grouped for better comparison:

Variance from curve efficiency' of coals high in fixed carbon and low in volatile carbon.

\begin{tabular}{|c|c|c|c|c|c|c|}
\hline No. & Locality. & $\begin{array}{c}\text { Variance } \\
\text { from curve. }\end{array}$ & $\begin{array}{l}\text { Fixed car- } \\
\text { bon in pure } \\
\text { coal. }\end{array}$ & $\begin{array}{c}\text { Ratio } \\
\text { VC to C. }\end{array}$ & $\begin{array}{l}\text { Available } \\
\text { hydrogen. }\end{array}$ & Sulphur. \\
\hline & & Culories. & Per cent. & Per cent. & Per cent. & Per cent. \\
\hline 1.63 & Scranton, $\mathrm{Pa}$. & -312 & 91.09 & 1.13 & 2.30 & 0.77 \\
\hline 179 & Spadra, Árk.. & -214 & 87.01 & 2.93 & 3.01 & 2.14 \\
\hline 140 & Blacksburg, Va.................. & -33 & 86.89 & 3.20 & - 3.10 & .66 \\
\hline 162 & ....do........... & -115 & 86.50 & 4. 48 & 3.49 & .70 \\
\hline 211 & Coal Hill, Ark. & -270 & 85.18 & 4.65 & 3.50 & 2.01 \\
\hline 242 & Panama District, Ind. $\mathrm{T}$. . & -185 & 84.29 & 6.58 & 4.07 & 1.24 \\
\hline $239 \mathrm{~b}$ & Johnstown, $\mathrm{P}_{\mathrm{q}} \ldots \ldots \ldots \ldots$ & -147 & 83.89 & 5.82 & 3.67 & 2.29 \\
\hline $239 \mathrm{a}$ & Paris, Ark.... & -252 & 83.34 & 6.65 & - 3.61 & 2.85 \\
\hline 30 & Gary, W. Va.. & +12 & 82.87 & 6.02 & 2.83 & .55 \\
\hline 238 & Lloydell, Pa.. & -115 & 82.27 & 7.49 & 4.10 & 1.55 \\
\hline 236 & Bonanza, Ark. & -230 & 81.92 & 7.96 & 3.73 & 1.90 \\
\hline 228 & Seward, Pa... & -224 & 81.41 & 7.74 & 4.28 & 2.96 \\
\hline 190 & Georges Creek, $\mathrm{Md}$. & -106 & 80.94 & 9.02 & 3.42 & 1.51 \\
\hline 161 & Menlo, Ga....... & +163 & 80.57 & 6.73 & 3.39 & 1.31 \\
\hline 181 & Arkansas... & -215 & 80.45 & 9.15 & 3. 26 & 1.68 \\
\hline 206 & Midland, Ark. & -230 & 80.36 & 7.64 & 3.50 & 2.12 \\
\hline 237 & Wehrum, Pa. . & -133 & 79.77 & 9.11 & 4.20 & 3.88 \\
\hline 230 & ..... do ......... & -150 & 79.23 & 9.07 & 4.02 & 4. 06 \\
\hline
\end{tabular}

The average error for the 8 semianthracites, with fixed carbon of 83 per cent or more in pure coal, is 191 calories. The average error for the 10 highest-grade semibituminous, having a fixed carbon of over 79 per cent and a VC:C ratio (per cent) of 9.25 or less, is 158 calories. If this list of 18 coals be excluded from the table list the average error of the ratio curve is but 60.09 calories.

Other high-grade semianthracites which show calorific deficiency incidental to loss of volatile are the following:

Variance from curve efficiency of coals high in fixed carbon.

\begin{tabular}{|c|c|c|c|c|c|c|}
\hline No. & Locality. & $\begin{array}{c}\text { Variance } \\
\text { from curve. }\end{array}$ & $\begin{array}{l}\text { Fixed car- } \\
\text { bon in pure } \\
\text { coal. }\end{array}$ & $\begin{array}{c}\text { Ratio } \\
\text { vC to C. }\end{array}$ & $\begin{array}{l}\text { Available } \\
\text { hydrogen. }\end{array}$ & Sulphur. \\
\hline $\begin{array}{l}212 \\
123 \\
182\end{array}$ & $\begin{array}{l}\text { Kimmelton, } \mathrm{Pa} \ldots \ldots \\
\text { Huntington, Ark.... } \\
\ldots \ldots \text {. do.............. }\end{array}$ & $\begin{array}{r}\text { Calories. } \\
-92 \\
-100 \\
-60\end{array}$ & $\begin{array}{r}\text { Per cent. } \\
79.91 \\
79.66 \\
79.25\end{array}$ & $\begin{array}{r}\text { Per cent. } \\
9.42 \\
9.40 \\
10.00\end{array}$ & $\begin{array}{r}\text { Per cent. } \\
3.55 \\
3.36 \\
3.41\end{array}$ & $\begin{array}{r}\text { Per cent. } \\
2.09 \\
1.14 \\
1.27\end{array}$ \\
\hline
\end{tabular}

The last sample has a higher volatile carbon. The VC: $\mathrm{C}$ ratios are better studied in Plate III, in which the coals are arranged in the order of their fixed carbon in pure coal (ash and moisture free).

On the other hand, among these coals approaching devolatilization it is interesting to note signs that a relatively large proportion of carbon in the remaining volatile is favorable to a higher efficiency. For 
illustration: The coal at Sun, W. Va. (No. 240), with a relatively high volatile carbon ( $\mathrm{VC}: \mathrm{C}=10.68$ per cent) shows an excess of about 136 calories over the curve, though its available hydrogen, 3.65, is 0.45 below that of most of the coals near by in the series. ${ }^{a}$ Relatively high volatile carbon probably assisted low sulphur in Nos. 213, 196, and 70, among others. Contrariwise, in Nos. 162, 228, 237, and 238 low efficiencies accompany unusual diminution of the volatile carbon, in spite of the fact that the available hydrogen is fully up to or above the normal in these coals. Possibly sulphur may have exercised a depreciating influence in Nos. 228 and 237.

These observations seem to indicate that although the calorific values in the lower grades of coals do not seem affected by the relative amount of fixed carbon, too great a loss of volatile carbon impairs the efficiency of the fuel.

The range of error in the determination of the fixed carbon in a coal forbids basing too confident conclusions on a limited number of observations.

WEATHERING.

The changes of coal under exposure or weathering are indicated in the analyses by reduced $\mathrm{H}: \mathrm{O}$ ratios; by reduced available hydrogen; and in many cases by reduced volatile carbon ratios. Illustrations will be given later (p. 63) of these changes, invariably showing calorific deficiencies except in the high grades of coal. As a matter of fact weathering can in most cases be detected by the changes in the oxygen-hydrogen relations and by the marked calorific deficiencies.

\section{QUANTITATIVE RELATION OF OXYGEN TO COKING.}

\section{SUPPOSED ALGAL INGREDIENTS IN COALS.}

\section{SOUROE AND CHEMICAL EFFECTS.}

As stated in the introduction to this paper, one of the purposes of this comparative study was to ascertain the testimony of the ultimate chemical analyses as to the validity of a previously conceived working hypothesis in explanation of the coking property of coals. 'A few words will outline the basis of this hypothesis:

The brilliant investigations carried on by Renault ${ }^{b}$ and Bertrand ${ }^{c}$ as to the microscopical structure of a considerable number of bogheads and oil shales of various continents and geologic ages show that these rocks owe their peculiar physical and chemical characters (which include a relatively high percentage of volatile matter, a

\footnotetext{
$a$ The estimate of calorific value calculated from the chemical analysis of this coal was 312 calories less than the ascertained efficiency. See Prof. Paper U. S. Geol. Survey No. 48, 1906, p. 255.

$b$ Renault, B., Les micro-organismes des combustibles fossiles, St. Etienne, 1903.

cBull. Soc. d'hist. nat. Autun, vol. 9, 1897, p. 193; Trav. et mém. de l'Univ. de Lille, vol. 4, No. 21, 1898; Compt. rend. 8me sess. Cong. géol. internat., 1901, p. 453.
} 
generally high illuminating value, etc.) primarily to the presence of immense numbers of supposed gelatinous algæ which in these coals seem to have exercised a selective attraction for certain bituminous compounds. Algal matter in smaller proportions, and consequently with less distinct resultant characteristics in the coal, is found also in the "cannel-bogheads" and some of the "bogheadcannels." The conditions of accumulation and deposition attending the or:gin of many other coals were doubtless favorable for the mingling of algæ and different animal remains in varying quantities with the débris of higher plant types; though their preservation, at least in optically recognizable form, is most improbable in any but the rarest instances. Yet it is more than probable that the substances of these lower organisms, whether completely macerated and disorganized or not, contributed as ingredients to the mass of coal-forming material. It is therefore reasonable to admit that though not optically discernible now, or though all their original structure is obliterated, they have probably exerted some influence on the character and quality of the final converted organic residuum.

It is not important to discuss in this place either the source proposed by the French paleobotanists for the bituminous "enrichment" of the coal or the time of the bituminization, though, for my part, I am disposed to regard the enriching bitumen as derived from the decay of associated animal organisms, as well as from the putrefaction products of great quantities of the gelatinous algæ themselves. The relatively increasing importance of the bituminous matter in the more mature, older, or more altered condition of the fuel is due, I believe, to concentration as the result of devolatilization and reduction of the coal by the dynamochemical process, the larger part of the concentration being the result of loss of oxygen, which is in larger proportion at the outset. The oxygen loss is disproportionally great as compared to that of the hydrogen. The liquid putrefaction products of the algæ must almost certainly have entered into the groundmass of the coal and participated in the infiltration of the immersed structural vestiges of higher and more enduring types of vegetation. The progressive deoxygenation of the organic matter effects a concentration of the bituminous compounds in the body of the organic material which is undergoing the processes of coal formation; that is, it accomplishes bituminization. However, the important point, so far as we are at present concerned, is the connection, as described by the distinguished French paleobotanists and later virtually corroborated by Potonié, ${ }^{a}$ of these gelatinous ("sapropelic" of Potonié) elements with a highly bituminous quality of the fuel. 


\section{CHARACTERISTICS OF ALGAL COALS.}

We have next to note the following circumstances: (1) It will be seen on consulting the ultimate analyses published by the French paleobotanists that these algal (gelosic or sapropelic) coals are relatively high in hydrogen and low in oxygen, as is to be expected of coals that are tinged with the character of bitumen; (2) I have observed that those fuels, especially if Paleozoic and consequently more altered, are apt to fuse and even to swell on burning.

\section{POSSIBLE CONNECTION WITH COKING QUALITY.}

Now, these qualities, fusibility and swelling, concurrent with bituminization, which appear generally to characterize fuels known to contain recognizable quantities of gelatinous micro-algæ, are also necessary to the coking quality in coals. It is permissible, therefore, to inquire whether the coking property may not be due, at least among coals relatively low in fixed carbon, to some unascertained but not improbable proportion of gelatinous algal (sapropelic) matter entering into the original ingredient mass from which the coal was formed, and either directly or indirectly imparting to it this fusibility and tendency to swell.

Micro-algal ingredients, sometimes forming layers of considerable thickness, are recognized in peats, and their presence, occasionally in great numbers, has already been noted in a number of remarkable brown coals which have not been altered so far as to preclude satisfactory microscopicul examination. Yet the detection by means of the microscope of such minute and delicate organisms as the algæ. described from some of the bogheads and cannels, even if vestiges happened to be preserved, in coals so highly changed by the dyramochemical process as the coking coals, is a matter so difficult as perhaps to justify consideration as improbable. Being apparently barred at present from satisfactorily determining their presence by direct:mechanical means, we are therefore left to search the evidence of the chemical analyses.

Not only does it appear that among coals of the same degree of progressive devolatilization those with the greatest amount of recognizable micro-algæ show hydrogen and oxygen most nearly in the proportions shown in bitumen, but in general it also seems, conversely, that those normally sedimented coals whose ultimate analyses approach most nearly to that of bitumen bear the more distinct microscopical evidence of the presence of the algæ. The coals whose large volatile combustible matter contains relatively the highest hydrogen and the lowest oxygen, thys approaching nearest the bitumen analyses, are those in which the organic remains described as micro-algæ are most predominant and often best preserved. 
Of the following analyses No. $1^{a}$ represents the Torbane Hill boghead; No. $2{ }^{a}$ the Kerosene shale (Permian) of New South Wales; No. $3,^{b}$ a hard pitch; No. $4,{ }^{b}$ "pitch $\mathrm{E}$," used in briquetting tests.

Analyses of algal coals approaching bitumen and of pitches.

\begin{tabular}{|c|c|c|c|c|c|c|}
\hline No. & s. & FI. & c. & $\mathrm{O}+\mathrm{N}$. & Ash. & Moisture. \\
\hline$\frac{1}{2}$ & & $\begin{array}{l}8.50 \\
9.63\end{array}$ & $\begin{array}{c}65.44 \\
76.61\end{array}$ & $\begin{array}{l}3.44 \\
2.87\end{array}$ & $\begin{array}{l}22.62 \\
10.64\end{array}$ & \\
\hline $\begin{array}{l}3 \\
4\end{array}$ & $\begin{array}{r}0.88 \\
.66\end{array}$ & $\begin{array}{l}\text { 4. } 56 \mathrm{j} \\
4.22\end{array}$ & $\begin{array}{l}90.34 \\
91.30\end{array}$ & $\begin{array}{l}3.06 \\
2.99\end{array}$ & $\begin{array}{r}1.16 \\
.83\end{array}$ & $\begin{array}{l}0.33 \\
1.02\end{array}$ \\
\hline
\end{tabular}

The tentative inference that sapropelic matter and the bituminous concentration ${ }^{c}$ have a direct connection in these high-volatile coals is, I believe, quite justified.

If the inference is correct that in the high volatile coals high bituminization (concentration of bituminous substance) and gelatinous algal (or sapropelic) ingredient elements go together, and if the observation of the connection between the presence of the latter (and consequent bituminization) with the tendency of the coal to fuse and swell is well founded, it seems probable that such coals of high bituminization will contain algal elements and (what is more important) fuse on burning in the mass. In other words, we may conclude that high volatile coals whose analyses show sufficiently high bituminization will coke by the ordinary process. The degree of bituminization in these coals is indicated by the relative excess of hydrogen as compared with the diminished oxygen in dry coal. It is expressed by the ratio $\mathrm{H}: \mathrm{O}$.

\section{HYDROGEN-OXYGEN RATIOS OF COKING COALS}

\section{DESCRIPTION OF DIAGRAM IN PLATE III.}

The test of this working hypothesis lies in the examination of the $\mathrm{H}: \mathrm{O}$ ratios, dry-coal basis, of the coals with reference to the known behavior of the fuels in coking tests. The data essential to the study of the analyses for this purpose are set forth in diagram in Plate III. Sulphur is omitted from this diagram because it does not seem to influence the coking quality of the coal, though of course greatly affecting the quality of the coke from the metallurgic standpoint. Ash also is omitted as not essential to the comparison.

In this diagram all the coals are rearranged in the order of their fixed carbon percentages (F. C.) in pure coal, as given in Table 2, and

\footnotetext{
a Renault, B., Les micro-organismes des combustibles fossiles, p. 149.

$\checkmark$ Prof. Paper U. S. Geol. Survey No. 48, pp. 266, 267.

c The gradual development of distinctness in the chemical resemblance to bltumen as progressive devolatilization eliminates more and more of the oxygen is essentially mere concentration. I therefore employ this term in place of enrichment, which suggests that bitumen has been brought in from some source entirely outside of the bed of coal.
} 
with the same numbers. This order is chosen as conforming, to some extent, to the evolution of the coals. It is genetic in so far as it shows the progressive devolatilization of the coals-that is, the progress in their dynamochemical alteration or improvement.

In order to present the additional essential criteria in a simple and graphic arrangement for comparison, the hydrogen-oxygen ratios are platted as heavy continuous lines extending to the right, and the ratios of volatile carbon to carbon (VC:C) are platted as heavy broken lines extending to the left, from a point representing nearly complete devolatilization. In the figure columns both these ratios are expressed as percentages. For comparison with the $\mathrm{H}: \mathrm{O}$ ratios the available hydrogen has also been platted as light broken lines extending to the right.

The annotations as to coking, at the right, are mainly those based on the tests by the United States Geological Survey and kindly furnished by Mr. J. S. Burrows, chief inspector. Information from other sources has been incorporated regarding some coals not tested for coke by the Survey.

\section{INDICATIONS OF RATIO LIMITS.}

The evidence of the hydrogen-oxygen ratios as to the coking quality of the coals needs no extended discussion. A review of the wide fluctuations in the $\mathrm{H}: \mathrm{O}$ ratios, together with the annotations as to coking, strongly indicates, so far as the tests have been made or the information is at hand, that, below the highest of the semibituminous coals which are approaching anthracitization, those coals with a $\mathrm{H}: \mathrm{O}$ ratio (percentage) of 59 or more, with but one or two exceptions, make coke by the ordinary commercial process. Nearly all those below 59 and above 55, so far as tested, make a coke, and among those ranging down to a ratio of 50 a large percentage coke, while one or two of the tested coals coke at a slightly lower ratio. It would seem, however, that the cokes made from those coals with a $\mathrm{H}$ : $\mathrm{O}$ ratio less than 55 are usually very poor and apt to be brittle and dark.

It appears, therefore, that among coals which are not too far devolatilized practically all that are sufficiently bituminized-that is, have a $\mathrm{H}: \mathrm{O}$ ratio of 59 or over-are almost certain to possess the coking fusibility, and that coke of good quality may usually be expected from coal with a ratio as low as 55 , while very poor results may be obtained when the ratio is as low as 50 . The best cokes obtained by the ordinary process are made from coals having a ratio of 60 or over. ${ }^{a}$ In the $\mathrm{H}: \mathrm{O}$ ratios of Table 2 and Plate III no oxygen compensation is made for sulphur in pyrite.

$a$ The coking tests made by the United States Geological Survey are based on the ordinary beehive-oven process. 


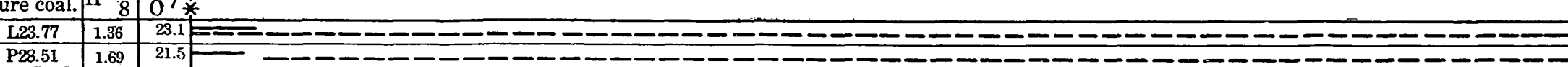

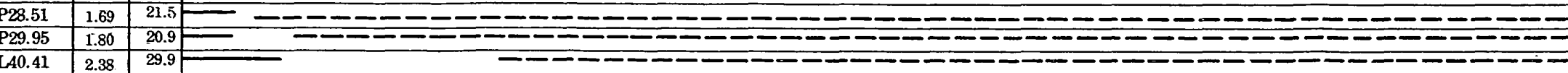

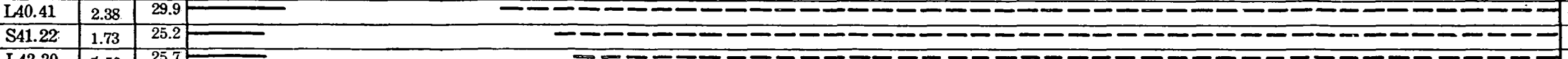

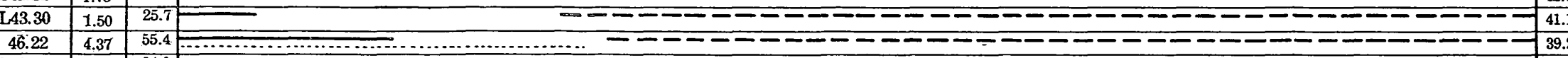

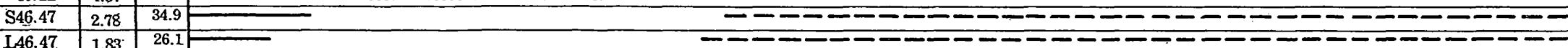

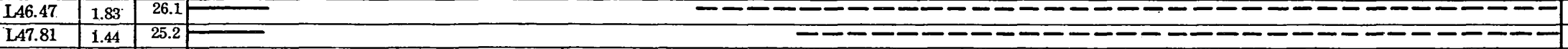

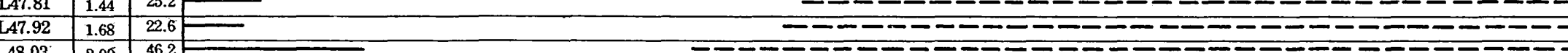

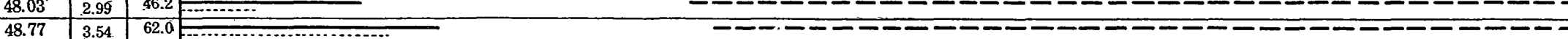

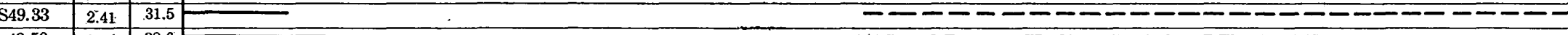
\begin{tabular}{c|c|c|c|}
49.59 & 2.45 & 38.6 & $=28.0$ \\
\hline 54971. & 2.64 & 28.0 &
\end{tabular} \begin{tabular}{r|c|c|c|c|}
49.86 & 2.93 & 40.3 \\
\hline 150.43 & 2.06 & 2.1 \\
\hline
\end{tabular}

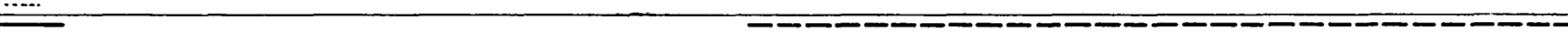
2.71 $\frac{29.2}{31.3}=0$

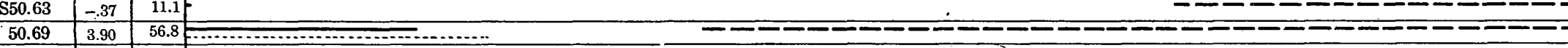

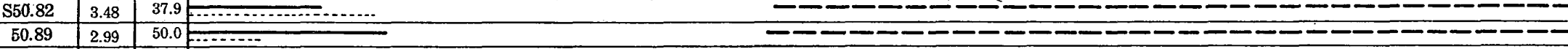
\begin{tabular}{llll}
50.93 & 1.18 & 26,1 \\
\hline
\end{tabular}

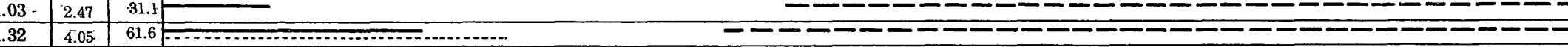

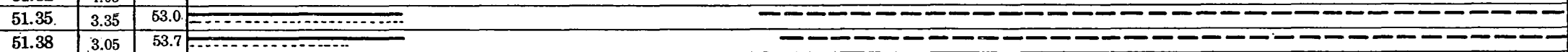

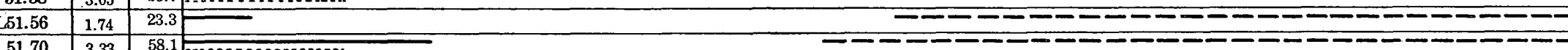

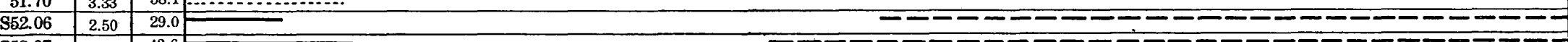

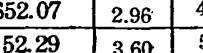

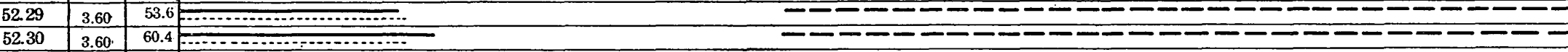

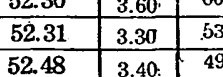
1549 77 3.50 ${ }^{3.56 .1}$ ….............

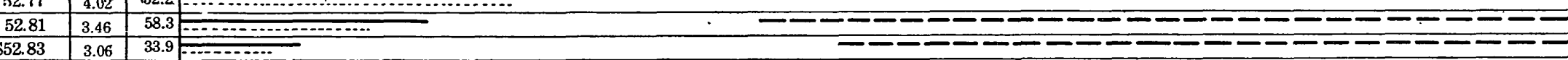

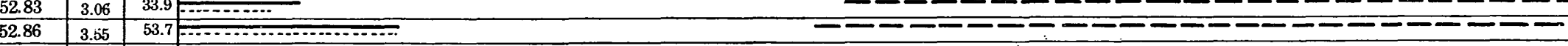

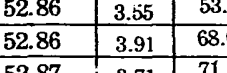
\begin{tabular}{l|l|l|l|l|l}
52.87 & 3.71 & 71.8 \\
\hline 53.00 & 3.45 & 59.3 \\
\hline
\end{tabular}

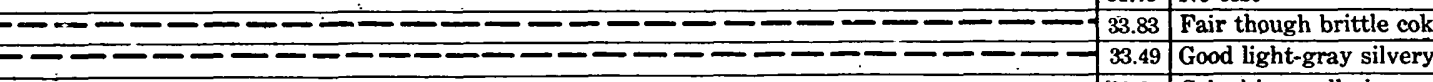
Distilled for oil No coking test Burned to ash. Cokes fairly well No tes -ーーーーーーーー- -

DIAGRAM SHOWING HYDROGEN-OXYGEN RATIOS OF COALS. 
\begin{tabular}{|l|l|l|}
\hline No. & Lot. & Locality. \\
\hline
\end{tabular} \begin{tabular}{|c|c|l|}
\hline $52 \mathrm{~b}$ & Wyo.2225 & Almy \\
\hline 120 & Ill.18 & Lasall \\
\hline
\end{tabular}

\begin{tabular}{|l|l|l|l|}
\hline 120 & M.1.18 & Lasale \\
\hline 338 & N.Mex.3811 & West of Putnam \\
\hline
\end{tabular}

\begin{tabular}{|l|l|l|}
\hline 22 & Tex.4 & Hoyt \\
\hline 74 & Ind.2 & Boomeville \\
\hline
\end{tabular}

\begin{tabular}{|r|l|l|}
\hline 87 & Ind.16 & Linton \\
\hline 149 & Ind.7B & Little \\
\hline
\end{tabular}

\begin{tabular}{|l|l|l|}
\hline 43 & Mo.1 & Sittrague \\
\hline
\end{tabular}

\begin{tabular}{|l|l|l|}
\hline 32 & Colo.1 & Sprague \\
\hline 72 & Lafayette \\
\hline
\end{tabular}

\begin{tabular}{|l|l|l|}
\hline 98 & Ind.5 & Lehigh \\
\hline
\end{tabular}

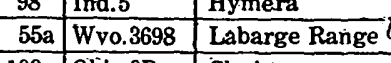

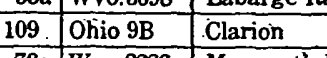

\begin{tabular}{l|l|l}
\hline $73 \mathrm{C}$ & Wyo.2283 & Mammoth Hill \\
\hline
\end{tabular}

\begin{tabular}{|l|l|l|}
\hline 38 & I1.27 & Auburn \\
\hline 168 & Ohio 10 & Mineral City \\
\hline 113 & Ma. & Huntsville \\
\hline
\end{tabular}

\begin{tabular}{|c|l|l|}
\hline 113 & Mo.6 & Huntsville \\
\hline 31 & Mont.1 & Red Lodge \\
\hline &
\end{tabular}

\begin{tabular}{|l|l|l} 
& & Med Lodge \\
\hline 53 & Mll.25B & Germantown \\
\hline
\end{tabular}

\begin{tabular}{|l|l|l|}
\hline 76 & Ill.24 & Springfield \\
\hline 107 & Ind.98 & Machill \\
\hline
\end{tabular}

\begin{tabular}{c|l|l|l}
\hline 107 & Ind.98 & Mackss \\
\hline 10 & Ind T 5 & Lehigh \\
\hline
\end{tabular}

\begin{tabular}{|l|l|l|}
\hline 10 & Ind.T.5 & Lehigh \\
\hline 94 & Ill.23B & Donkville \\
\hline
\end{tabular}

\begin{tabular}{l|l|l|l|l|l}
\hline 42 & 111.8 & \\
\hline
\end{tabular}

\begin{tabular}{|l|l|l}
\hline 90 & Mo.5 & Higbee \\
\hline
\end{tabular}

\begin{tabular}{r|l|l}
\hline 15 & Mo.7A & Noringer \\
\hline 130 & $K y .2$ & E \\
\hline
\end{tabular}

\begin{tabular}{|c|l|l|}
\hline 130 & Ky. 2 & Earlington \\
\hline 662 & Colo.3498 & Meeker \\
\hline
\end{tabular}

\begin{tabular}{|c|c|c|}
\hline 45 & III.23A & Donkville \\
\hline 172 & Ohio 12A & Bellaire \\
\hline
\end{tabular}

\begin{tabular}{l|l|l}
\hline 81a & Ariz.411. & Near St. Michaels \\
\hline & &
\end{tabular}

\begin{tabular}{|l|l|l|}
\hline 81a & Ariz.41 & Near St. Michaels \\
\hline 28 & Mo. $7 \mathrm{~B}$ & Noringer \\
\hline 24 & Tex. 3 & Olsen \\
\hline 117 & Ind.8 & Terre Haute \\
\hline
\end{tabular}

\begin{tabular}{l|l|l}
\hline 62 & Inl.15 & Terre Hau \\
\hline
\end{tabular}

\begin{tabular}{l|l|l}
\hline 102 & Ind.9 & Macksville \\
\hline 138 & Kans.4 & Atchison \\
\hline
\end{tabular}

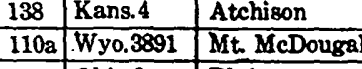

\begin{tabular}{|l|l|l|l|}
\hline 154 & Ohio 8 & Dixie \\
\hline 16 & Mos & Yestom \\
\hline
\end{tabular}

\begin{tabular}{|l|l|l}
\hline 16 & Mo.3 & Mendota \\
\hline 91 & Ind.12 & Hartwell \\
\hline 92 & Oh. & Saporo \\
\hline
\end{tabular}

\begin{tabular}{|l|l|l|}
\hline 92 & Ohio 2 & Superio \\
\hline 82 & Ml.26 & Linool \\
\hline
\end{tabular}

\begin{tabular}{|l|l|l|l|l}
\hline 40 & Ind.3 & Booneoville \\
\hline
\end{tabular}

\begin{tabular}{|l|l|l|l|l}
\hline 57 & Ill.29B & Livingston \\
\hline 53:i & Wyo.3917 & Fort Steele \\
\hline
\end{tabular}

\begin{tabular}{|l|l|l|l|l|l}
\hline 532 & Wyo.3917 & Fort Steele \\
\hline 12 & Mo.7C & Noringer \\
\hline
\end{tabular}

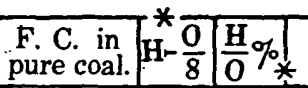

$\begin{array}{lll}553.02 & 2.28 & 28.5\end{array}$ \begin{tabular}{l|l|l|}
\hline 53.13 & 3.80 & 56.0 \\
\hline S53.25 & 2.93 & 35.5 \\
\hline
\end{tabular}

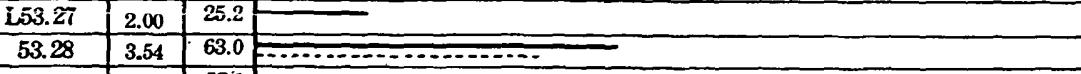

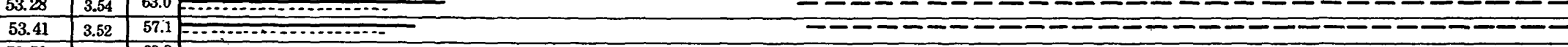

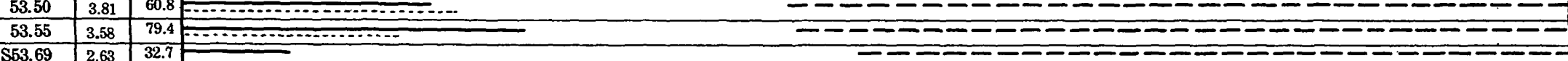

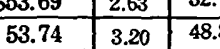
\begin{tabular}{l|l|l|l}
53.75 & 3.57 & 60.8 \\
\hline
\end{tabular} \begin{tabular}{l|l|l|l|}
\hline 53.83 & 3.48 & 54.4 \\
\hline 5
\end{tabular}

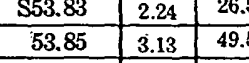

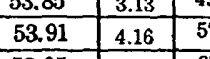
\begin{tabular}{l|l|l}
53.95 & 3.63 & 6 \\
\hline 5530 & 205 & 35 \\
\hline
\end{tabular}

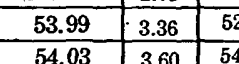
\begin{tabular}{l|l|l|l}
54.03 & 3.60 & 54.8 \\
\hline 54.03 & 3.73 & 56.5 & \\
54.09 & 2.63 & 4.5 &
\end{tabular} \begin{tabular}{|l|l|l|l|}
\hline 54.07 & 2.63 & 48.5 \\
\hline 54.20 & 3.54 & 51. \\
\hline 54 & 3.25 & 54.1 \\
\hline
\end{tabular} \begin{tabular}{l|l|l|l|}
54.21 & 3.60 & 62.5 \\
\hline 54.27 & 2.87 & 50.1 \\
\hline 5.28 & 3.24 & 59.2 &
\end{tabular} \begin{tabular}{l|l|l|}
\hline 54.28 & 2.87 & 59.1 \\
\hline 5.45 & 2.5 & 31.4 \\
\hline
\end{tabular} \begin{tabular}{r|r|r|r}
544.45 & 2.65 & 3.4 \\
\hline S54.46. & .99 & 19.2 \\
\hline
\end{tabular} \begin{tabular}{|l|l|l|}
\hline 54.48 & 3.18 & 50.3 \\
\hline
\end{tabular} \begin{tabular}{l|l|l|l}
\hline 54.55 & 3.95 & 67.4 \\
\hline 5.58 & 304 & 36. \\
\hline
\end{tabular} \begin{tabular}{l|l|l|l|}
54.58 & 3.04 & 34 \\
\hline 54.59 & 3.11 & 550 \\
\hline
\end{tabular} \begin{tabular}{|l|l|l|}
\hline $\mathbf{L} 54.68$ & 2.18 & 2.1 \\
\hline 54.68 & 3.77 & 6.5 \\
\hline
\end{tabular} \begin{tabular}{llll}
\hline 54.68 & 3.77 & 5.15 \\
\hline 54.76 & 3.26 & 50.9 \\
\hline
\end{tabular} \begin{tabular}{l|l|l|l}
54.76 & 3.64 & 59.1 \\
\hline 54.79 & 4.05 & 97. \\
\hline
\end{tabular} \begin{tabular}{l|l|l|l|}
\hline 54.79 & 2.93 & 35.0 \\
\hline 54.81 & 3.78 & 56.0 \\
\hline 5.93 & 2.9 &
\end{tabular} \begin{tabular}{l|l|l|l}
54.93 & 2.98 & 5.05 & \\
\hline 54.97 & 3.53 & 5 & \\
\hline & 5.05 &
\end{tabular} \begin{tabular}{l|l|l|l}
54.97 & 3.53 & 57.0 \\
\hline 55.00 & 3.61 & 60.5 \\
\hline
\end{tabular} \begin{tabular}{l|l|l|}
55.14 & 3.35 & 53. \\
\hline 55.16. & 3.32 & 56. \\
\hline 5.2.
\end{tabular} \begin{tabular}{l|l|l|}
\hline 55.16. & 3.32 & 56.4 \\
\hline 55.24 & 3.29 & 52.2 \\
\hline
\end{tabular} \begin{tabular}{|c|c|c|c|}
\hline 555.36 & 2.02 & 24.2 \\
\hline 55.43 & 2.64 & 44.3 \\
\hline
\end{tabular}

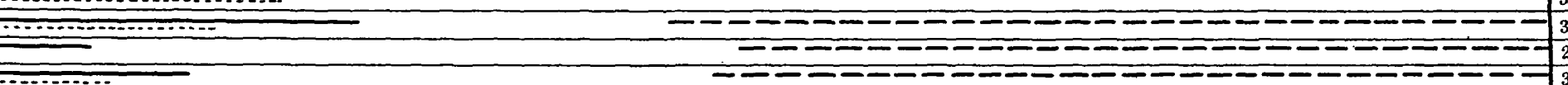

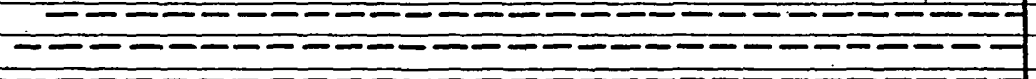

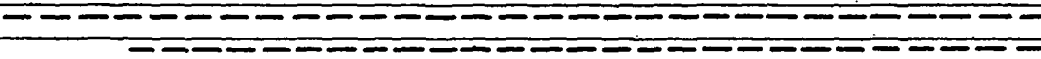

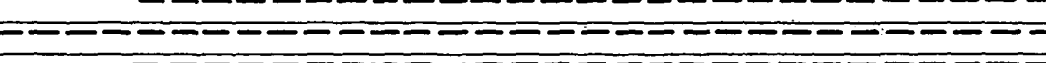

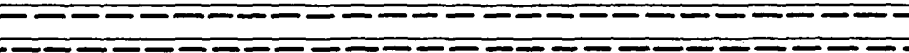

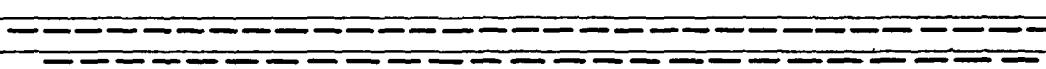

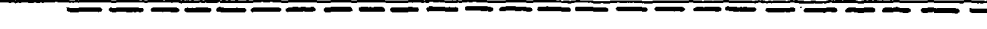
$=--0-0-0-1-0-0-0$ - - - - -

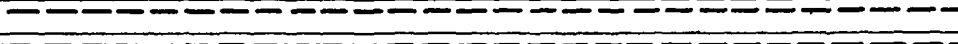

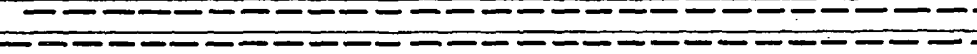

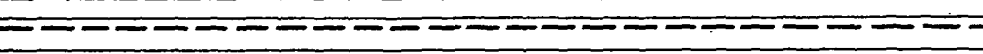

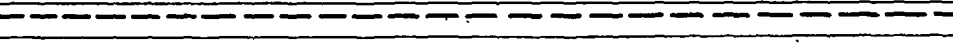
- - - - - - - - - - - - - - $-\cdots$

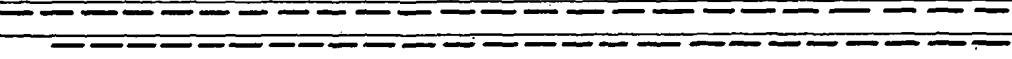

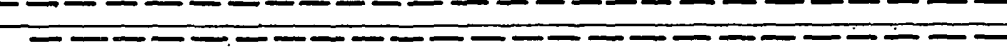

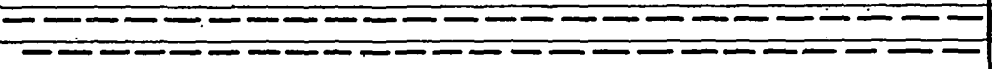

BULLeTIN 382 PLATE III-B

*The limits of the diagram include $\frac{H}{\mathrm{P}}$ percenteges 
\begin{tabular}{ll}
.81 & Said to make coke \\
\hline
\end{tabular}

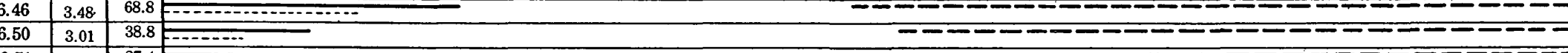
566.51
56.58

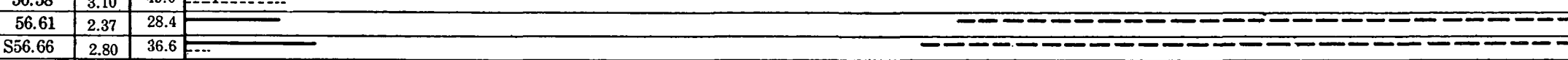

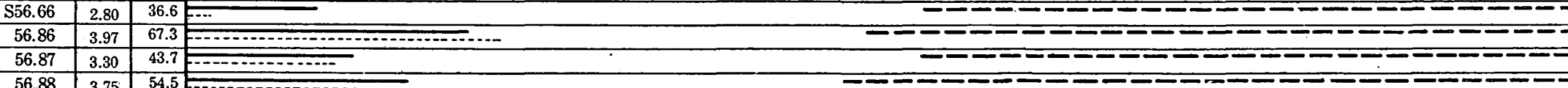

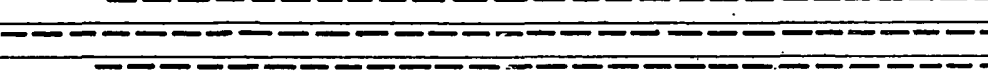
(56.4.

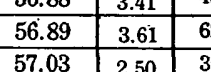
- - - -

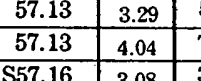

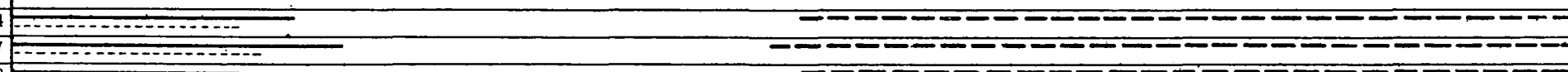
3.08 39.3

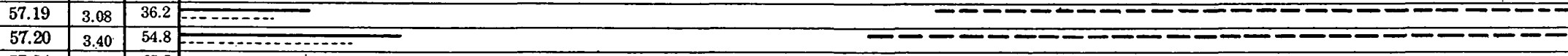
\begin{tabular}{l|l|l|l|l}
57.24 & 3.88 & 6 & \\
57.27 & 3.21 & 4 & \\
5.21 & &
\end{tabular}

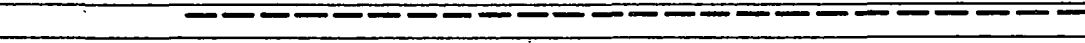

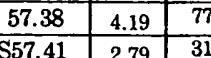

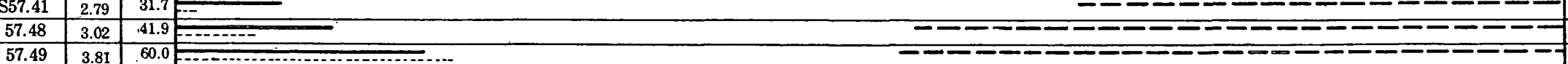
Good coke, metallic ring 75 Poor, dense coke

37 No test

\begin{tabular}{ll} 
Good coke \\
.33 & Said to be noncoking \\
\hline
\end{tabular} Said to be noncoking
Very brittle, dense coke Said to coke well Good coke

11 Once coked commercially \begin{tabular}{l}
86 \\
37 \\
Finned tecavy coke \\
\hline
\end{tabular}

\begin{tabular}{l|l}
49 & No coke from test \\
39 & Good but brittle coke \\
\hline
\end{tabular} \begin{tabular}{l|l|}
\hline 1.05 & Coked well \\
\hline 7.73 & Noncoking \\
\hline
\end{tabular}

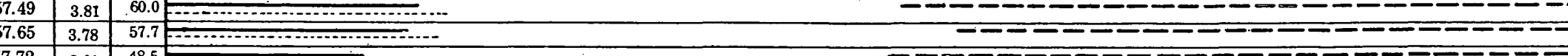

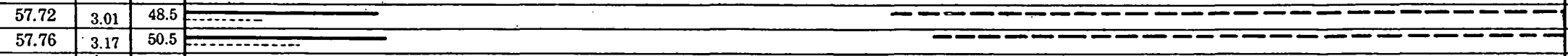

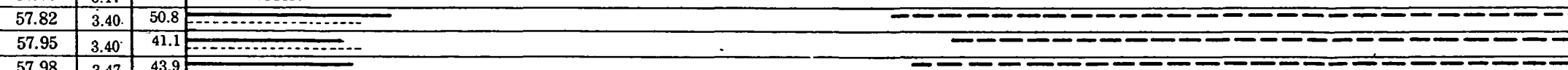

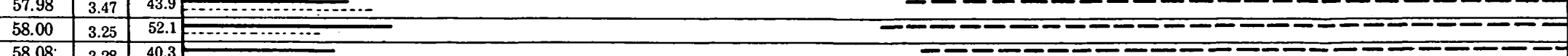

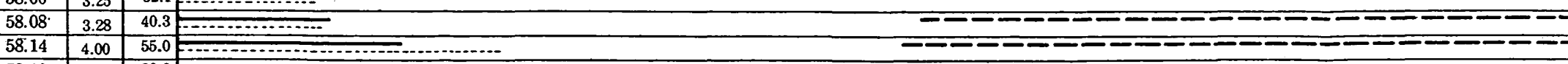
\begin{tabular}{l|l|l|l|l}
\hline 58.19 & 3.42 & 39.0 & $\ldots \ldots \ldots \ldots \ldots$ \\
\hline 58.22 & 3.46 & 41.6 & $\ldots \ldots \ldots \ldots \ldots \ldots \ldots \ldots \ldots$ \\
\hline
\end{tabular}

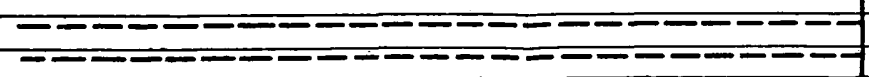
\begin{tabular}{l|l}
24.13 \\
30.08. & Good coke; metallic ring \\
\hline
\end{tabular} No coke from test \begin{tabular}{l|l}
7.88 & Fairly good coking \\
\hline 66 & Partially coked in test \\
\hline
\end{tabular} \begin{tabular}{ll}
8.30 & No test \\
\hline 5.53 & Poor dark-gray coke \\
\hline
\end{tabular} 28.52
No test; said to coke \begin{tabular}{ll}
\hline .03 & Noncoking \\
\hline .79 & Coke; medium cells \\
\hline
\end{tabular} DIAGRAM SHOWING HYDROGEN-OXYGEN RATIOS OF COALS 


\section{1}

(20)

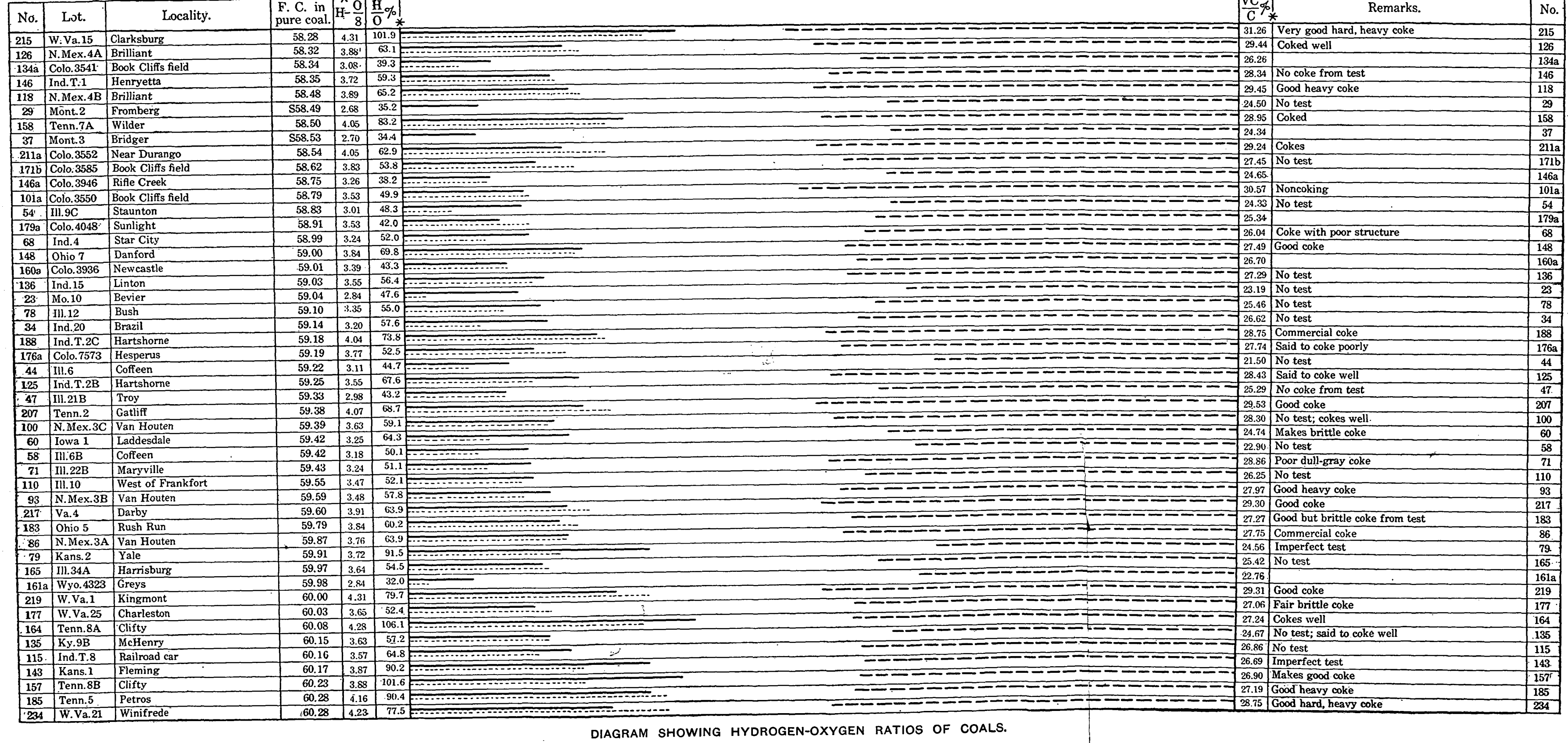

* The limits of the diagram include $\frac{H}{O}$ percentages over 10 and under $290, \frac{V C}{C}$ percentages under 57 , and availablt over 2.7. 
U. S. GEOLOGICAL SURVEY

\begin{tabular}{|c|c|c|}
\hline No. & Lot. & Locality. \\
\hline 224 & Ky. 6 & \begin{tabular}{|l} 
Miller Creek \\
\end{tabular} \\
\hline 88 & Rans.6 & Jewett \\
\hline 186 & Tenn. 3 & Gatliff \\
\hline & Wýo. 3570 & \begin{tabular}{|l|} 
Oyster Ridge \\
\end{tabular} \\
\hline & IIll:11B & \\
\hline 171c & Colo.3932 & \\
\hline 2082 & \begin{tabular}{|l|} 
Wyo. 4303 \\
\end{tabular} & Willow Creek \\
\hline 104 & IIll. $34 \mathrm{~B}$ & Harrisburg \\
\hline 155 & Pa.13 & Creighton \\
\hline 156. & Temn.1 & Fork Ridge \\
\hline 112 & Iil.12B & Bush \\
\hline $72 \mathrm{a}$ & Colo. 3545 & Book Cliffs field $a$ \\
\hline $215 \mathrm{a}$ & \begin{tabular}{|l|} 
Wyo.4299 \\
\end{tabular} & \begin{tabular}{|l} 
Willow Creek \\
\end{tabular} \\
\hline 114 & Ala.2 & \begin{tabular}{|l|} 
Carbon Hill \\
\end{tabular} \\
\hline 229 & Ky.1 & Straight Creek \\
\hline 122 & IIll.13 & \begin{tabular}{|l|} 
Benton \\
\end{tabular} \\
\hline 116 & III.12C & \begin{tabular}{|l|l|} 
Bush \\
\end{tabular} \\
\hline 175 & W.Va.22B & Hernshaw \\
\hline & W.Va.23A & Monarch \\
\hline $149 \mathrm{a}$ & \begin{tabular}{|l|} 
Colo.3546 \\
\end{tabular} & Book Cliffs field \\
\hline & W.Va.23B & Monarch \\
\hline 170 & \begin{tabular}{|l|l|} 
IIl.11C \\
\end{tabular} & Carterville \\
\hline 218 & Va.2 B & Crab Orchard \\
\hline 204 & Ky.1B & Straight Creek \\
\hline 145 & III.11 & \begin{tabular}{|l} 
Carterville \\
\end{tabular} \\
\hline 141 & N.Mex.5 & Blossburg \\
\hline $146 \mathrm{c}$ & Wyo.4302 & Willow Creek $b$ \\
\hline $62 \mathrm{a}$ & Utah 4013 & South of Sunnyside $a$ \\
\hline 221 & Va.1 & Crab Orchard \\
\hline 220 & Pa.10 & Bruce \\
\hline 233 & Ky. 5 & Big Black Mountain \\
\hline $208 \mathrm{~b}$ & Colo.4010 & Gulch \\
\hline 127 & IIll.12D & Bush \\
\hline \begin{tabular}{l|l|}
169 \\
\end{tabular} & Pa.6 & East of Millsboro \\
\hline 192 & \begin{tabular}{|l|} 
W.Va.22A \\
\end{tabular} & Hernshaw \\
\hline 226 & Pa.5 & Ellsworth \\
\hline 85 & Ala.2B & \begin{tabular}{|l|} 
Carbon Hill \\
\end{tabular} \\
\hline 214 & Pa.11 & Charleroi \\
\hline $136 \mathrm{a}$ & Colo.3640 & Book Cliffs field \\
\hline 159 & Ala.1 & Horse Creek \\
\hline 147 & IIl.19B & Ziegler \\
\hline 174 & \begin{tabular}{|l|l|} 
Tenn.4 \\
\end{tabular} & Oliver Springs \\
\hline 84 & IIll.19E & \begin{tabular}{|l|} 
Ziegler \\
\end{tabular} \\
\hline 173 & Kans. 5 & West of Mineral \\
\hline \begin{tabular}{|l|l|}
65 \\
\end{tabular} & Kans.2 B & Yale \\
\hline 95 & mll.19C & \begin{tabular}{|l|l|} 
Ziegler \\
\end{tabular} \\
\hline 97 & IIll.3. & Marion \\
\hline 201 & W.Va.16. & Mononga \\
\hline
\end{tabular}

\begin{tabular}{|c|c|}
\hline \begin{tabular}{|l|}
$\begin{array}{c}\text { F. C. in in } \\
\text { pure coal. }\end{array}$ \\
$\mathrm{H}$
\end{tabular} & $\mathrm{H}$ \\
\hline \begin{tabular}{l|}
60.39 \\
6.3
\end{tabular} & \\
\hline 60.54 & $\frac{3.5}{4.0}$ \\
\hline 60.61 & \\
\hline 60.68 & \\
\hline 60.71 & \\
\hline 60.74 & \\
\hline 60.76 & \\
\hline $\begin{array}{l}-60.77 \\
60.84\end{array}$ & \\
\hline 60.87 & \\
\hline 60.89 & \\
\hline 60.91 & \\
\hline 60.95 & \\
\hline 60.96 & \\
\hline 61.02 & \\
\hline$\frac{61.02}{61.02}$ & \\
\hline$\frac{6.02}{61.18}$ & \\
\hline$\frac{2.10}{61.19}$ & \\
\hline 61.23 & \\
\hline 61.30 & \\
\hline 61.42 & \\
\hline 61.43 & \\
\hline 61.48 & \\
\hline 61.49 & \\
\hline 61.60 & \\
\hline 61.62 & \\
\hline 61.70 & \\
\hline 61.71 & \\
\hline 61.91 & \\
\hline 61.97 & \\
\hline 62.22 & \\
\hline 62.26 & \\
\hline 62.27 & \\
\hline 62.31 & \\
\hline 62.31 & \\
\hline 62.46 & \\
\hline 62.54 & \\
\hline 62.59 & \\
\hline 6264 & \\
\hline 62.69 & -4. \\
\hline$\frac{6274}{62.92}$ & \\
\hline 63.15 & \\
\hline 63.26 & \\
\hline$\frac{63.26}{6927}$ & \\
\hline & \\
\hline
\end{tabular}

(i)

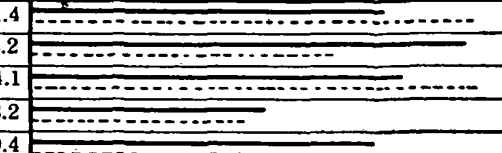

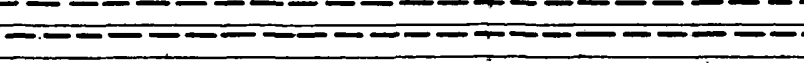
-

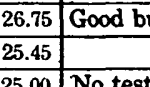

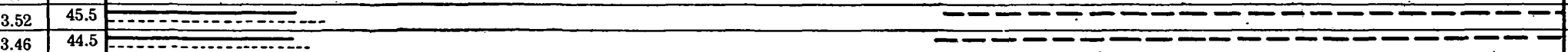

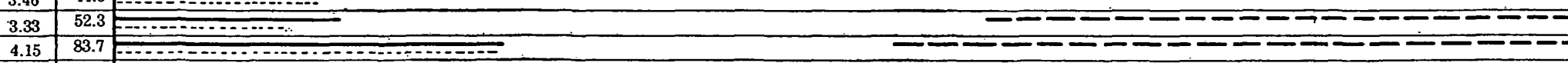

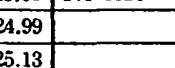
Coked well No test; said to coke well 3.80
3.33 No test

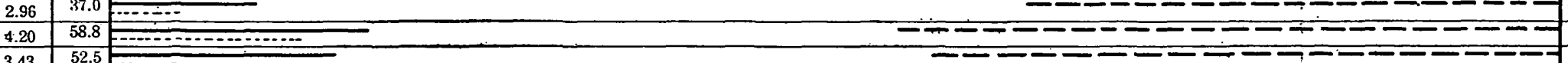

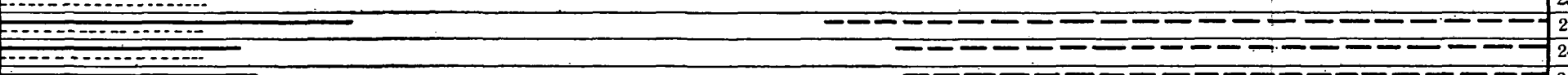
No test

Coked imperfectly

Coked commercially 70.4 : -

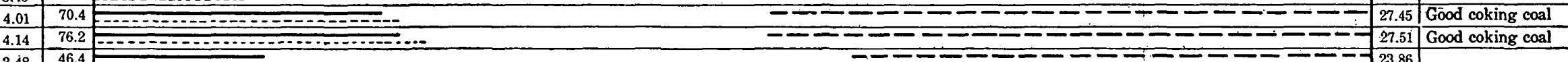

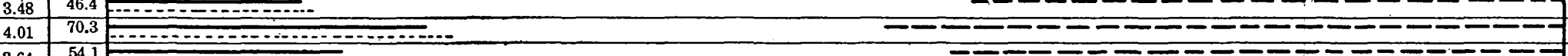

Cokes well No test; strong coke on III.11D : …............................ 57.0 \%................. 72.5 : - - -

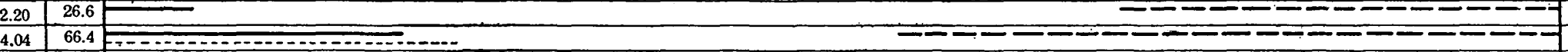

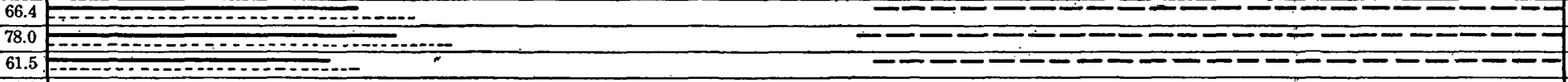

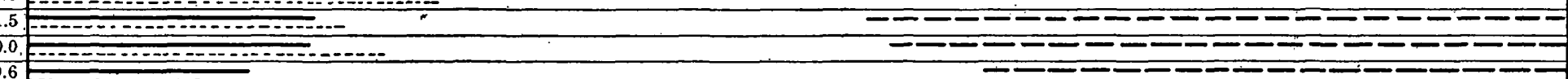
${ }^{85.4} \mathrm{mon}$

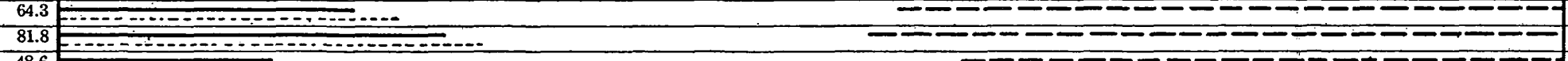
3.13
4.14

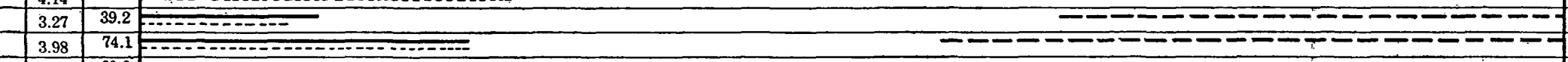

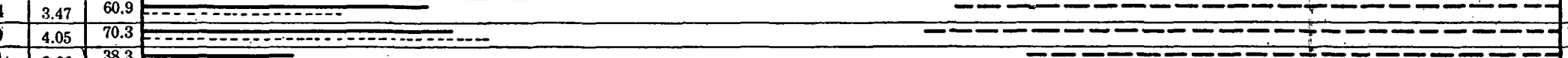
-

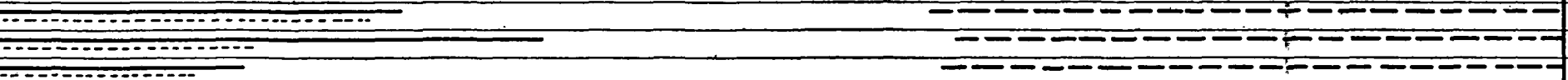

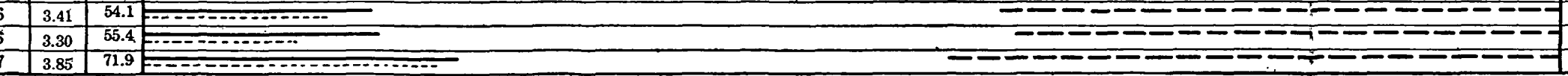
\begin{tabular}{|l|l|}
\hline & 204 \\
\hline Toed commercially & 215 \\
\hline
\end{tabular} Good heavy coke \begin{tabular}{l}
\hline Good hard coke \\
Makes good coke
\end{tabular} Good but very brittle coke No test; said to coke No test \begin{tabular}{l|l} 
Makes fine coke \\
\hline
\end{tabular} Fine coking caal \begin{tabular}{|l|l|l}
\hline Soft, dense, \\
\hline
\end{tabular} Cokes well Is coked from test 18 No coke from te Said to coke \begin{tabular}{l|l} 
No test \\
No coke from test \\
\hline Poor brittle coke
\end{tabular} DIAGRAM SHOWING HYDROGEN-OXYGEN RATIOS OF COALS.

* The limits of the diagram include $\frac{H}{O}$ percentages over 10 and under $290, \frac{V C}{C}$ percentages under 57 , and available $H$ over 2.7. 


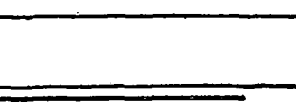

154.9:

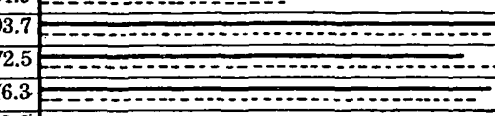

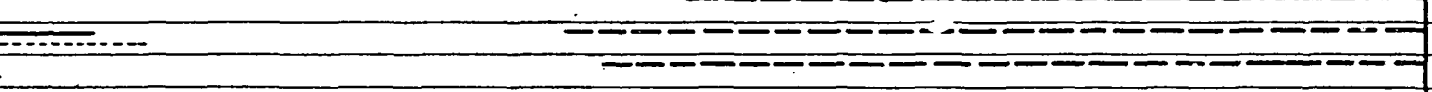
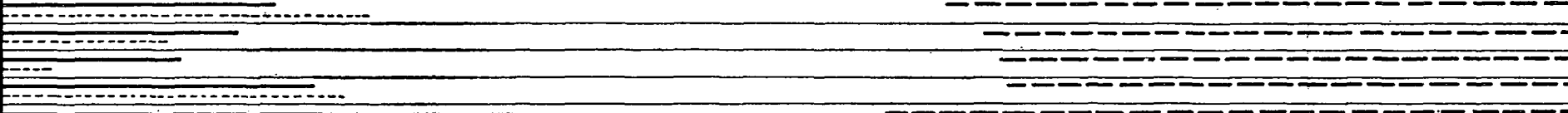

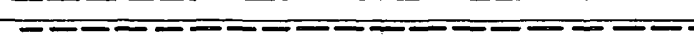

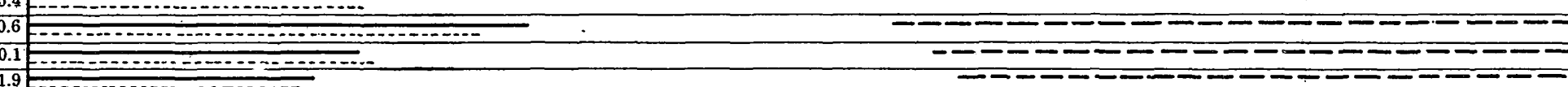
1.8.

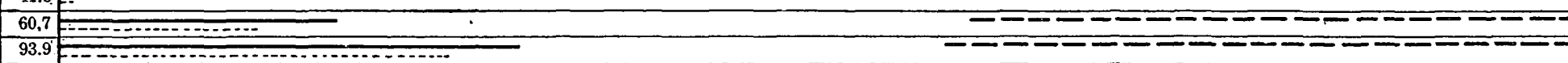

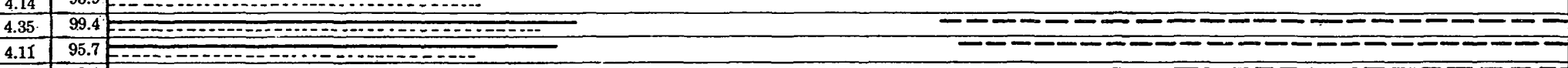
3.84 74.2: ${ }_{4.30}{ }_{96.1}{ }_{97}$

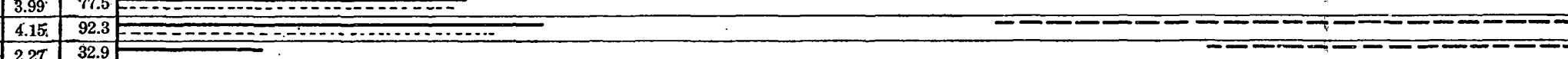

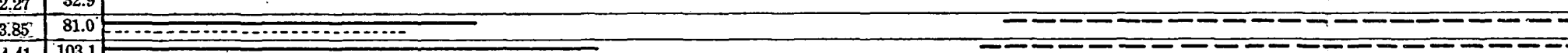

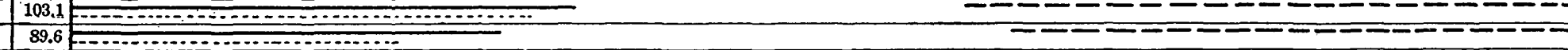

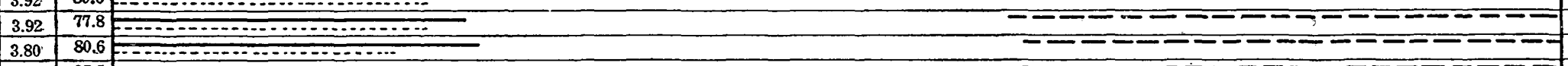

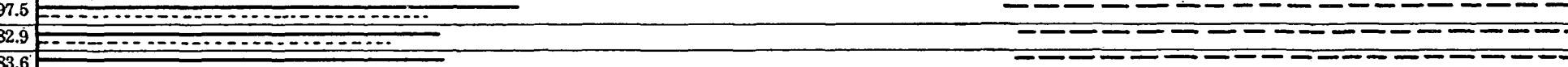

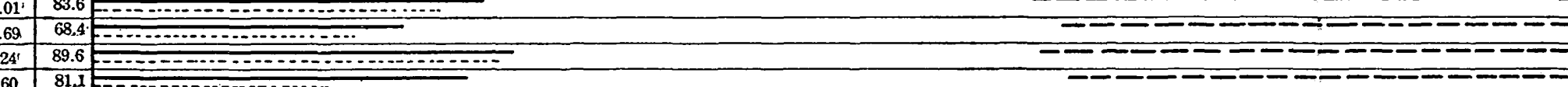

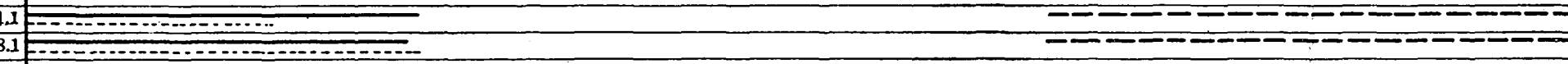

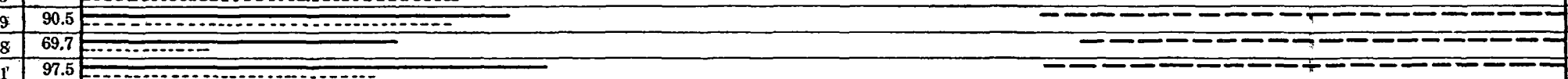
-

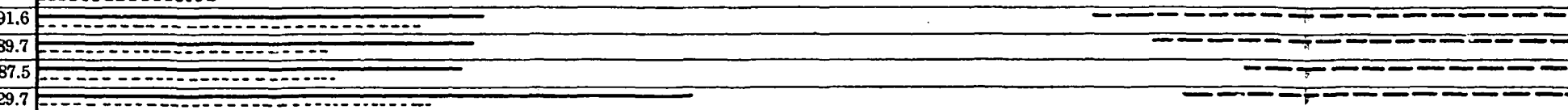
\begin{tabular}{l} 
D. \\
\hline
\end{tabular} \begin{tabular}{ll}
13.69 & Good heavy coke \\
\hline 13.26 & Makes good coke \\
Tough, dense coke; commercial
\end{tabular} \begin{tabular}{ll}
13.69 & Good heavy coke \\
\hline 13.26 & Makes good coke \\
Tough, dense coke; commercial
\end{tabular}

DIAGRAM SHOWING HYDROGEN-OXYGEN RATIOS OF COALS.

* The limits of the diagram include $\frac{H}{O}$ percentages over 10 and under $290, \frac{V C}{C}$ percentages under 57 , and available $H$ over 2.7 .

Gooes well

Dark-gray coke; small cell structure Good coking coal Good hard, heavy c Fairly good coke; large cells Said to coke we

Strong, hard, heavy coke Fine strong coke Makes excellent coke Very good coke Good heavy commercial coke Said to make good col
Said to coke well

Good strong, heavy coke
Very good coke; commercial Very good coke; comm
Commercially coked
Makes a good coke Good coke

\begin{tabular}{l} 
Good heavy coke \\
\hline
\end{tabular} .46 Makes good coke; high ash
30 21.02 Coked commercially 9.96 Good, heavy, silvery coke; metalliz 20.89 Good coke with cross fracture No test
2.65
Very good coke \begin{tabular}{ll}
.61 & Very good coke \\
\hline
\end{tabular} Poor coke from test Heavy, light-gray silvery coke 
U. S. GEOLOGICAL SURVEY

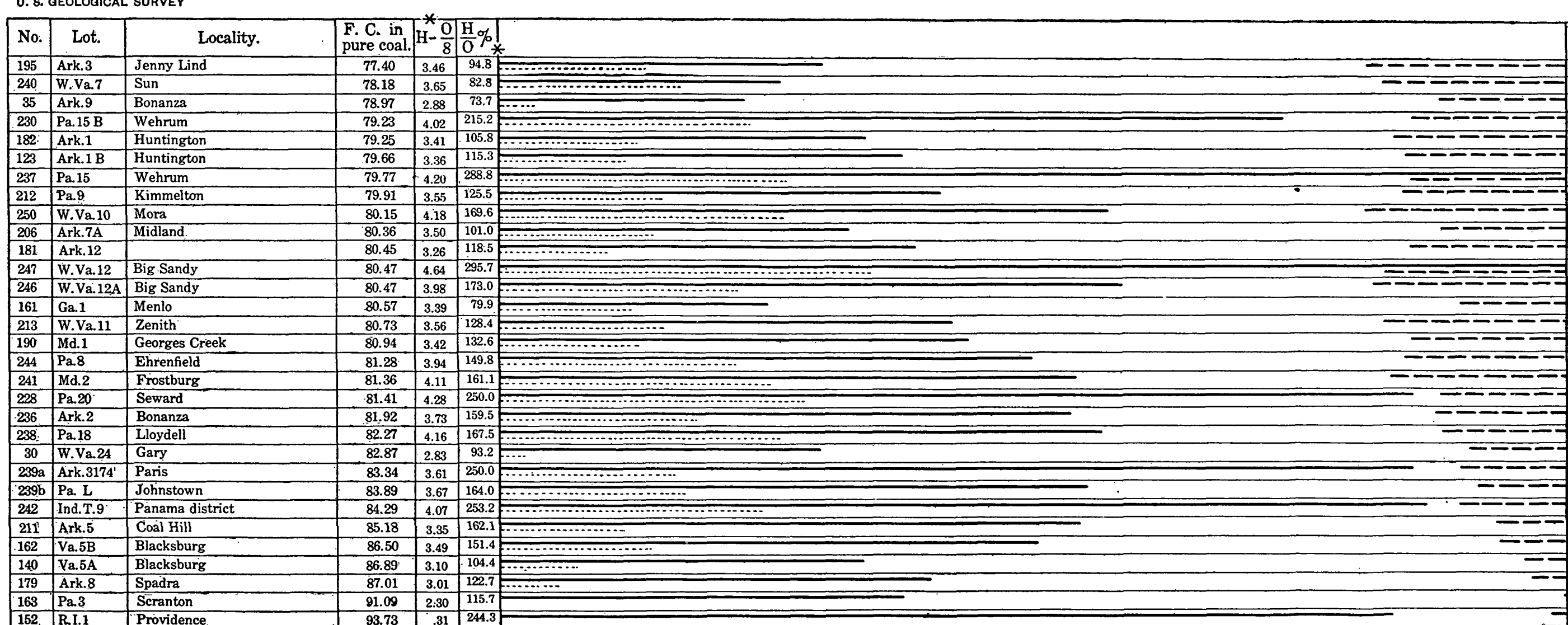

\begin{tabular}{|l|l|l|l|}
\hline 163 & Pa.3 & Seranton \\
\hline 152. & R.I.1 & Providence \\
\hline
\end{tabular}
DIAGRAM SHOWING HYDROGEN-OXYGEN RATIOS OF COALS.

*The limits of the diagram include $\frac{H}{O}$ percentages over 10 and under $290, \frac{V C}{C}$ percentages under 57 , and available $H$ over 2.7 .

Good quality coke

\begin{tabular}{ll}
\hline .71 & No coke from test \\
\hline & Cokes in by-product ovens \\
\hline
\end{tabular}

Soft, dense coke; poor cells

.11 Soft dense coke in test; coked in by. product ovens. 2

\begin{tabular}{ll}
7.64 & No test. Test of Ark.7B. produced no coke \\
\hline 9.15 & No test \\
\hline
\end{tabular}

.158 No test

\begin{tabular}{|l|l|}
\hline Good coke & 24 \\
\hline
\end{tabular}

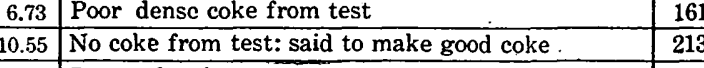

\begin{tabular}{|l|l|l|}
\hline 9.02 & Poor soft coke & 190 \\
\hline 9.49 & Soft dense coke from test & 244 \\
\hline & Lo & 241 \\
\hline
\end{tabular}

No. test. Poor ' coke once shipped.

7.96
7.96

7.49 No test

\begin{tabular}{l|l|l|l}
\hline & \\
\hline
\end{tabular}

4.65 No test

.

\begin{tabular}{l|l|}
\hline .20 & No test \\
\hline 2.93 & No test \\
\hline 1.18 & No test \\
\hline
\end{tabular}

\begin{tabular}{r|r|}
-7.93 & No test \\
\hline 1.18 & No test \\
\hline-1.98 & Not a fuel \\
\hline
\end{tabular}

t: said to be coked


APPLICATION TO ALGAL HYPOTHESIS.

Applying these observations to our tentative hypothesis to account coincidently for both bituminization and fusibility, the conclusion that gelosic (or sapropelic) elements have entered into the composition of certain of the coals in the list seems justified. So far as the coals low in fixed carbon are concerned, I am disposed to regard it as essentially confirmed.

The Barnett, Mo., coal (No. 203) with a fixed carbon (pure coal) percentage of 49.76 and a $\mathrm{H}: \mathrm{O}$ ratio of $94.9 \mathrm{I}$ regard as most probably gelosic (sapropelic). So also with the coal from Sprague, Mo. (No. 43), with 53.55 fixed carbon and $79.4 \mathrm{H}: \mathrm{O}$ ratio, and Atchison, Kans. (No. 138), with 54.79 fixed carbon and $97.9 \mathrm{H}: \mathrm{O}$ ratio. I have not personally examined specimens from any of the above-mentioned coals. Provisionally, I am inclined to believe that small portions of gelosic matter probably entered into others of the coals whose ratio percentage is conspicuously above that of the associated bituminous coals having nearly the same percentage of fixed carbon, though lower than those mentioned. Among the most prominent of these mention may be made of Stone Canyon, Cal. (No. 147b), with 46.22 fixed carbon; Altoona, Iowa (No. 63), with 48.77; Hymera, Ind. (No. 80), with 52.87; Clarksburg, W. Va. (Nos. 205 and 215), with 55.71 and 58.28, respectively; Wilder, Tenn. (No. 158), with 58.50; Yale, Kans. (No. 79), with 59.91, and Clifty, Tenn. (No. 164), with 60.08. If an unknown, probably very small, amount of gelatinous algal matter entered into the composition of these coals, it probably has been optically obliterated, if not quite macerated. In passing it may be remarked that the provisional hypothesis appears to harmonize in all respects with the tendency of the coking coals to cohere when reduced to a fine powder under the pestle, discovered by Max Pishel ${ }^{a}$ since the preparation of these tables.

\section{COKING OF HIGH FIXED CARBON COALS.}

VOLATILE-CARBON RATIOS.

The reader will have noted in passing down the $\mathrm{H}$ : $\mathrm{O}$ ratio columns in Plate III that after reaching a fixed carbon in pure coal of 66 or 67 per cent, $\mathrm{H}: \mathrm{O}$ ratios of 60 per cent or over characterize all the coals. Accordingly it should follow that all these coals possess the fusing quality and are susceptible of coking. This is practically true, for it appears that nearly all the coals in this portion of the list will coke up to a fixed carbon of about 79 per cent, beyond which, as may be noted in the "remarks," some of the coals do not coke well by the ordinary 
process, while others apparently refuse to coke. A typical example of the latter kind is No. 35 from Bonanza, Ark., with 78.97 fixed carbon and a ratio of 73.7. Inspection of the columns of $\mathrm{VC}: \mathrm{C}$ ratios shows that the high fixed carbon coals which apparently are noncoking are relatively low in volatile carbon, while certain other coals with a fixed carbon as high as 80 are said to coke well, although sometimes with considerable waste of uncemented carbon. The volatile of these high fixed carbon coking coals, it will be observed, seems to be characterized by a relatively high proportion of carbon. According to the tests, and so far as the present series of analyses illustrates, it would seem that coals of over 79 per cent of fixed carbon in pure coal can not be depended upon for coking by the ordinary process if the volatile carbon to carbon ratio (VC:C) is less than 10 per cent. Several of these highest-grade semibituminous coals, which are approaching the semianthracite group and whose volatile carbon ratio is less than 10 , are said to give good results in by-product ovens. An example is No. 237 from Wehrum, $\mathrm{Pa}$., in which the fixed carbon is 79.77 per cent and the VC:C ratio 9.11 per cent.

\section{CONSULTATION OF EFFICIENCY ERRORS.}

Another method of distinguishing the coking from the noncoking coals in this group with over 78 or 79 per cent of fixed carbon, more practical and perhaps more reliable than observation of the volatile carbon ratios, is consultation of the efficiency errors, for the examples before us seem to indicate that the highly developed coals which do not possess the coking quality show very marked deficiency errors. This is well illustrated by the analyses of the higher semibituminous and the semianthracite fuels from Arkansas.

\section{HYDROGEN AND OXYGEN LOSSES IN THE PROGRESSIVE DEVEL- OPMENT OF COAL.}

An explanation of the general upward progress of the hydrogenoxygen ratios in coals of over 66 per cent fixed carbon (all such in the tables being high) may be found in the more unequal rate of loss in the hydrogen and the oxygen during the more advanced stages of the progressive devolatilization of the coals. Observation of the relative loss of hydrogen and oxygen in the different groups of coals (dry-coal basis) shows that the curve of the hydrogen, though inclined steeply at first in passing from cellulose and lignose through the peats into the lignites, grades very gently through the great body of subbituminous, bituminous; and lower semibituminous coals, but pitches more rapidly near the semianthracite rank. The oxygen curve, on the contrary, exhibits a much steeper gradient, dropping 
through a much wider range, while passing through the subbituminous and bituminous coals; but before reaching the semibituminous coals it begins to decline more rapidly than the hydrogen curve, and this acceleration continues, so that in many coals the oxygen percentage, as will have been noted, becomes considerably less than the hydrogen. Examples are Nos. 179, 190, 193, 211, 212, 213, 228, $230,231 \mathrm{~b}, 236,237,239 \mathrm{a}$, and $239 \mathrm{~b}$. This relatively accelerated loss of oxygen as compared with that of hydrogen is expressed in the increase of the ratios.

\section{AVAILABLE HYDROGEN AS INDEX OF COKING COALS.}

I have been very greatly interested since the completion of the first draft of this table in December to learn from my chemical colleagues of the well-known hypothesis of the dependence of the coking principle upon the relative amount of available hydrogen. This method of determining from the ultimate analyses whether coals will coke, which has been discussed by Percy, is said to apply successfully in certain areas and groups of coals, though in other groups and regions it is regarded as a failure. ${ }^{a}$ On account of the unusually wide range in age, kinds, and characters of the coals represented in the accompanying tables, it has been very interesting to compare the available hydrogen with the observations as to the coking quality. In the column to the right in Table 2 will be found the available hydrogen of all the coals. The same data are transferred, with their corresponding numbers, to Plate III, in which they are platted as light broken lines. Examination of the hydrogen percentages in this table shows that while they tend to parallel the $\mathrm{H}: \mathrm{O}$ ratios there are many variances, because in general high total hydrogen means high available hydrogen, but not necessarily a high ratio with oxygen.

The diagram shows that while practically all the coals with an available hydrogen of 3.80 or more will coke well unless they are too high in fixed carbon, some good cokes result from fuels with less than 3.50. Several of the tests show cokes from coals with as low as 3.20 available hydrogen. Note the following examples:

Coking coals with low available hydrogen.

\begin{tabular}{|c|c|c|c|c|c|}
\hline No. & $\begin{array}{c}\text { Fixed } \\
\text { carbon. }\end{array}$ & $\begin{array}{l}\text { Available } \\
\text { hydrogen. }\end{array}$ & No. & $\begin{array}{c}\text { Fixed } \\
\text { carbon. }\end{array}$ & $\begin{array}{l}\text { Available } \\
\text { hydrogen. }\end{array}$ \\
\hline $\begin{array}{l}10 \\
14 \\
26\end{array}$ & $\begin{array}{l}54.07 \\
51.38 \\
50.89\end{array}$ & $\begin{array}{l}2.63 \\
3.05 \\
2.99\end{array}$ & $\begin{array}{r}85 \\
124\end{array}$ & $\begin{array}{l}62.31 \\
63.76\end{array}$ & $\begin{array}{l}\text { 3. } 13 \\
\text { 3. } 29\end{array}$ \\
\hline
\end{tabular}

$a$ For discussion of the relation of the available hydrogen to the coking quality, see Fulton, John, Coke: a treatise on the manufacture of coke and other prepared fuels, and the saving of by-products; Scranton, 1905, pp. 31-38. 
Other coals with much higher available hydrogen fail in the tests, as shown in the following examples:

Noncoking coals with high available hydrogen.

\begin{tabular}{|c|c|c|c|c|c|}
\hline No. & $\begin{array}{c}\text { Fixed } \\
\text { carbon. }\end{array}$ & $\begin{array}{l}\text { Available } \\
\text { hydrogen. }\end{array}$ & No. & $\begin{array}{c}\text { Fixed } \\
\text { carbon. }\end{array}$ & $\begin{array}{l}\text { Available } \\
\text { hydrogen. }\end{array}$ \\
\hline $\begin{array}{l}31 a \\
40 \\
96\end{array}$ & $\begin{array}{l}56.87 \\
55.16 \\
56.42\end{array}$ & $\begin{array}{l}3.30 \\
3.32 \\
3.42\end{array}$ & $\begin{array}{l}147 \mathrm{a} \\
236\end{array}$ & $\begin{array}{l}57.95 \\
81.92\end{array}$ & $\begin{array}{l}3.40 \\
3.73\end{array}$ \\
\hline
\end{tabular}

This method also breaks down in the highest semibituminous coals. The loss in volatile in most of the coals of that category leads to a falling off in the available hydrogen. However, on account of the relatively more rapid oxygen loss in the higher coals the available hydrogen percentages sometimes persist after the coal refuses to coke, as in the Bonanza, Ark., coal (No. 236).

It may have been its failure as a coking index for the coals which are approaching semianthracitization at the Allegheny Front, in Cambria County, Pa., that led Fulton ${ }^{a}$. to regard this method as of doubtful reliability.

\section{HYDROGEN-OXYGEN RATIO THE BEST INDEX.}

On the whole it is fairly evident that in coals of less than 79 per cent fixed carbon (in pure coal) the $\mathrm{H}: \mathrm{O}$ ratios, dry-coal basis, offer surprisingly reliable, narrowly defined, and logical criteria for determining the presence of the coking quality from the ultimate analysis. It has also been noted that in the succeeding and higher coals coking is generally possible if the amount of carbon in the volatile is relatively large; also that most of the coals whose $\mathrm{H}: \mathrm{O}$ ratio is high but which refuse to coke are clearly distinguished by their marked calorific deficiency with reference to the $\mathrm{C}:(\mathrm{O}+\mathrm{ash})$ ratio and efficiency curve.

STATUS OF ALGAL HYPOTHESIS.

Since practically all coals in the table having fixed carbon contents of 66 per cent or over are found to show high $\mathrm{H}: \mathrm{O}$ ratios, and possess the coking capacity thereby indicated, the provisional algaelement hypothesis can not be regarded as demonstrated by the ultimate chemical analysis; that is, it does not seem tenable to conclude that all of these coals fuse by reason of the presence of an alga-element. 'Yet the tentative hypothesis appears to have such strong support in coals of higher volatile that it commands respect- 
ful consideration. It appears that in the course of the concentrations incident to progressive devolatilization, more rapid loss of oxygen brings about in the higher coals the same approach to bituminization (high $\mathrm{H}: \mathrm{O}$ ratios) that in the lower coals resulted from the nature of the ingredient matter. That sapropelic influences, even in the higher coals, bear directly on the best coking results is not precluded from possibility. The conspicuous tendency of the recognized alga coals to preserve not only a high hydrogen but also a very high percentage of volatile carbon, may perhaps account for the persistence of relatively high carbon in the volatile, and for the apparently concomitant tendency to fuse, in some of the semibituminous coals which have fixed-carbon contents of 80 per cent or more. Examples of such high-volatile carbon coals are the following:

Coals high in fixed carbon, showing also high volatile carbon ratios.

\begin{tabular}{|c|c|c|c|c|c|c|c|}
\hline No. & Location. & $\begin{array}{c}\text { Fixed } \\
\text { carbon. }\end{array}$ & $\begin{array}{l}\mathrm{VC}: \mathrm{C} \\
\text { ratio. }\end{array}$ & No. & Location. & $\begin{array}{l}\text { Fixed } \\
\text { carbon. }\end{array}$ & $\begin{array}{l}\mathrm{VC}: \mathrm{C} \\
\text { ratio. }\end{array}$ \\
\hline $\begin{array}{l}241 \\
213\end{array}$ & $\begin{array}{l}\text { Frostburg, Md.......... } \\
\text { Zenith, W. Va......... }\end{array}$ & $\begin{array}{l}81.36 \\
80.73\end{array}$ & $\begin{array}{l}10.39 \\
10.55\end{array}$ & $\begin{array}{l}246 \\
250\end{array}$ & $\begin{array}{l}\text { Big Sandy, w. Va..... } \\
\text { Mora, W. Va............... }\end{array}$ & $\begin{array}{l}80.46 \\
80.15\end{array}$ & $\begin{array}{l}11.06 \\
11.63\end{array}$ \\
\hline
\end{tabular}

MIXTURE OF COALS FOR COKING.

The data given in Plate III are rich in suggestions as to blending of coals in order to obtain either the best coking results, ${ }^{a}$ or successful treatment of coals that refuse to coke well by the ordinary process. These suggestions relate not only to the mixing, according to the practicabilities of the regional trade conditions, of coals with relatively high $\mathrm{H}: \mathrm{O}$ ratios and moderate fixed carbon, like that at Blossburg, $\mathrm{N}$. Mex., ${ }^{b}$ with others whose ratios are hardly up to the standard for good fusion; but also to the mingling of certain coals high in fixed carbon with others rich in volatile matter-that is, high in hydrogen and carbon. For example, the high $\mathrm{H}: \mathrm{O}$ ratios of the rich-volatile coals listed below promise mutually beneficial economies if finely ground and mixed with such coals high in fixed carbon as those in the second part of the table, more especially since in some of the latter there appears to be waste off fixed carbon when coked by the ordinary process.

a The sulphur and ash which so thoroughly control the market value of the coke are not considered in this discussion. For percentages of these, see Tables 1 and 2.

$b$ See No. 141 (F. C. 61.49, H: O ratio 72.5); also Brilliant and Van Houten: No. 126 (F. C. 58.32); No. 118 (F. C. 58.48); No. 100 (F. C. 59.39), and No. 86 (F. C. 59.87). It would be interesting to note trials of coals such as No. 138, from Atchison, Kans. (F. C. 54.79), or Sprague, Mo., No., 43 (F. C. 53.55), or Hartshorne, Ind. Ter., No. 125 (F. C. 59.25) when comminuted and mixed for the ovens with some coals with lower ratios from the Rocky Mountain coal fields; though the sulphur and ash of Nos. 138 and 43 are too high for tolerance in commercial coke. 
Comparison of two classes of coals suggested for mixing.

COALS RICH IN VOLATILE MATTER, WITH HIGH H:O RATIOS.

\begin{tabular}{|c|c|c|c|c|c|c|c|}
\hline No. & Locality. & $\begin{array}{c}\text { Fixed } \\
\text { carbon. }\end{array}$ & $\begin{array}{c}\mathrm{H}: O \\
\text { ratio. }\end{array}$ & No. & Locality. & $\begin{array}{l}\text { Fixed. } \\
\text { carbon. }\end{array}$ & $\begin{array}{r}\because \mathrm{H}: \mathrm{O} \\
\text { ratio. }\end{array}$ \\
\hline $\begin{array}{l}155 \\
.164 \\
167 \\
169 \\
172\end{array}$ & 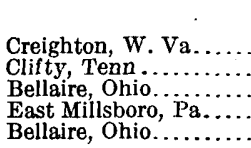 & $\begin{array}{r}\text { Per cent. } \\
60.77 \\
60.08 \\
56.86 \\
62.26 \\
54.55\end{array}$ & $\begin{array}{r}\text { Per cent. } \\
83.7 \\
106.1 \\
67.3 \\
85.4 \\
67.4\end{array}$ & $\begin{array}{l}193 \\
205 \\
215 \\
222\end{array}$ & 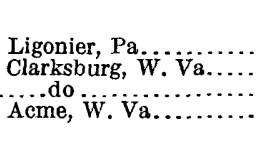 & $\begin{array}{r}\text { Per cent. } \\
75.30 \\
55.71 \\
58.28 \\
63.88\end{array}$ & $\begin{array}{r}\text { Per cent. } \\
152.0 \\
77.0 \\
101.9 \\
100.6\end{array}$ \\
\hline
\end{tabular}

COALS HIGH IN FIXED CARBON.

\begin{tabular}{|c|c|c|c|c|c|c|c|}
\hline $\begin{array}{r}30 \\
161 \\
212 \\
213\end{array}$ & $\begin{array}{l}\text { Gary, w. Va....... } \\
\text { Menlo, Ga ............. } \\
\text { Kimmelton, Pa........ } \\
\text { Zenith, W. Va......... }\end{array}$ & $\begin{array}{l}82.87 \\
80.57 \\
79.91 \\
80.73\end{array}$ & $\begin{array}{r}93.0 \\
79.9 \\
125.5 \\
128.4\end{array}$ & $\begin{array}{l}228 \\
230 \\
244\end{array}$ & $\begin{array}{l}\text { Seward, } \mathrm{Pa} . \ldots \ldots \ldots \ldots \\
\text { Wehrum, } \mathrm{Pa} \ldots \ldots \ldots \ldots \\
\text { Ehrenfeld, } \mathrm{Pa} \ldots \ldots \ldots \ldots\end{array}$ & $\begin{array}{l}81.41 \\
79.23 \\
81.28\end{array}$ & $\begin{array}{l}250.0 \\
215.2 \\
149.8\end{array}$ \\
\hline
\end{tabular}

It is possible that some of the coals last mentioned or some of those farther north in Pennsylvania might mix to advantage with some of the high-volatile and high-ratio coals of Michigan, the Lower Verne coal for instance.

\section{GENERAL OBSERVATIONS ON THE TABULATED COALS.}

RANGE OF THE SAMPLES.

A general view of Plate III shows the wide range of the coals which have been investigated by the United States Geological Survey. The ultimate analyses, standardized under the direction of $\mathrm{N}$. W. Lord, include most of the commercial coals and extensive coal areas of the country.

\section{RANK OF PEATS AND LIGNITES.}

It is interesting to note that although the peats (Nos. 1 and 6 , marked P), not having been subjected to the action of dynamochemical agencies, naturally gravitate to the foot of the scale of fixed carbon percentages, they are preceded in the scale by the Fort Union (Eocene) brown lignite from Glendive, which consists largely of a compressed accumulation of logs and sticks. The low fixed carbon of this coal is probably due to the lack of maceration or putrefaction previous to the development of antiseptic conditions. With the development of asepticity in a coal-forming mass, no. further obliteration of the vegetal structures occurs except such as result from infiltration and compression (deformation). In the normal course of events the dynamochemical influences follow.

Following the peats are mingled brown coals (denoted by L) and subbituminous coals (S) more familiarly known as "black lignites." Interspersed among both of these types occur some of the lower grade. 
bituminous coals as recently classified by M. R. Campbell by their color and characteristics of weathering. Among the latter are several which, as we have already noted, appear to be somewhat gelosic (sapropelic), a relatively low fixed carbon being characteristic of that type of coal.

\section{EXPLANATION OF HIGH OXYGEN.}

Remembering that the hydrogen-oxygen ratios are based on moisture-free coal, the persistence of a relatively high oxygen content and consequently low ratio, even in certain of the coals of moderate fixed carbon, is striking. Excluding the coals that have taken up oxygen as a result of exposure or weathering, ${ }^{a}$ the high oxygen of the low-ratio coals remaining in any group characterized by a definite fixed carbon may be explained either by (1) abundant natural charcoal, which has given the sample an abnormally high fixed carbon, or (2) differences in the original ingredients and conditions of deposition which have given the coal a chemical aspect approaching that of humic or ulmic acid, in contrast to the coals whose high $\mathrm{H}: \mathrm{O}$ ratios give them a bituminous aspect.

\section{QUANTITATIVE RELATION OF VOLATILE CARBON AND HYDROGEN.}

One of the most significant features indicated graphically in Plate III is the relations suggested by the two sorts of volatile ratios. The rapid increase in fixed carbon in the peats and lignites at the beginning of the column is of course accompanied by a decrease in the volatile carbon, as expressed by the VC: $\mathrm{C}$ ratios. This decrease is nearly parallel to the decrease in volatile combustible matter which is the difference between the fixed carbon and "pure coal." But even before the lignites are passed over it is evident that to a certain extent a coordinate relation exists between the volatile carbon and the hydrogen. The coals whose hydrogen is relatively high as compared to the oxygen are seen almost invariably to have a high volatile carbon; so that the lines representing the two ratios tend conspicuously to approach or withdraw from each other throughout the greater part of the diagram. The Barnett (Mo.) coal (F. C. 49.76) shows this especially well, and evidently has a very large proportion of both hydrogen and carbon in the volatile. Presumably these two elements are largely in chemical union at the moment of escape. On the other hand the distant retreat of the ratios in the weathered coal from the Labarge Range (F. C. 50.63) shows most convincingly a great amount of highly anticalorific oxygen, evidently the overwhelming component in the volatile combustible matter.

$a$ Coals with $a, b$, and $d$ affixed to their locality, in Pl. III, are examples more or less affected by exposure. 


\section{LOSS OF VOLATILE MATTER.}

Some points relating to the devolatilization of the coals deserve special notice. The relative decrease of the volatile-carbon ratios as compared to the increase in the fixed carbon column seems to be rapid in passing from 40 to 50 per cent fixed carbon. Above this the relative loss of volatile carbon is slight up to near 63 , but still higher the loss appears slightly to accelerate; and in the coals having 70 per cent or more of fixed carbon the ratios seem to fall off a little more rapidly. The unusually low volatile-carbon ratios of the noncoking high semibituminous coals is well seen in the retreat of the $\mathrm{VC}: \mathrm{C}$ lines for these coals in Plate III.

The falling off of carbon in the volatile of the higher coals is accompanied by a general decrease in the oxygen as compared to the hydrogen. The higher $\mathrm{H}: \mathrm{O}$ ratios show that the volatiles are becoming richer in hydrogen and lower in oxygen in passing to the semianthracite group. At the same time, however, the amounts of available hydrogen fluctuate in marked reactions, though tending to hold their own fairly well from 65 to 75 per cent fixed carbon. Above this they react wildly, and on approaching the anthracites they decline rapidly, regardless of the $\mathrm{H}: \mathrm{O}$ ratios. Yet, as $\mathrm{I}$ remarked in the discussion of the curve variance, the loss in calorific efficiency in the latter coals seems to me disproportionately large as compared to the loss of available hydrogen.

\section{RELATION OF STAGE OF COAL FORMATION TO CLASSI- FICATION.}

\section{LIKE ANALYSES FOR COALS OF DIFFERENT ORIGIN.}

In passing down the columns of Plate III the reader will doubtless have noted that the middle-grade bituminous coals of the Cretaceous and Tertiary mingle with the lower-grade coals from the Eastern Interior basin, and are like them as to fixed carbon contents, $\mathrm{H}: \mathrm{O}$ ratios, and relative volatile carbon. So it is also in the higher bituminous coals. There are in general no appreciable differences to be noted in the ultimate chemical analyses. In illustration of this fact, attention may be called to the agreement in fixed carbon, hydrogenoxygen ratios, and volatile-carbon ratios, as well as in the actual percentages of composition, between such coals as those from the Raton-Trinidad district ${ }^{a}$ of upper Cretaceous age, and the high-grade eastern, Paleozoic coals with which they are associated in the table; or, to cite a specific illustration, between Van Houten, N. Mex. (No. 86, F. C. 59.87) and Rush Run, Ohio (No. 183, F. C. 59,79), or

a Allowing for low sulphur in the western coals here mentioned. See No. 141 (F. C. 61.49), No. 199 (F. C. 61.23 ), and No. 100 (F. C. 59.39). 
Darby, Va. (No. 217, F. C. 59.60). In the lower grades of bituminous coals the Cretaceous and Tertiary samples apparently have slightly higher volatile-carbon ratios as compared with the $\mathrm{H}$ : $\mathrm{O}$ ratios than the Paleozoic coals of the same rank. This may be due to the amount of resin in most of the former. Under advanced devolatilizing influences the resin appears to be transformed, possibly to disappear in the volatile. ${ }^{a}$

\section{DISTINCT CATEGORIES IMPOSSIBLE.}

Plate III in connection with Table 2 conclusively shows the futility of looking in the ultimate analyses for characters by means of which coals may be grouped into distinct and natural categories. Such a classification is an impossibility with only the current data. There are no distinct lines of separation of coals into any categories. From the very circumstances of coal formation-the constantly varying ingredients, conditions of accumulation and deposition, and relations and intensities of the processes-it is evident a priori that between each type and any other type there must be, since coal is merely a mixture of chemical compounds, every degree of intergradation. The classification of coals on the basis of their chemical analysis must therefore be absolutely arbitrary, with very finely drawn as well as purely empirical distinctions.

\section{COMPARISON OF ·TYPES.}

The discrimination between lignites and subbituminous coals presented in Table 1, which agrees with Campbell's classification (see p. 10), has the great merits of simplicity and naturalness of grouping, readiness of application, and practical freedom from technical criteria. It is the only kind of classification that is adapted to common usage. Yet the difficulties due to the transitions from group to group are not less real and perplexing. Neither is it strange that, being based on physical characters and weathering criteria, it does not conform wholly to the conditions indicated by the analyses.

The fixed carbon column of Plate III shows conspicuously a somewhat indiscriminate mingling of lignites $(\mathrm{L})$, subbituminous coals (S), and low-grade bituminous coals. In the ratio columns the intermingling of lignites and subbituminous and bituminous coals appears to be limited to border zones, the more important transgressions being those caused by weathering of the coals. ${ }^{b}$ So far as present analyses are competent to serve as a basis for calculations it seems that in most coals the $\mathrm{H}: \mathrm{O}$ ratio may provisionally be regarded as ranging up to 22 in the peats; from 22 to 29 in the lignites (brown coals); 
from 28 to 38 in subbituminous coals; and from 31 upward in the younger low-grade bituminous coals, or from 40 upward in the Paleozoic coals. The ratios, as may be noted in Plate III, do not all fall within these limits; but it is believed that additional data (which are much needed) will show that they fall generally within the limits here provisionally outlined. The lowest ratio for a Paleozoic coal in the table is 38.3 for a Zeigler analysis (F. C. 62.74). Mr. Campbell's classification is thus seen greatly to lower the under limit of the bituminous category, so as to include therein a large number of coals which are much less advanced in the coal-forming process than the lowest grade of the American Paleozoic coals.

It is well known that the coals of certain districts exhibit characteristics peculiar to the district or perhaps to their kind. For example, the xyloid lignites of North Dakota are in general marked by low H:O ratios; the Kootenai coals of the Great Falls field have comparatively low hydrogen and carbon in their volatile, and consequently low $\mathrm{H}: \mathrm{O}$ ratios, though, on account of the great amount of charcoal, their fixed carbon is as high as that of many of the fine coking coals of the Appalachian trough; ${ }^{a}$ but it is also true that the differences due to geologic period are, in coals of the same initial classes of ingredient matter and conditions of biochemical action, obliterated, so far as may be seen in the ultimate analysis, by dynamic influences expressed in metamorphism and progressive devolatilization

OBLITERATION OF DISTINCTIONS AS A RESULT OF REgIONAL METAMORPHISM.

Comparative examination of the coals assembled in the accompanying tables shows most convincingly the efficient work of the dynamochemical processes in yiping out all the important distinctions due to differences in the age of the fuel. Under this action the coals of all epochs undergo essentially the same experience of progressive devolatilization, deoxygenation, and concentration, though not without great waste, of carbon and hydrogen. The closeness of the agreement between the corresponding advanced stages of the older and the younger coals is shown by their industrial adaptation as well as by the ultimate chemical analysis. The high-grade coking coal and semianthracite of the western Upper Cretaceous and Tertiary formations are as truly coking and semianthracite as though they had grown in the vast umbrageous swamps of the Paleozoic. The brown coals of North Dakota are progressively transformed to semibituminous and to bituminous as they extend farther within the regions of the increased geodynamic action which effected the further upthrust of the Rocky Mountains. The Cretaceous coals of 
the Crested Butte, Colo., region are transformed to semibituminous coking coals and to anthracites under dynamic influences, the chief of which is, I believe, horizontal thrust pressure under loading. Only very rarely, and in very restricted localities, is the metamorphism due to plutonic intrusives or overflows.

To a limited but convincing extent these changes may be followed in the same bed as well as in the same geologic formation and region. It appears only to be necessary that the coals be of the same kind at the beginning in each case. If xyloid lignites they become xyloid bituminous coals; if cannel brown coals they become bituminous cannels, etc. There appears to be no important difference in mode of formation or composition between the Upper Cretaceous cannel coals near Cedar Valley in Utah and those of the upper Pottsville in eastern Kentucky. The dull, dense, "amorphous" bands, sometimes approaching a bastard cannel, which may not infrequently be observed in the Paleozoic coals of the Appalachian trough, are both in their nature and in the conditions of their formation exactly like those similarly found in the Cretaceous and Tertiary coals and in the Pennsylvania anthracites. The differences, principally relating to the degree of elimination of the oxygen content, mark the progress of the dynamochemical work in the process of coal formation.

\section{OXYGENATION AND WEATHERING OF COALS.}

\section{CHANGES IN LOW-GRADE COALS.}

Both in connection with the discussion of the causes of variance from the $\mathrm{C}:(\mathrm{O}+\mathrm{ash})$ ratio and efficiency curve, and in the review of the comparative standing of the $\mathrm{H}$ : $\mathrm{O}$ ratios in Plate III, it has been noted that in general the lower classes of coals take oxygen on exposure to the atmosphere. This, together with some immediate loss of compressed volatile matter, appears to mark the first phase of weathering. Later, and on prolonged exposure, there seems to be considerable loss of carbon and hydrogen also, especially in the humic (ordinary) coals.

EFFICIENCY LOSSES IN WEATHERING.

The consideration of this subject engages us only in so far as it obviously affects the efficiency of the ratio curve. The analytical data now available in the reports of the coal-testing work are unfortunately deficient as to such samples and localities as alone will put in the hands of geologists and engineers the data necessary for knowing the total efficiency losses endured by some of our thinly covered or long mined, not to mention weathered, coals. An inquiry to show the kinds, degrees, and rapidity of loss under varying conditions would require a large number of ultimate analyses; but I am 
confident that the results of a series of such observations would in many cases prove surprising as well as important.

The amount of oxygen that is assimilated and the rapidity with which it is taken up by certain subbituminous coals and lignites seem to indicate very unstable chemical conditions in the combustible matter of these coals as they lie deeply buried in the strata. It will later be seen that in some coals the amount of this absorbed oxygen exceeds the capacity of the hydrogen to form water.

\section{LOSSES SHOWN BY ANALYSES AND RATIO-EFFICIENCY CURVE.}

Mention has been made of the almost invariable calorific deficiency, as indicated by the curve, of -those coals that have been weathered, taken from shaly or thinly covered mines, or country banks, or deep but abandoned mines. Most of these coals are from geologic formations or regions in which the coals are exceedingly low in sulphur, so that many of them should show excess curve errors if wholly unaffected; and this seems to be borne out by some of the better samples from the same districts. The few comparisons given below are offered rather as suggestions and as bases for rough estimates than as careful calculations based on representative, not to say ample, material.

Following are the analyses of two coals from the Lewis (Cretaceous) shale, 22 and 24 miles northwest of Fort Steele, Wyo. The coal is subbituminous. The first, No. 53a of Table 1, is from an entry near the foot of the shaft; the second was taken near the surface of the ground.

Comparison of two coals to show effect of weathering.

\begin{tabular}{|c|c|c|c|c|c|c|c|c|c|c|c|}
\hline No. & S. & $\mathrm{H}$. & C. & 0 & Ash. & Moisture. & F.C. & $\mathrm{H}: \mathrm{O}$ & Av. H. & Calories. & $\begin{array}{l}\text { Curve } \\
\text { error. }\end{array}$ \\
\hline $\begin{array}{l}53 a \ldots \ldots \ldots \\
\text { Wyo.3919a... }\end{array}$ & $\begin{array}{r}0.85 \\
.31\end{array}$ & $\begin{array}{l}5.16 \\
4.90\end{array}$ & $\begin{array}{l}63.57 \\
59.86\end{array}$ & $\begin{array}{l}22.05 \\
29.39\end{array}$ & $\begin{array}{l}3.80 \\
4.12\end{array}$ & $\begin{array}{l}8.70 \\
9.34\end{array}$ & $\begin{array}{l}55.36 \\
55.57\end{array}$ & $\begin{array}{l}24.2 \\
18.3\end{array}$ & $\begin{array}{l}2.02 \\
1.23\end{array}$ & $\begin{array}{l}6,310 \\
5,636\end{array}$ & $\begin{array}{r}+30 \\
-219\end{array}$ \\
\hline
\end{tabular}

$a$ Bull. U. S. Geol. Survey No. 316, 1907, p. 256.

The second of these analyses does not differ widely from the first if the first be recalculated after adding 10 per cent of oxygen. The difference in calories between the two analyses is 674 . If a lump allowance of 50 calories is made for difference in ash, etc., in the second, we shall have left 624 calories as a rough estimate for the loss in weathering. In this case the loss would be about 62 calories for each 1 per.cent of added oxygen. This is not far from the actual anticalorific value of oxygen in a coal having the same $\mathrm{C}:(\mathrm{O}+\mathrm{ash})$ ratio as 53a. The effect of the added $\mathrm{O}$ is seen both in the reduced $\mathrm{H}: \mathrm{O}$ ratio of the weathered specimen and in the $\mathrm{VC}: \mathrm{C}$ ratio, which in the weathered is 19.48 as compared with 23.80 in the shaft coal. The fact that adding 10 per cent of oxygen to No. 53a creates a 
small deficiency in the hydrogen, the carbon, and the $\mathrm{H}: \mathrm{O}$ ratio, as well as in the available hydrogen, indicates either some loss of carbon and hydrogen in the deteriorated sample or that the absorbed oxygen is a little under 10 per cent, possibly as low as 7 per cent.

It will be borne in mind that the ratio-efficiency curve errors, which show large deficiencies in these deteriorated coals, may represent but portions of the real calorific losses; for the added oxygen has naturally had the effect of lowering the $\mathrm{C}$ : $(\mathrm{O}+\mathrm{ash})$ ratios, thus placing them lower in the curve. It is interesting to note, however, that the calorimetrically ascertained efficiencies of these weathered coals generally exceed those calculated by Du Long's formula.

\section{LOSSES SHOWN BY H:O AND VC:C RATIOS.}

Evidence of the effects of exposure or weathering is often obvious in the ratios as well as in the calorific deficiencies. This is represented graphically in Plate III. Usually the drop is more conspicuous in the VC: $\mathrm{C}$ ratios as here tabulated. Examples of coals from prospects whose ratios are to be interpreted as indicating deterioration are No. 62a (F. C. 61.62) and No. 72a (F. C. 60.89), both being bituminous coals. The subbituminous coal at Fall River, Wyo. No. 9a (F. C. 41.22), is placed among the brown coals below the other subbituminous coals in Plate III, as the result, I believe, of exposure.

A striking illustration of profound deficiencies in both ratios is seen in No: $2 b$, a subbituminous coal from the Labarge Range, Wyo. (F. C. 50.63), in which the $\mathrm{H}: \mathrm{O}$ ratio is but 11.1 , while the $\mathrm{VC}: \mathrm{C}$ ratio is only 17.47. More remarkable still, there is a deficiency of 0.37 in the hydrogen necessary to form water in union with the oxygen of the coal. It therefore seems probable that part of the oxygen in this coal exists as $\mathrm{CO}, \mathrm{CO}_{2}$, or atmospheric oxygen. The table contains three other analyses (Nos. 55a, 44a, and 39a) from the same formation and district. The four analyses are repeated below.

Comparison of coals from same district, to show effects of weathering.

\begin{tabular}{|r|r|r|r|r|r|r|}
\hline No. & S. & H. & C. & O. & Ash. & $\frac{\mathrm{C}}{\text { O+ash }}$ \\
\hline r & & & & & & \\
\hline 45a & 0.84 & 5.68 & 63.81 & 25.75 & 2.84 & 2.23 \\
$39 \mathrm{a}$ & 2.10 & 5.74 & 61.76 & 25.96 & 3.41 & 2.10 \\
2b & .61 & 5.49 & 62.05 & 24.56 & $\mathbf{5 . 7 7}$ & 2.04 \\
& & & 48.65 & 38.57 & 6.87 & 1.07 \\
\hline
\end{tabular}

\begin{tabular}{|r|r|r|r|r|r|r|r|}
\hline No. & $\begin{array}{c}\text { Mois- } \\
\text { ture. }\end{array}$ & $\begin{array}{c}\text { F.C.in } \\
\text { pure } \\
\text { coal. }\end{array}$ & VC: C. & H : O.a & Av. H. & $\begin{array}{c}\text { Cal- } \\
\text { ories. }\end{array}$ & $\begin{array}{c}\text { Curve } \\
\text { crror. }\end{array}$ \\
\hline & & & & & & \\
\hline $55 \mathrm{a}$ & 10.22 & 53.81 & 27.94 & 28.6 & 2.46 & 6,558 & -43 \\
$44 \mathrm{a}$ & 10.78 & 52.06 & 28.85 & 29.0 & 2.50 & 6,057 & -140 \\
$39 \mathrm{a}$ & 9.02 & $56.5 \mathrm{1}$ & 23.37 & 27.4 & 2.32 & 6,039 & -90 \\
2b & 13.83 & 50.63 & 17.47 & 11.1 & -.37 & 4,468 & -150 \\
\hline
\end{tabular}

a The H: $\mathrm{O}$ ratio is calculated on the moisture-free basis. 
Nos. 55a and 39a are from drifts, and, although probably somewhat affected by influences from the surface, are relatively fresh. No. $44 a$, as might be suspected from its marked deficiency error, is from a prospect. It is presumably either deeper or newer than No. $2 \mathrm{~b}$, which is also from a prospect, since it shows less change from the composition of the deeper coals.

Since No. 39a, the third coal of the series, appears to agree in its main criteria with No. $2 b$, and since it may be, perhaps, safely regarded as not seriously, weathered, it will be taken for comparison with the latter. A glance at the two analyses shows that the important differences between these coals concern the oxygen, the available hydrogen, and the calorific values. Examination of these differences makes it evident that if a little over. 20 per cent of oxygen be added to that in No. 39a and the analysis of the latter be then recalculated to 100 per cent, the resultant percentages will fall reasonably close to the corresponding elements in No. $2 \mathrm{~b}$ without further compensation. It therefore seems probable that the prospect coal in a less weathered state was essentially like that of the drift coal, No. 39a. The increase in oxygen was, perhaps, nearer 25 per cent. The accession of that amount of oxygen closely corresponds to the difference in the calorific values of the two coals, which amounts to 1,571 calories-that is, nearly 65 calories to each 1 per cent of added oxygen. This agrees closely with the ascertained anticalorific value of oxygen in a coal having a $\mathrm{C}:(\mathrm{O}+$ ash $)$ ratio near 2.00. Compensation for the difference in moisture, etc., in the coals seems to justify the conclusion that over 20 per cent of added oxygen has entered into combination with the fuel elements of the weathered coal.

It will also be observed that the assimilation of 20 per cent of oxygen in a coal like No. 39a will accomplish a little more than the extinction of its available hydrogen, causing a deficit of 0.18 in the amount necessary to form water. On the other hand, the elimination of 20 per cent of the oxygen in No. $2 \mathrm{~b}$, the weathered coal, will make available 2.13 per cent of hydrogen, which, if the analyses be recalculated to 100 per cent, will approach still closer to that of the other analyses.

Thus, in short, the evidence drawn from (a) the comparison of the analyses of the more with the less weathered fuel, $(b)$ the probable loss in calorific value, and $(c)$ the amount of the reduction of available hydrogen agrees in indicating a probable assimilation of 20 per cent or more of oxygen in the course of weathering. All things considered, it is perhaps safe to estimate the falling off in the efficiency of this subbituminous fuel at nearly one-fourth of its original heating power in the calorimeter. 
The sample just discussed on account of its availability among the analyses studied in the preceding pages is not to be regarded as extraordinary or even unusual among weathered coals of its class. More strongly marked hydrogen deficiencies and more conspicuous degradations are to be found among the field samples. ${ }^{a}$ Analyses of surface samples of coals of these grades are of little value in determining the characteristics of the coal, except in so far as they indicate the approximate amounts of sulphur and ash. Many of the analyses of coals from deep prospects and country banks are not to be taken as showing the real merits of the fuel.

It appears that in the lignites (brown coals) the deterioration is still greater; and it follows, almost as a certainty, that in some of the peats, particularly among the xyloid or more fibrous types, the loss of calorific value during the periods of drying, manufacture, and storage-that is, between the moment of exhumation from the pit bottom and the time of deposition in the crucible or on the gratemay be very serious. It may not be extreme to suggest that this loss possibly amounts in certain cases to as much as that incurred through weathering in some of the subbituminous coals.

\section{UNDERGROUND WEATHERING.}

The analyses bear evidence, according to my tentative interpretation, that the phenomena of weathering are not confined to outcrops or shallow prospects. There are a number of coals in which I suspect oxygenation to have taken place to some extent in shallow mines or country banks and drifts which have not penetrated too far - from the surface. An example of these is No. 2a from near Miles, Mont. ${ }^{b}$

A sample showing what I am inclined to interpret as oxygenation as the result of exposure to air for a long period in a large mine of good depth comes from the No. 6 mine at Rock Springs, Wyo. This mine is said to have been abandoned about ten years ago. The coal is subbituminous and of high quality, as will be observed from the analysis. ${ }^{c}$

Below is given, from Table 1, the analysis (air-dried basis) of No. 144, the coal from No. 10 mine at Rock Springs, Wyo., as in car sample at the fuel-testing plant of the United States Geological Survey; and following it the analysis from the abandoned No. 6 mine, recalculated to the same percentage of moisture as No. 144.

\footnotetext{
a See analyses published in Bull. U. S. Geol. Survey No. 316. Examples are Wyoming 3695 and 3697, p. 237.

$b$ See also No. 4a from near Glendive, Mont.; Nos. 175a, 166a, 146ic, 72a, and 62a.

$c$ Analysis included by courtesy of Mr. M. R. Campbell.
} 
Comparison of coals shouing effect of long exposure to air in abandoned mine.

\begin{tabular}{|c|c|c|c|c|c|c|c|c|c|c|c|c|}
\hline No. & N. & S. & H. & c. ${ }^{\circ}$ & 0. & Ash. & Moisture & Calories. & H: $\mathrm{O}$. & Av. H. & VC:C. & F.C. \\
\hline $4 \ldots \ldots \ldots$ & $\begin{array}{l}1.52 \\
1.46\end{array}$ & $\begin{array}{r}0.86 \\
.46\end{array}$ & $\begin{array}{l}5.37 \\
5.01\end{array}$ & \begin{tabular}{|l|}
70.30 \\
66.32
\end{tabular} & $\begin{array}{l}18.32 \\
22.03\end{array}$ & $\begin{array}{l}3.63 \\
4.72\end{array}$ & $\begin{array}{l}6.00 \\
6.00\end{array}$ & $\begin{array}{l}6,955 \\
6,340\end{array}$ & $\begin{array}{l}36.2 \\
26.1\end{array}$ & $\begin{array}{l}3.08 \\
2.23\end{array}$ & $\begin{array}{l}26.49 \\
15.41\end{array}$ & $\begin{array}{l}57.19 \\
62.88\end{array}$ \\
\hline
\end{tabular}

If to sample 144, from the active mine, we add 5 per cent of oxygen and recalculate to a basis of 100 per cent, compensating the calorific value, we have:

Recalculation of analysis of sample 144.

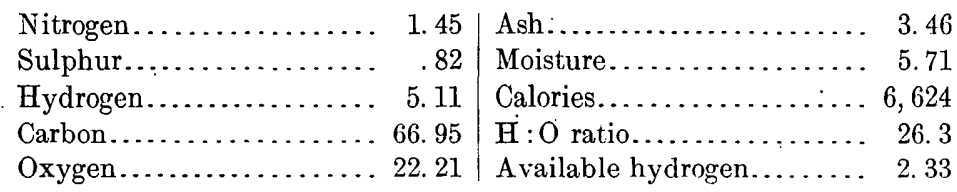

This analysis, as will at once be recognized, approaches substantially that of the sample from the abandoned mine. In nitrogen, carbon, and hydrogen the agreement is satisfactorily close, as is also the amount of available hydrogen, which becomes 2.33 compared with 2.23. In fact, the agreement between the recalculated No. 144 and the abandoned-mine analysis is sufficiently close to justify the conclusion that, together with the other presumable changes, 5 per cent or more of oxygen had probably been assimilated in the coal deep in the old mine on account of exposure to air since its abandonment. The difference in the calorific value is disproportionate to that which might reasonably be expected from the mere addition of 5 per cent of oxygen, and offers ground for the suspicion that there. has been a small loss in carbon and hydrogen. The calorific difference, roughly compensated for difference in ash and sulphur, amounts to about 535 calories, or about 105 to each 1 per cent of assumed oxygen increase. This, as shown on page 40 , is probably as much as 10 calories in excess for added oxygen.

It is probable that in the subbituminous coals, and more especially in the lignites, oxygenation begins immediately after the coal is blasted from the face in the mine. Zincken ${ }^{a}$ quotes Bischoff to the effect that the brown coal of Pützchen absorbed 11 per cent of oxygen from the atmosphere in eight days. More recently Stremme and Späte ${ }^{b}$ have shown some absorption even by sapropelic coals standing for various periods in a museum. It should be noted, however; that the sapropelic or alga coals are very much less susceptible to oxidation on exposure than are the more bituminous coals, which are humic.

a Physiographie der Braunkohlen, 1867, p. 8. See also Muck, Chemie der Steinkohlen, 1891, p. 109.

b Zeitschr. angew. Chemie, vol. 20, pt. 43, 1907, p. 1841; also Zeitschr. Deutsch. geol. Gesell., Monatsber., Nos. 7 and $8,1907$. 
It is not impossible that some of our peats will be found to assimilate still greater quantities of oxygen on exposure. This question, as: well as that of the immediate loss of volatile in freshly mined lignites: or subbituminous coals, is one deserving careful examination. The results of the very interesting, as well as important, investigations recently published by Parr and Hamilton, ${ }^{a}$ show that deterioration. is strongly marked and rapid, even within short periods, in coals so old and well established in coal formation as those of the Illinois region, where an efficiency of 2 to 10 per cent may be lost on exposure for seven months. A still greater susceptibility to change is, I believe, to be expected in the higher-grade bituminous coals of some portions of the western Mesozoic and Tertiary coal fields, in which the dynamic influence is still in vigorous action, locally at least, as: shown by rapid loss of volatile, and in which, on account of lack of time in which the volatile might effect its escape (with concomitant readjustment of compounds to comparative equilibrium in conformity to the new conditions), it may be assumed that the hydrocarbon compounds are in a state of highly unstable equilibrium. The susceptibility to deterioration is doubtless far greater in many of the subbituminous coals and lignites.

\section{LOSSES BY WEATHERING IN SHIPMENT.}

A comparison of the calorific values of the car samples with the ratio curve on the one hand and with a few mine samples collected by the field geologists on the other, seems to me to warrant the apprehension that in some samples at least a considerable deterioration has occurred before the actual analysis of the fuel. My personal opinion, based upon quite insufficient data, is that the car samples of most of these lignites and of many of the subbituminous coals are calorifically deficient to an extent of 50 calories as compared to the probable efficiency of freshly mined and tightly sealed mine samples, provided the latter are analyzed immediately upon opening. It may not be overhazardous to estimate that some of the published calorific values are as much as 200 calories less than the efficiency of the coal in the ground. The coal No. 51a, from Batan Island, P. I., may be mentioned as a good example of probable loss between the coal bed and the crucible. Analyses Nos. 3, 13, 19, 22, 32, 56, 83, and 144 also appear to justify suspicion.

The amount of loss depends not only upon the kind of coal, but also on the conditions of loading, the kind of car, the size of the fragments, the weather, the period of transit (which for many coals. is over three weeks), and the mode of sampling from the car. The present method of air drying the coal in an oven under a current of 
warm air in the laboratory may also be mentioned as seeming most favorable to the oxygenation of the fuel and its consequent rapid calorific deterioration.

For commercial purposes the current methods of sampling and analysis appear to be very satisfactory and even indispensable, since they show the composition of the coal as it is ordinarily received at its industrial destination. Yet it is possible that a thorough investigation of the impairment of the lowest-grade fuels on exposure will show a calorific loss in some coals that is so great within a short time as perhaps to call for new methods of handling.

The above observations, it must be remarked, are disconnected and fragmentary, and crude both as to methods and results. Their purpose is mainly to stimulate observation. I anticipate, however, that properly made tests and careful calculations, based on adequate data, will show the importance of the subject to have been on the whole understated.

\section{SUMMARY.}

1. Coals with high oxygen and low ash will, in general, have very nearly the same efficiency in the calorimeter as other coals with alternated percentages, low oxygen and high ash, if the total carbon is the same. This applies to both air-dried and moisture-free coals.

2. Oxygen and ash are of very nearly equal anticalorific or negative value, ash being probably slightly more injurious in most coals; the negative value of the oxygen of moisture is not far different from that of the oxygen combined in the coal.

3. The calorific value of coals in general is essentially indicated by the balance between the total carbon, on the one hand, and the sum of the two great impurities, oxygen and ash, on the other, the hydrogen, nitrogen, and sulphur being usually negligible as "constants."

4. Except in the presence of unusual variations of hydrogen or sulphur, the efficiencies of the coals, if ash be constant, rank nearly in the order of the ratios $\mathrm{C}: \mathrm{O}$, which in each kind of coal marks the progress of coal formation under dynamochemical influences.

5. Oxygen and ash being of approximately equal anticalorific potency the efficiencies of the coals conform fairly closely to the order of the ratios $\mathrm{C}:(\mathrm{O}+\mathrm{ash})$, so that among coals of all kinds those having the same ratios are found to have not far from the same efficiency. The causes of the greater departures are mentioned in the next paragraph.

6. A miscellaneous series of coals of all kinds, ages, and regions, when platted according to the $\mathrm{C}:(\mathrm{O}+\mathrm{ash})$ ratios and calorific values as components, describe a curve to which they conform very closely, the average variance being less than 1 per cent of the calorific value. The greatest variances are among $(a)$ weathered coals, $(b)$ 
those having 79 per cent or more of fixed carbon in pure coal-that is, those undergoing anthracitization-and $(c)$ the boghead-cannel group, in which the hydrogen is excessively high, so that the efficiencies describe a higher curve characteristic of the group.

7. The departures from the ratio-efficiency curve on account of unusually high or low available hydrogen are generally not large. High sulphur is usually attended and compensated by high hydrogen, the converse being true to a less extent. Unusually high sulphur acts, on the whole, as a diluent, while very low sulphur leaves the relative field to the heat-determining elements. Consequently tho variances from the curve on account of the neglected constantshydrogen, sulphur, and nitrogen-are rarely over 2 per cent unless in the exceptions noted in paragraph 6 .

8. Types of coals are initially determined by the nature of the ingredient matter, the conditions of deposition, and the extent of operation of the first or biochemical process in coal making; but progressive devolatilization, lithification, cleavage, and other accompanying alterations result from the second or dynamochemical stage of coal formation, which in each kind removes the essential distinctions of age or region, even tending ultimately to obliterate the differences in kind. Consequently any classification of coals based on the present form of ultimate analyses must be arbitrarily defined. There is intergradation in all parts of the process of coal conversion and coal alteration, as well as in the ingredient matter and conditions of deposition.

9. The weathering of the lower grades of coal, especially the lignites, bituminous coals, and peats, is marked by the accession of oxygen, which is taken into combination. This increase of the oxygen contents, which seems to indicate lack of equilibrium in the hydrocarbon compounds of the normal coal, readily permits a calorific deficiency, which, on account of the high anticalorific value of oxygen, is often serious. It is possible that in many cases considerable increase of oxygen and consequent loss of efficiency are suffered by the lower-class fuels between removal from the bed and deposit in the grate or the chemical crucible.

10. The adaptability of a coal to coking by the ordinary process appears to be indicated with a fair degree of certainty by the ratio of the hydrogen to the oxygen, moisture-free basis. Practically all coals with $\mathrm{H}: \mathrm{O}$ ratios of 59 (per cent) or over seem to possess the quality of fusion and swelling necessary to good coking. Most coals with ratios down to 55 will make coke of some kind, while a few coals with ratios as low as 50 coke in the beehive oven, though very rarely producing a good article. The coking property seems to depend, not so much on the amount of available hydrogen, which is a very imperfect index of the proportion of the elements in the 
volatile, but on the relative amount of the hydrogen as compared to that of the oxygen. In those coals undergoing change to anthracite, the hydrogen-oxygen ratio may fail as a guide; the failures appear, however, to be readily distinguished by the marked calorific deficiencies shown by the $\mathrm{C}:(\mathrm{O}+\mathrm{ash})$ ratio and efficiency curve. The data examined, though insufficient to serve as a basis for a conclusion, seem to point toward the need of a relatively high carbon element in the remaining volatile combustible of coals with 79 per cent or more of fixed carbon (pure coal), in order to secure either the best coking results or the calorific efficiency indicated by the $\mathrm{C}:(\mathrm{O}+\mathrm{ash})$ ratio-efficiency curve. 


\section{PARTIAL BIBLIOGRAPHY.}

\section{SURVEY PUBLICATIONS ON COAL.}

A bibliography of United States Geological Survey publications containing references to coal is. given in Bulletin 34.1, Contributions to Economic Geology, 1907, part 2, pages 419-436. The following publications treating of the work of the Survey fuel-testing plants contain many' analyses of coals. The Survey's supply of those designated by an asterisk is exhausted, but they can be purchased from the Superintendent of Documents, Government Printing Office, at the prices named. Copies of the others can be obtained free by applying to the Director of the Geological Survey.

Bulletin 261.* Preliminary report on the operations of the coal-testing plant of the United States Geological Survey at the Louisiana Purchase Exposition, St. Louis, Mo., 1904; E. W. Parker, J. A. Holmes, M. R. Campbell, committee in charge. 1905. 172 pp. 10 cents.

Professional Paper 48.* Report on the operations of the coal-testing plant of the United States Geological Survey at the Louisiana Purchase Exposition, St. Louis, Mo., 1904; E. W. Parker, J. A. Holmes, M. R. Campbell, committee in charge. 1906. In three parts. $1492 \mathrm{pp} ., 13 \mathrm{pls}$. $\$ 1.50$.

Bulletin 290.* Preliminary report on the operations of the fuel-testing plant of the United States Geological Survey at St. Louis, Mo., 1905, by J. A. Holmes. 1906. 240 pp. 20 cents.

BULLETIN 323.* Experimental work conducted in the chemical laboratory of the United States fuel-testing plant at St. Louis, Mo., January 1, 1905, to July 31, 1906, by N. W. Lord. 1907.49 pp. 10 cents.

'Bulletrin 332. Report of the United States fuel-testing plant at St. Louis, Mo., January 1, 1906, to June 30, 1907; J. A. Holmes in charge. 299 pp.

Bulletin 336.* Washing and coking tests of coal and cupola tests of coke conducted by the United States fuel-testing plant at St. Louis, Mo., January 1, 1905, to June 30, 1907, by Richard Moldenke, A. W. Belden, and G. R. Delamater, with introduction by J. A. Holmes. 1908. 76 pp. 10 cents.

Bulletrin 362.* Mine sampling and chemical analyses of coals tested at the United States fuel-testing plant, Norfolk, Va., in 1907, by J. S. Burrows. 1908. $23 \mathrm{pp}$. 5 cents.

Bulletin 363. Comparative tests of run-of-mine and briquetted coal on locomotives, including torpedo-boat tests and some foreign specifications for briquetted fuel, by W. F. M. Goss. 1908. 57 pp., 4 pls.

Bulletin 368. Washing and coking tests of coal at Denver, Colo., by A. W. Belden, G. R. Delamater, and J. W. Groves. 1909. 54 pp., 2 pls. 


\section{MISCELLANEOUS RECENT PUBLICATIONS.}

The following books and papers treat of the composition of coals: 1905.

Donath, Ed., Betrachtungen über das Backen und über die Bildung des Steinkohle, Oesterr. Zeitschr. Berg. und Hüttenwesen, January 11, 18, 25.

Fulton, J., Coke, A treatise on the manufacture of coke and other prepared fuels. Scranton.

Potonie, H., Die Entstehung der Steinkohle und verwandter Bildung einschliesslich des Petroleums. Berlin. $45 \mathrm{pp}$.

1906.

Bement, A., The sampling of coal. Jour. Am. Chem. Soc., vol. 28, pp. 632-639.

Campiele, M. R., The classification of coals. Trans. Am. Inst. Min. Eng., vol. 36, pp. 324-340.

Frazer, Persifor, The classification of coals. Trans. Am. Inst. Min. Eng., vol. 36, pp. 825-833.

Parr, S. W., Composition and character of Illinois coals. Bull. Illinois State Geol. Survey No. 3.

- The classification of coals. Jour. Am. Chem. Soc., vol. 28, pp. 1425-1432. Also Mines and Minerals, December.

1.907.

Dirke, H, B., Illinois coal tests. Eng. Record, February 25.

Greenwell, A., and Elsden, J. V., Analyses of British coals and coke and the characteristics of the chief coal seams worked in the British Isles. London. $405 \mathrm{pp}$.

Grout, F. F., The composition of coal. Econ. Geology, April-May, pp. 225-241.

Headden, W. R., A study of some Colorado coals. Proc. Colorado Sci. Soc., vol. 8, pp. 281-300.

Keighley, F. C., Why do some coals coke? Mines and Minerals, October.

MacCallum, H., The classification of coal. Canadian Min. Jour., May 1.

Muck, F., Die chemie der Steinkohle. Leipzig. $66 \mathrm{pp}$.

PARR, S. W., Heat production and the constituents of coal. Eng. and Min. Jour., June 29.

Parr, S. W., and Hamilton, N. D., The weathering of coal. Econ. Geology, October-November, pp. 692-703. Sta., $37 \mathrm{pp}$.

The weathering of coal. Bull. No. 17, Univ. Illinois Eng. Exper.

Potonie, H., Historiches zur Frage nach der Genesis der Steinkohle. Natụrw. Wochenschr., vol. 6, pp. 113-117.

Woodman, J. E., Coal sampling. Canadian Min. Jour., May.

1908.

CAmpbell, M. R., A practical classification of low-grade coals. Econ. Geology, March-April, pp. 134-142.

Dowling, D. B., Classification of coals by the split volatile ratio. Canadian Min. Jour., April 15, pp. 143-146.

Pishel, M. A., A practical test for coking coal. Econ. Geology, June-July, pp. $265-270$.

Porter, F. C., and Ovitz, F. K., The nature of the volatile matter in coal as evolved under different conditions. Jour. Am. Chem. Soc., vol. 30, pp. 1486-1507.

White, David, Some problems in the formation of coal. Econ. Geology, JuneJuly, pp. 292-318. 